University of Louisville

ThinkIR: The University of Louisville's Institutional Repository

Electronic Theses and Dissertations

$5-2015$

\title{
Characterizing the neuropeptide pathways between the forebrain and the pons.
}

Ali Al-Magableh

University of Louisville

Follow this and additional works at: https://ir.library.louisville.edu/etd

Part of the Anatomy Commons, and the Neuroscience and Neurobiology Commons

\section{Recommended Citation}

Al-Magableh, Ali, "Characterizing the neuropeptide pathways between the forebrain and the pons." (2015). Electronic Theses and Dissertations. Paper 2080.

https://doi.org/10.18297/etd/2080

This Doctoral Dissertation is brought to you for free and open access by ThinkIR: The University of Louisville's Institutional Repository. It has been accepted for inclusion in Electronic Theses and Dissertations by an authorized administrator of ThinkIR: The University of Louisville's Institutional Repository. This title appears here courtesy of the author, who has retained all other copyrights. For more information, please contact thinkir@louisville.edu. 


\title{
CHARACTERIZING THE NEUROPEPTIDE PATHWAYS BETWEEN THE FOREBRAIN AND THE PONS
}

\author{
By \\ Ali Al-Magableh
B.S., Jordan University of Science and Technology, Irbid, Jordan 2000 \\ B.S., Northern Illinois University DeKalb, IL, 2002 \\ M.S., Chicago State University, Chicago IL, 2007 \\ M.S., University of Louisville, Louisville, KY 2013
}

\author{
A Dissertation \\ Submitted to the Faculty of the \\ School of Medicine of the University of Louisville \\ in Partial Fulfillment of the Requirements \\ for the Degree of \\ Doctor of Philosophy \\ in Anatomical Sciences and Neurobiology \\ Department of Anatomical Sciences and Neurobiology \\ University of Louisville \\ Louisville, Kentucky
}

May, 2015 



\title{
CHARACTERIZING THE NEUROPEPTIDE PATHWAYS BETWEEN THE FOREBRAIN AND THE PONS
}

\author{
By \\ Ali Al-Magableh \\ B.S., Jordan University of Science and Technology, Irbid, Jordan 2000 \\ B.S., Northern Illinois University DeKalb, IL, 2002 \\ M.S., Chicago State University, Chicago IL, 2007 \\ M.S., University of Louisville, Louisville, KY 2013
}

\begin{abstract}
A Dissertation Approved on
\end{abstract}
December 1, 2014

By the following Dissertation Committee:

Dissertation Director, Dr. Robert Lundy

Dr. Charles Hubscher

Dr. Martha Bickford

Dr. Robin Krimm

Dr. Thomas Mitchell 


\section{ACKNOWLEDGMENTS}

I owe anything I claim to have accomplished in this dissertation to Dr. Robert Lundy Jr. who set an extraordinary example to me as a mentor, a teacher, and a leader. I know his hard work, patience, and perseverance will remain a lifelong influence. I thank him for his patience, respect, and appreciation of my weaknesses and strengths. I will always remember Dr. Lundy as the best example of a professor and mentor of a rare value. I also owe this humble accomplishment to my committee members (former and current); Drs. Martha Bickford, Robin Krimm, Thomas Mitchell, Nigel Cooper, and Charles Hubscher. I also owe heartfelt gratitude to Dr. Fred Roisen for his support and appreciation. Additional thanks to the Department of Anatomical Sciences and Neurobiology chair and staff. I thank Dr. Guido for his support and Mrs. Donna Bottorff for her patience and understanding. A special thank you to Mr. Arkadiusz Slusarczyk and Mr. Michael Eisenback, to my friends and former lab mates, floor mates, and classmates for their support and friendship. Finally, I should thank the people who became the most recent cause of motivation and main source of hope and happiness. First, the fruit of my life, my son Faisal Ali Magableh to whom I dedicate this humble accomplishment, I pray that it will be the spark for lifelong positive influence. I pray that he grows to be a functional member of this society and the world. Second, I would like to thank my parents for their help and support. My mother in particular was the main force that kept me going and this humble accomplishment is owed in part to her. I also thank my father for his prayers. Last, I would like to acknowledge my brothers and sisters for their help and support. 


\section{ABSTRACT \\ CHARACTERIZING THE NEUROPEPTIDE PATHWAYS BETWEEN THE FOREBRAIN AND THE PONS}

Ali Al-Magableh

December 1, 2014

Many current health problems including obesity, hypertension, stroke, heart disease, and type 2-diabetes can be attributed to diet. One powerful determinant of food selection is how good or bad a food 'tastes' (e.g. affective value), and is ranked highly by consumers as their top reason for choosing a food (e.g. preference). Learning plays an important role in the establishment and strengthening of food preference and, thus in guiding food choice and calories consumed. The basis of such learning is provided, in part, by limbic system modulation of gustatory neural processing at lower levels in the medulla and pons. I hypothesize that specific limbic system neuropeptide pathways underlie this neural modulation and, thus, function in assigning affective value to taste information and establishing preference behavior. I have identified two neuropeptides, corticotrophin releasing hormone $(\mathrm{CRH})$ and somatostatin $(\mathrm{Sst})$, which are expressed in limbic system neurons projecting to the pontine taste area. Studying the cellular components and nature of these different cell type projections and locations helps us understand the role that forebrain plays in controlling ingestive behaviors in the hindbrain. In doing so, I was able to prove that the inhibitory neurotransmitter of GABA is expressed by Sst-producing neurons potentially to exert a neuromodulatory function. 
TABLE OF CONTENTS

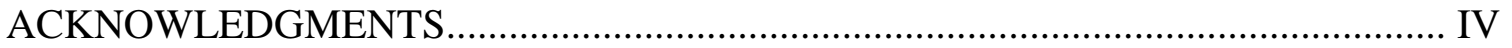

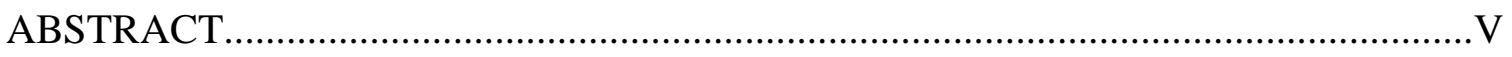

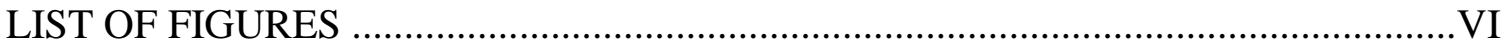

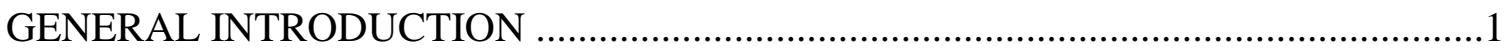

I. ABLATING THE SOMATOSTATIN PRODUCING CELL TYPES WITHIN THE AMYGDALA-PBN PROJECTIONS

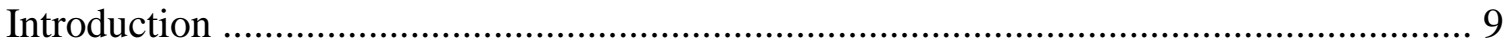

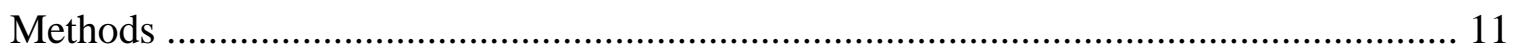

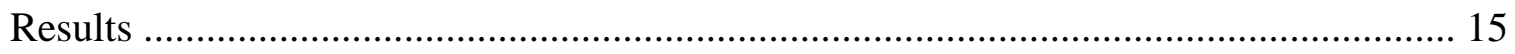

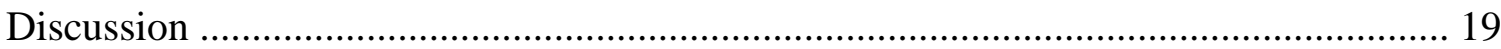

II. MAPPING THE SOMATOSTATIN AND CORTICOTROPIN RELEASING FACTOR CELL TYPES THAT PROJECT TO PARABRAICHIAL NUCLEUS FROM THE AMYGDALA AND BED NUCLUES OF STRIA TERMINALIS.

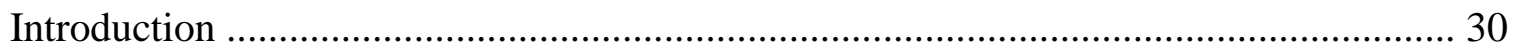

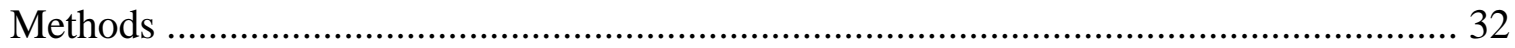

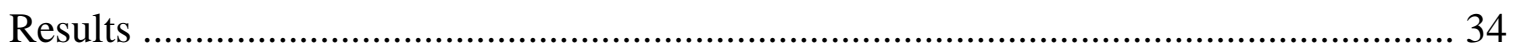

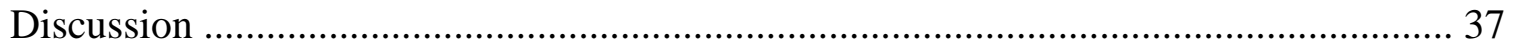




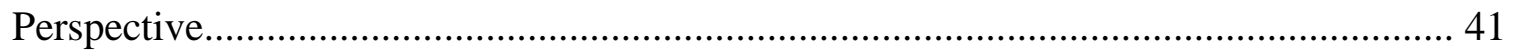

III. SYNAPTIC ORGANIZATION OF CONNECTIONS BETWEEN THE CENTRAL NUCLEUS OF AMYGDALA, BEDNUCLUES OF STRIA TERMINALIS AND PARABRACHIAL NUCLEUS IN MICE

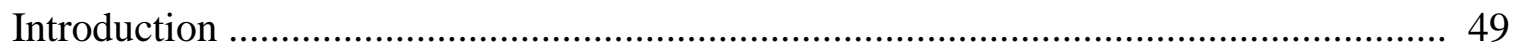

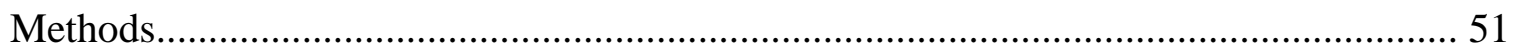

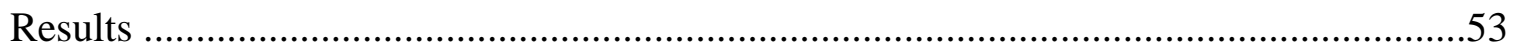

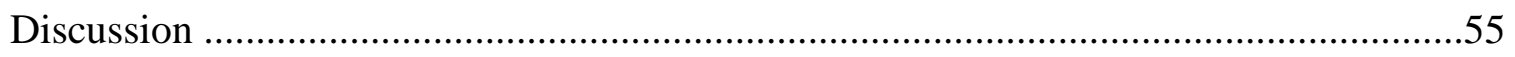

IV. SUMMARY AND FUTURE DIRECTIONS................................................64

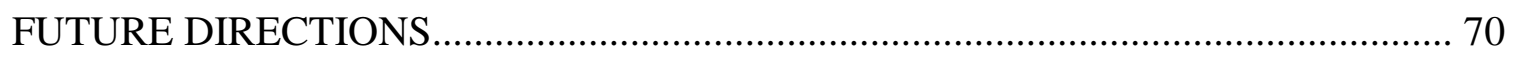

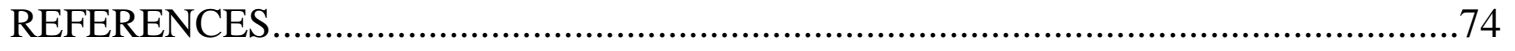

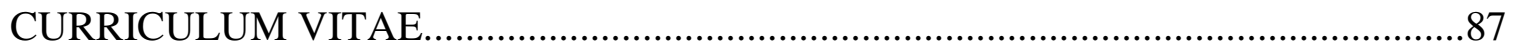




\section{LIST OF FIGURES}

1. Figure showing a schematic diagram of floxed NTR-mCherry and CRF-Cre

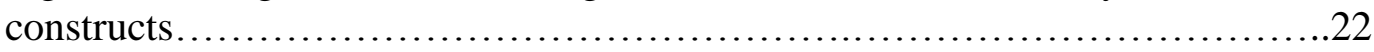

2. Schematic diagram of single vector containing the CMV-LoxP-NTR-mCherry and CRF-Crecassettes.

3. Crh producing Y1 cell line transfected with CMV-NTR-mCherry construct individually, with CMV-LoxP-NTR-mCherry construct , and with both CMVLoxP-NTR-mCherry and CRF-Cre.

4. Images of DRG neurons electroporated with lox-STOP-lox/NTRmCherry, Sst promoter-Cre, and CMV-YFP plasmids ...................................24

5. FACS analysis showing the number of HEK 293 cells expressing NTR/mCherry or blank plasmid and treated with increasing concentration of CB1954 or the solvent DMSO.

6. FACS analysis showing the percentage of HEK 293 cells expressing NTR/mCherry or blank plasmid and treated CB1954 or the solvent DMSO

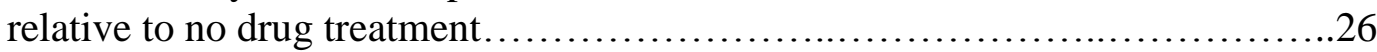

7. Images of HEK 293 cells transfected with both Ad5-Crh-cre virus and Ad5-loxstop-lox-NTR/mCherry virus and treated with DMSO or $600 \mathrm{mM}$ CB1954. 27

8. Images of HEK 293 cells transfected with both Ad5-CMV-cre-GFP virus and Ad5-lox-stop-lox-NTR/mCherry virus and treated with DMSO or $600 \mathrm{mM}$ CB1954. .28

9. Confocal image of mCherry fluorescent cells in the CeA of Sst-Cre mice following injection of AAV2-EF1alpha-DIO-NTRmCherry-WPRE

10. Photomicrograph of a slice taken from a mouse brain showing CTb-488 tracer injection into the caudal region of the PBN with the superior cerebellar peduncle boundaries outlined

11. Neurolucida reconstructions of $\mathrm{CTb}-488$ injections into the PBN of a group of $\mathrm{Sst} / \mathrm{TdTomato}$ mice and a group of $\mathrm{Crh} / \mathrm{TdTomato}$ mice in a 3D representations 
12. Montage images of TdTomato expression in the amygdala and BNST of an Sst/TdTomato mouse and Crh/TdTomato mouse. .45

13. Graphs show the average of retrogradely labeled neurons in the CeA, BNST and LH following injections of CTb-488 into the caudal PBN of Crh/TdTomato and Sst/TdTomato mice; with graphs the average percentage of retrogradely labeled neurons that co-expressed Crh or Sst 47

14. Photomicrographs of neurons projecting to the caudal PBN and TdTomato fluorescence in the CeA and BNST of an Sst/TdTomato mouse and $\mathrm{Crh} / \mathrm{TdTomato}$ mouse showing a CTb-488 retrogradely labeled neurons alone, TdTomato positive peptidergic cells alone, and the two images merged. 48

15. Low and high magnification fluorescent images of TdTomato reporter expression in the PBN of offspring from breeding Sst-Cre and Crh-Cre mice with floxed TdTomato mice. 59

16. Confocal images of TdTomato fluorescence in the CeA and PBN resulting from breeding Sst-Cre and floxed TdTomato reporter mice and mCherry fluorescence in the CeA and PBN resulting from injection of AAV2-Ef1 $\alpha$-DIO-mCherry into

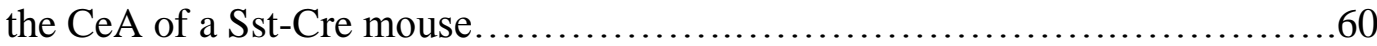

17. Electron microscope images DAB-labeled andSst-positive terminal in the PBN following floxed viral injection into the CeA of an Sst-Cre mouse and images of Crh terminal in the PBN of offspring from breeding Crh-Cre and floxed TdTomato mice. 61

18. The distribution of gold particle densities relative to cut-off value for Sst and $\mathrm{CRH}$ terminals in the PBN .62 


\section{GENERAL INTRODUCTION}

Sensory systems play a fundamental role in allowing us to perceive and interact with the world around us. The central nervous system processes sensory information in such a way that an identical stimulus may elicit distinct reactions under different environmental and behavioral conditions. This is possible because information processing in sensory circuits is modifiable at every level of the pathway. Such neuromodulation enables flexibility in neural circuits, which enables adaptive behavior in response to changing conditions. In the gustatory system, adaptive behavior is manifest in the final decision to ingest or reject the contents of the oral cavity. Activity in gustatory pathways plays an important role in this decision by transmitting information about stimulus intensity, quality, and affective value.

Peripherally, the taste system is composed of taste buds that contain chemically sensitive receptor cells and are distributed in distinct subpopulations on the palate, pharynx, larynx, and dorsal surface of the tongue. The majority of taste buds reside in three subpopulations on the tongue, the fungiform, foliate, and circumvallate papilla (Norgren et al., 1989). Gustatory information is conveyed from the tongue via three cranial nerves. Information from the fungiform papillae on the anterior two-thirds of the tongue is conveyed to the first central synapse in the nucleus of the solitary tract (NST) by the chorda tympani branch of the facial nerve (CT). Information from the 
Circumvallate papillae on the posterior tongue is conveyed to the NST by the glossopharyngeal nerve (GL). Finally, information from taste receptors on the palate is conveyed to the NST by the greater superficial petrosal branch of the facial nerve (GSP) (Boudreau et al., 1987; Frank et al., 1983; Sollars and Hill, 2005).

The vast majority of taste stimuli fall into one of five categories, sweet, salt, sour, bitter, and umami, with some stimuli evoking sensations of multiple qualities (Bartoshuk, 1978). Gustatory preference and aversion for taste stimuli are defined here as the unlearned predisposition of an animal to consume or expel taste stimuli in the oral cavity. Most studies that examine the effects of damage to gustatory structures utilize either brief-access licking (10-30 s) or taste-reactivity tests in an effort to isolate orosensory processes from post-ingestive feedback. Fluid stimuli infused directly into the oral cavity produce stereotypically oromotor responses that are characterized as ingestive or aversive ((i.e. taste reactivity measure (Grill and Norgren, 1978a)). Peripheral nerve lesion studies indicate that unconditioned responding to a specific class of taste stimuli is not mediated solely by any one gustatory nerve and, by extension any one subpopulation of taste receptor cells in the oral cavity.

Transection of the CT nerve has been shown to reduce, but not eliminate, ingestive oromotor responses, while GL transection reduces aversive responses (Grill et al., 1992). This demonstrates that neither nerve exclusively controls either type of taste reactivity response. Subsequent experiments determined that combined transection of both the CT and GL nerves were required to eliminate unconditioned ingestive and 
aversive oromotor responses to $\mathrm{NaCl}$, sucrose, and quinine $\mathrm{HCl}(\mathrm{Grill}$ and Schwartz, 1992). Similar competency is observed following transection of the CT or GL when brief-access licking is the measure. Concentration-response functions were shifted slightly to the right; however, the animals still adjusted their licking as a function of stimulus concentration (Spector et al., 1996; St John et al., 1994). These studies indicate that normal unconditioned responsiveness to stimulus intensity depends on centrally converging inputs from multiple peripheral gustatory nerves.

In the NST, axons from the CT, GL, and GSP nerves distribute in a roughly somatotopic order. Input from the CT and GSP is most dense in the rostral portion of the NST and that from the GL is concentrated more caudal (Corson et al., 2012). Electrophysiological recording of taste responses in the NST demonstrate some degree of convergence from different oral taste receptor populations (Travers and Norgren, 1995). As expected, neural processing in the NST plays an important role in an animal's ability to use taste information to guide preference and aversion behavior. Innate concentrationdependent intake of preferred and avoided stimuli is severely disrupted by damage to the gustatory region of the NST (Flynn et al., 1991; Shimura et al., 1997b). Importantly, the ability to express learned and physiologically dependent taste-guided behaviors like conditioned taste aversion (CTA) and sodium appetite is unaffected by damage to the gustatory NST (Grigson et al., 1997). The induction of CTA and sodium appetite switches the behavioral response to a gustatory stimulus from ingestion to rejection or vice versa (Berridge et al., 1984; Breslin et al., 1992). From the NTS, the primary rostral 
target of axons from the anterior region of the NST is the parabrachial nucleus (PBN) in the Pons.

The PBN serves as the second central synapse for ascending gustatory information and plays a critical role in taste-visceral associations that alter gustatory affective value. In contrast to deficits observed following damage to the NST, damage to PBN does not eliminate innate concentration-dependent intake of preferred and avoided stimuli (Spector et al., 1993).However, the same damage to the PBN prevents the ability to acquire a CTA or express a sodium appetite(Grigson et al., 1998; Reilly et al., 1993; Scalera et al., 1995). Damage to the gustatory region of the thalamus, the third synaptic relay in the ascending gustatory system, did not affect these behavioral responses (Reilly and Pritchard, 1996; Scalera et al., 1997). Furthermore, chronically decerebrate rats, in which neural connections between the forebrain and hindbrain are severed, also fail to express CTA or sodium appetite (Grill and Norgren, 1978c; Grill et al., 1986). These findings implicate: 1) circuits connecting the forebrain and PBN in experience-dependent modification of taste-guided behavior and 2) projections from the PBN to the forebrain in affective responses arising from gustatory stimuli.

At least three ventral forebrain sites, the lateral hypothalamus (LH), central nucleus of the amygdala $(\mathrm{CeA})$, and bed nucleus of the striaterminalis (BNST) receive taste information directly from the PBN ( $\mathrm{Li}$ and Cho, 2006; Norgren, 1976) and send projections back to the PBN (Holstege et al., 1985; Hopkins and Holstege, 1978; Kang and Lundy, 2009; Panguluri et al., 2009; Zhang et al., 2010). Electrolytic lesions of the 
LH have been reported to reproduce the effects of PBN lesions on learned taste aversions and expression of a salt appetite (Roth et al., 1973; Schwartz and Teitelbaum, 1974). Axons from the PBN, however, both terminate in, and pass through, the lateral hypothalamus (Halsell, 1992; Norgren, 1974; Saper and Loewy, 1980). These earlier LH lesions destroyed both neurons and fibers of passage. More recent evidence indicates that smaller, fiber sparing, ibotenic acid lesions in the posterior part, but not the anterior part, of the lateral hypothalamus attenuate taste aversion learning (Dayawansa et al., 2011; Ruch et al., 1997; Ruch et al., 1999). These experiments further showed that larger lesions involving about $3 \mathrm{~mm}$ of the anterior-posterior extent of the LH disrupted the expression of sodium appetite produced by furosemide.

The $\mathrm{CeA}$ is the major forebrain recipient of PBN gustatory afferent axons and participates in the expression of sodium appetite (Galaverna et al., 1992; ZardettoSmith et al., 1994). Based on the effects of excitotoxic lesions, the contribution of this particular amygdala subnucleus in the acquisition of a CTA apparently depends upon whether the method of conditioned stimulus presentation incorporates a response component (Bermudez-Rattoni and McGaugh, 1991; Dunn and Everitt, 1988; Schafe and Bernstein, 1996; Schafe et al., 1998; Yamamoto et al., 1995). Both electrolytic and excitotoxic lesions of the CeA disrupt the elaboration of a CTA when animals are conditioned with an intra-oral taste presentation, but only electrolytic lesions disrupt CTA when conditioning involves bottle presentation of the taste (Schafe et al., 1998). Yet other studies employing transient blockade of gene expression showed that disruption of cAMP response element-binding protein (CREB) or c-fos in a region overlapping CeA 
impairs learning (Lamprecht and Dudai, 1996; Lamprecht et al., 1997; Yasoshima et al., 2006). Similar to brainstem gustatory cells, the response of CeA neurons to a gustatory CS is also altered following the establishment of a conditioned taste aversion (Yasoshima et al., 1995).

The BNST has been less studied as a component of the gustatory system compared to the LH and CeA. Nevertheless, evidence suggests that the BNST participates in the processing of sodium appetite behavior (Reilly et al., 1994; ZardettoSmith et al., 1994). Thus, a potential mechanism for the behavioral changes associated with CTA and sodium appetite involves modulation of taste processing in the PBN by descending forebrain inputs. Indeed, changes in PBN taste responses are normally coincident with CTA and sodium appetite, but are absent in decerebrate animals(Shimura et al., 1997a; Shimura et al., 1997c; Tokita et al., 2004). Following induction of sodium appetite a common finding is decreased sensitivity of PBN taste cells to sodium salt. A common finding after acquisition of a CTA is an enhanced neural response to the conditioned taste stimulus. Moreover, activation of the LH, CeA, and BNST has been shown to modulate taste processing in the PBN (Li et al., 2005; Li and Cho, 2006; Lundy and Norgren, 2001; Lundy and Norgren, 2004). Activation of the BNST and CeA primarily inhibited taste responses, while inhibition and excitation of taste responses occurred equally often during LH activation. The net effect of activating these descending inputs to the PBN was to increase the chemical selectivity of taste neurons (Lundy and Norgren, 2001; Lundy and Norgren, 2004). This demonstrates that the relative responsiveness of $\mathrm{PBN}$ neurons to different classes of taste stimuli is malleable, 
potentially providing a mechanism by which the forebrain can alter taste perception and subsequent feeding behavior.

Despite extensive characterization of the role these ventral forebrain regions play in taste-guided behavior (Caulliez et al., 1996; Ciccocioppo et al., 2003; Dayawansa et al., 2011; Galaverna et al., 1992; Gotoh et al., 2007; Kwon and Houpt, 2012; ndradeFranze et al., 2010; Pompei et al., 1991; Touzani et al., 2009) and processing of taste information in the PBN, the cellular mechanisms that mediate these interactions have remained ill defined. Prior studies in rodents have shown that several neuropeptide cell types in the LH, CeA, and BNST including somatostatin, neurotensin, corticotrophin releasing hormone, cholecystokinin, enkephalin, and substance $\mathrm{P}$ project to the PBN (Moga and Gray, 1985; Moga et al., 1989; Panguluri et al., 2009; Veening et al., 1984).Unfortunately, most of these studies used stereotaxic guided injections of a retrograde tracer into the PBN. The PBN consists of different regions processing gustatory, visceral, and somatosensory signals and, thus, none of these neurochemical pathways could be ascribed with certainty as providing input to the gustatory region of the PBN. To overcome this limitation, one study injected a retrograde tracer into the gustatory responsive region of the PBN under electrophysiological guidance (Panguluri et al., 2009). This study revealed that somatostatin (Sst) and corticotrophin releasing hormone (CRH) cell types in the $\mathrm{CeA}$ and BNST provide descending input to the gustatory PBN. Thus, these specific peptidergic pathways may play an important role in regulating taste responses in the PBN. Both Sst and CRH have been shown to influence food intake and/or taste preference (Bassant et al., 2005; Ciccocioppo et al., 2003; Feifel 
and Vaccarino, 1990; Feifel and Vaccarino, 1994; Fekete et al., 2007; Heinrichs et al., 1993; Heinrichs and Richard, 1999; Karasawa et al., 2014; Parrott, 1990; Scalera, 2003; Stengel et al., 2010). Indeed, injection of CRH into the PBN disrupts expression of a sodium appetite in rats, while injections of a $\mathrm{CRH}$ receptor antagonist had the opposite effect, increasing sodium chloride intake(Silva et al., 2006).

Because the sources of neuromodulatory input to taste circuits contain numerous cell types and are interconnected with one another, elucidation of the role that specific neurochemical pathways play in central taste processing has been hindered. The goal of the present experiments was to understand how specific peptidergic pathways of ventral forebrain origin control neural processing in the brainstem. 


\section{CHAPTER I}

ABLATING THE SOMATOSTATIN PRODUCING CELL TYPES WITHIN THE AMYGDALA-PBN PROJECTIONS

\section{Introduction}

Gene suicide systems have been used for nearly 30 years and are an efficient and powerful tool in selective ablation of specific cell types by differentially targeting expression of intracellular toxins (Breitman et al., 1987). One method of selectively ablating cells is known as gene-directed enzyme prodrug ablation utilizing the Nitroreductase enzyme (NTR) and one of its substrates. Nitroreductases are primarily bacterial proteins from the oxidoreductases group that exists in alternative forms in eukaryotes and include the oxygen-insensitive $\mathrm{NAD}(\mathrm{P}) \mathrm{H}$ Nitroreductase NADH dehydrogenase. One of the inherent features of these enzymes is their ability to reduce certain compounds in oxygen-independent manner to form intermediary substrate compounds some of which are highly toxic. These substrates are known as prodrugs and are by themselves mostly non-toxic. However, in the presence of Nitroreductase (NTR) they acquire cytotoxicity.

An aziridine prodrug compound named CB1954 (5-aziridin-1-yl-2,4dinitrobenzamide) has been successfully used as an NTR-dependent cytotoxin in a mechanism involving DNA cross-linking. Initially, NTR is reduced by NADH or NADPH and the prodrug then binds to NTR to be transformed into a potent DNA 
interstrand cross-linking compound, which subsequently causes the death of the NTRexpressing cell (Anlezark et al., 1992; Edwards, 1993; Knox et al., 1993; Lindmark and Muller, 1976). This E. coli Nitroreductase (NTR) enzyme system seems to be more appropriate in functional studies of the adult central nervous system because it is capable of ablating both dividing and non-dividing cells (Clark et al., 1997; Drabek et al., 1997; Felmer et al., 2002).

My goal was to develop a viral system capable of directing expression of the NTR gene to specific cell populations in the CeA using Cre expression driven by the promoter for Sst or $\mathrm{CRH}$ in rats. Thus, peptide producing neurons in isolation can be rapidly ablated following treatment with the prodrug CB1954 allowing assessment of their role in central taste processing and learned taste preference. A better understanding of the neural mechanisms in the brain underlying addition of affective meaning to gustatory stimuli is relevant to a better understanding of overconsumption and obesity.

As depicted in Figure 1, one construct will contain a ubiquitous cytomegalovirus promoter (CMV) followed by a floxed stop sequence then the genes coding for NTR and the fluorescent reporter mCherry. The second construct will contain the promoter for Sst or CRH followed by the gene coding for Cre recombinase. By cloning the CMV-LoxP-NTR-mCherry and CRF-Cre cassettes into the same pAdTrack vector, a single Adenovirus vector expressing Cre specifically in neurons with CRF or Sst transcript, which will then remove the LoxP sites allowing CMV driven expression of the prodrug converting enzyme NTR (Figure 2). Adenovirus infected cells 
will exhibit green fluorescence (GFP expression), while infected cells that additionally have CRF or Sst transcript will exhibit red mCherry fluorescence and NTR gene expression.

\section{MATERIALS AND METHODS}

\section{Gene Cloning and PCR:}

Primers for SS and CRF were designed using "Primer-3" according to the sequences for our genes of interest obtained from the Rat Genome Sequence Database (NIH), while those for NTRmCherry were based on the sequence provided by the supplier Dr. Michael Benson, Department of Biomedical Sciences at Baylor College of Dentistry. Primer sequences were:

$\underline{\text { SS, }}$ 5' GGACTAGTCCATGTATTGCTGGCCAAGGAC 3' (F) and 5' GCTCTAGAGCCCAGTAGCGTCTCCTTCAGC 3' (R)

$\underline{\text { CRF }}$, 5' CCGCTCGAGGAGAGACGTCTCCGGGGGC 3' (F) and 5' CGGAATTCGGCTCATAACTCCTTTATGTGCTTGC 3' (R) NTRmCherry, 5' CCGCTCGAGTCGAGAACAGGTGAGTGTCG 3' (F) and 5' ATTTGCGGCCGCCCCCCTGAACCTGAAACATA 3' (R).

Rat genomic DNA was extracted using DNeasy blood and tissue kit (Qiagen) according to the manufacturer's protocol. PCR product was obtained using 0.25 units of high fidelity DNA polymerase LA Taq (TaKaRa) and carried out in $50 \mu 1$ reactions containing $1 \times$ LA PCR Buffer (TaKaRa), $10 \mu \mathrm{M}$ each of forward and reverse primers, $0.2 \mathrm{mM}$ dNTP mix, and $100 \mathrm{ng}$ of DNA. PCR products were viewed on $2 \%$ agarose gel 
electrophoresis. Bands of interest were then excised and purified using a Gel Purification Kit (Qiagen). The lox-STOP-lox sequence was cut from pBS302 plasmid (AddGene \#11925) using SpeI and EcoRI restriction enzymes, while Cre was cut from pCAG-Cre plasmid (AddGene \#13775) using EcoRI and NotI restriction enzymes. DNA was ligated into pBlueScript KS cloning vector (pKS) and/or pIRES, pAdTrack or ZsGreen expression vectors. Ligated products were used to transform DH5 $\alpha$ competent cells. Colonies were randomly selected and propagated overnight in $5 \mathrm{ml} \mathrm{LB}$ broth with antibiotic followed by DNA extraction using a Mini-Prep kit (Qiagen) according to manufactures protocol. Extracted DNA was digested with appropriate enzymes and viewed on $2 \%$ agarose gel to verify ligation. Positive colonies were then sequenced at the University of Louisville DNA Core and analyzed using NIH online software. Colonies were then propagated via Midi-Prep kit (Qiagen) according to manufacturer protocol.

\section{Cell Culture:}

HEK 293FT or CRH expressing Y1 (ATCC: CCL-79) cells were grown in DMEM base media with $10 \%$ FBS, $1 \%$ L-glutamate and $1 \%$ penicillin-streptomycin and seeded at 2,000 cells $/ \mathrm{cm}^{2}$. Cells were allowed to grow for 2 days before transfection or viral infection. For transfection, lipofectamine and DNA were added at a ratio of 3:1. Fluorescent Assisted Cell Sorting (FACS) was used to quantify the number of red (experimental NTR/mCherry expression) and green (control ZsGreen1 expression) fluorescent cells. 


\section{CB1954:}

The prodrug CB1954 (Sigma) was dissolved in DMSO at a stock concentration of $25 \mathrm{mg} / \mathrm{ml}$. Further dilutions were made in culture media or physiological saline. For IP treatment, CB1954 was administered three consecutive days at $40 \mathrm{mg} / \mathrm{kg}$. For intraamygdala delivery, the prodrug was administered once at a concentration of $150 \mu \mathrm{M}(200$ nl). Animals were euthanized with a lethal dose of Nembutal four days after the initial treatment and tissue containing the amygdala processed for immunofluorescent detection of neurons using the RBFox3/NeuN antibody (Novus Biologicals).

\section{Dorsal Root Ganglion (DRG) Cell Culture:}

Two week old rats $(n=2)$ were anesthetized using Ketamine. DRG's were excised bilaterally and immediately placed in media on ice. DRG's were washed with DMEM/F12/PS, then incubated with $2 \mathrm{mg} / \mathrm{ml}$ collagenase $-5 \mathrm{mg} / \mathrm{ml}$ dispase solution and incubated at $37^{\circ} \mathrm{C}$ for a total of $45 \mathrm{~min}$ with constant stirring. The enzyme solution was removed and the cells washed once with DMEM/F12/10\%FBS/1XN2 media then titurated in DMEM/F12/FBS media to get a single cell suspension. The cells were centrifuged for 5 minutes at 800 RPM. Supernatant was removed and the pellet was resuspended in $100 \mu \mathrm{L}$ of Nucleofection media (Ambion). $1 \mu \mathrm{g}$ of each plasmid DNA was added to the cell suspension and placed in the electroporation device. N2 media was immediately added to the cells, mixed well and plated on a PDL/Laminin coated 24 well plate. 


\section{Brain Injection:}

One month old rats $(n=4)$ or mice $(n=2)$ were anesthetized using Nembutal (50 $\mathrm{mg} / \mathrm{kg}$ ) or Ketamine/Xylazine solution $(100 / 10 \mathrm{mg} / \mathrm{kg})$ and secured via ear bars in a stereotaxic apparatus in a BL2 hood. The skull was exposed and holes drilled through the bone overlying the amygdala. In rats, following packaging and purification by SignaGen Laboratories $1 \mu \mathrm{L}$ of AD5_CRF-Cre virus $\left(1.8 \times 10^{10} / \mathrm{ml}\right)$ and Ad5_lox-STOPlox/NTRmCherry virus $\left(3.8 \times 10^{10} / \mathrm{ml}\right)$ was injected into the amygdala using a $10 \mu \mathrm{L}$ Hamilton syringe and 33g needle mounted in a Microinjection Unit (David Kopf) attached to the stereotax. For mice, the NTR/mCherry construct was ligated into a floxed AAV helper plasmid (MIT, Rachael Neve) and package into AAV, serotype 2 (ViroVek). The AAV2-EF1alpha-DIO-NTR/mCherry virus was injected $(600 \mathrm{nl})$ into the CeA of Sst-Cre mice using a microinjector and 34 gauge needle (WPI). All animals were euthanized with a lethal dose of Nembutal $(150 \mathrm{mg} / \mathrm{kg})$ and perfused transcardially with saline followed by $4 \%$ paraformaldehyde. The brains were extracted, cryoprotected and cut at a thickness of $50 \mathrm{um}$ on a freezing microtome.

\section{qRT-PCR:}

Fourteen days post-surgery, half of the animals received an intraperitoneal injection of the prodrug CB1954 and the other half $0.9 \%$ saline. The analgesic buprenex was administered for two days post CB1954 infusion. Seven days post CB1954 injection, animals were administered a lethal dose of Nembutal $(150 \mathrm{mg} / \mathrm{kg})$ and either perfused through the ascending aorta (for immunohistochemistry) or decapitated and brains extracted, blocked for tissue containing the amygdala, and rapidly frozen on dry 
ice for subsequent RNA extraction. RNA was isolated by first cutting thick sections (250 $\mu \mathrm{m})$ of amygdala tissue using a cryostat and rapidly thawing and re-freezing on a glass slide inside the cryostat chamber. The amygdala was dissected bilaterally within the cryostat chamber under $5 \mathrm{X}$ magnification using established anatomical landmarks (i.e. bounded dorsal by the striatum, medial by the optic tract, and lateral by the external capsule). The instruments and working area was sprayed with RNase Zap (Ambion/Applied Biosystems) to ensure a RNA free environment. The excised brain tissue was placed in micro centrifuge tubes with QIAzol lysis reagent (Qiagen) on ice to optimize conditions for high quality RNA. cDNA synthesis by reverse transcription was perfumed using $1 \mu \mathrm{g}$ of DNAse1 (Ambion Inc.) treated RNA and iScript cDNA synthesis kit (Bio-Rad Laboratories) according to the manufactures protocol. Briefly, qRT-PCR was performed using a $20 \mu \mathrm{l}$ reaction volume containing $1 \mu \mathrm{L}$ of cDNA, $1 \mu \mathrm{l}$ of each forward $(\mathrm{F})$ and reverse $(\mathrm{R})$ sequence specific primers, $10 \mu \mathrm{l}$ of SYBR select (Applied Biosystems), and $7 \mu 1$ of nuclease free water. All the qRT-PCR reactions were performed using a Corbett single color real-time PCR detection system (Corbett, USA). Standard curves were obtained using a ten-fold serial dilution of cDNA and measured in triplicate. Expression of rat $18 \mathrm{~S}$ gene was used as an internal control and the quantity of mRNA expressed relative to $18 \mathrm{~S}$ mRNA levels. The PCR efficiency and correlation coefficient values were taken into account before estimating the relative expression.

\section{RESULTS}

\section{CRH promoter, Sst promoter, and NTR/mCherry expression}


Our initial In vitro studies demonstrated that CRH expressing Y1 cells transfected with both CMV-LoxP-NTR-mCherry and CRF-Cre vectors expressed red mCherry fluorescence (Figure 3C), but not when transfected with the LoxP-NTR-mCherry vector alone (Figure 3B). However, mCherry fluorescence was observed when cells were transfected with the CMV-NTR-mCherry vector lacking LoxP sites (Figure 3A). Thus, the LoxP sites prevented NTR-mCherry expression in the absence of CRH promoter driven Cre expression.

To test the function of our Sst-Cre construct dorsal root ganglion cells (DRG) were electroporated with plasmids containing $1 \mu \mathrm{g}$ DNA each for pIRES_lox-STOPlox/NTRmCherry, pBlueScript_Sst-Cre, and CMV-YFP. The yellow YFP fluorescence in Figure 4 shows that the electroporation was successful. The mCherry fluorescence seen in the neuron of the top row (left panel) indicates an Sst positive neuron, while the lack of mCherry fluorescence in the neuron of the bottom row (left panel) indicates a DRG neuron that does not express Sst. These results suggest that our Sst promoter is functional and drove Cre expression that in turn recognized the lox sites to remove the STOP sequence allowing NTR/mCherry to be expressed. The finding that not all DRG neurons were mCherry positive further indicates specificity as only a subpopulation of DRG's are Sst positive.

\section{CB1954 induced toxicity in vitro}

In order to assess the function of our NTR gene, HEK 293 cells were transfected with ZsGreen expression plasmid alone or ZsGreen containing our NTR/mCherry 
sequence and then treated with increasing concentration of CB1954 or DMSO. The number of red fluorescent cells (NTR/mCherry expression) decreased with increasing concentration of CB1954 (Figure 5, pNTR/mCherry-CB1954). CB1954 was without effect on cell survival in the absence of NTR/mCherry (Figure 5, pZsGreen-CB1954). By representing cell survival as a percentage relative to no drug treatment, the first signs of toxicity were observed at $100 \mathrm{mM} \mathrm{CB} 1954$ (Figure 6, filled squares).

\section{Viral delivery of genes in vitro}

To test viral delivery of our constructs we sent our CRH-Cre and lox-STOPlox/NTR/mCherry plasmid DNA to SignaGen Laboratories for Ad5 virus production and purification. Hek293 cells were then co-infected with Ad5_CRH-Cre $\left(5 \times 10^{7}\right)$ and Ad5_lox-STOP-lox/NTR/mCherry $\left(5 \times 10^{7}\right)$ viruses or with Ad5_CMV-Cre-GFP $(1 \mathrm{x}$ $\left.10^{6}\right)$ and Ad5_lox-STOP-lox/NTR/mCherry $\left(5 \times 10^{7}\right)$ viruses. Unfortunately, SignaGen failed to include the GFP reporter gene in our Ad5_CRH-Cre virus; however, numerous cells show mCherry fluorescence in the presence of Ad5_CRH-Cre (Figure 7). These results indicate that Ad5 successfully delivered our genes of interest for expression. However, we did not observe any evidence of cell death when treated with $600 \mathrm{mM}$ CB1954 (Figure 7, bottom right) compared to control treatment with DMSO (Figure 7, top right). This negative result did not appear due to the $\mathrm{CRH}$ promoter. We also did not observe any evidence of cell death in the presence of $600 \mathrm{mM} \mathrm{CB} 1954$ when HEK 293 cells were co-infected with Ad5-lox-STOP-lox/NTR/mCherry virus and Ad5-CMV-

Cre-GFP virus (Figure 8, bottom right) compared to control treatment with DMSO (Figure 8, top right). 


\section{Viral delivery of genes in vivo}

Two rats received $1 \mu \mathrm{l}$ injections of Ad5-CRH-Cre $\left(1.8 \times 10^{7}\right)$ and Ad5-loxSTOP-lox-NTR/mCherry $\left(3.4 \times 10^{7}\right)$ viruses into the CeA. At this concentration we were unable to detect mCherry fluorescence even when tissue was immuno-stained using an anti-mCherry antibody (not shown). Additional tissue was used for PCR in an attempt to detect NTR/mCherry DNA albeit no band was visible (not shown). Additional surgeries that doubled the injection volume to $2 \mu \mathrm{L}$ were also unsuccessful. Injections of Ad5-loxSTOP-lox-NTR/mCherry into the CeA of Sst-cre mice were also unsuccessful in producing reporter expression. These results suggested that either Ad5 virus was inefficient at transducing cells in the CeA or our NTR/mCherry gene was no longer functional. To address this issue we removed the stop-lox-stop sequence to shorten the NTR/mCherry gene allowing it to be package into a floxed (DIO) AAV2 virus; AAV2EF1alpha-DIO-NTRmCherry-WPRE. Injection of this virus in Sst-cre mice revealed strong mCherry reporter fluorescence and, presumably, NTR. An example one of these injections is shown Figure 9. The red fluorescence is mCherry and the green fluorescence is RBFox3/NeuN (neuron specific marker). Despite injections of CB1954 directly into the amygdala where the floxed virus was expressed, at doses several fold higher than that required for cell death in culture, we could not detect any cell death using either immunocytochemistry or qRT-PCR (not shown). 


\section{DISCUSSION}

My Aim was to develop a novel virus based tool to enable study the role of specific peptidergic pathways in hindbrain taste processing and the processing of tasteguided behavior. Specifically, we wanted a tool that could ablate specific cell types in the forebrain to study the impact of their loss on: (1) the ability of amygdala activation to regulate neural processing of taste information in the PBN and (2) acquisition of conditioned taste aversion that normally produces a switch from acceptance to rejection of a taste stimulus.

Other methods including diphtheria toxin A (DTA) and thymidine kinase of HSV (tkHSV) have been effectively used in conditional ablation studies, but have many limitations. For example, tkHSV is only effective in ablating proliferating cells because it inhibits DNA synthesis (Wong et al., 1989). For our purposes, we required a method that ablates non-dividing cells. Diphtheria toxin A is effective in ablating neurons but was not chosen due to potential toxicity associated with handling. Instead, we selected an alternative method, NTR expression combined with the prodrug CB1954, to attempt selective ablation of cells in specific forebrain regions. Additionally, CB1954 has been shown to readily cross the blood-brain barrier simplifying delivery to the NTR expressing cells by intraperitoneal injection (Isles et al., 2001).

Using in vitro cell cultures, we showed that we successfully cloned and expressed the transgenes CRH, Sst, Cre-recombinase, and NTR/mCherry. As expected in the absence of Cre expression, the lox-stop-lox sequence upstream of NTR/mCherry gene 
prevented transcription as measured by fluorescent reporter expression. Cell survival assays in the presence of CB1954 further demonstrated expression of NTR. The cytotoxic effects of increasing concentrations of CB1954 on NTR expressing cells are consistent with previous research (Bridgewater et al., 1995; Clark et al., 1997; Drabek et al., 1997; Felmer and Clark, 2004).

To our surprise, the cytotoxic effects of CB1954 obtained in vitro with expression plasmids were not recapitulated once our gene constructs were package into Ad5. Although infection of HEK 293 cells with our Ad5-CRH-Cre and Ad5-lox-STOPlox/NTR/mCherry viruses produced the expected mCherry reporter expression, CB1954 treatment was without effect on cell survival. Additional experiments tested our viruses in vivo; however, we were unable to detect reporter expression. One possibility is that CeA neurons are not susceptible to infection by Ad5. While adenovirus vectors have many advantages in gene delivery, they also have limitations. The primary advantage of adenovirus is that it permits delivery of relatively large DNA sequences (Zhang et al., 2013). Human adenovirus serotype 5, in particular (Ad5), has been utilized as a gene delivery vector due to its efficient delivery and reduced pathological side effects. Several problems, however, have been identified in the course of development and application of Ad5-based gene therapy protocols such as inefficient gene transfer to target cells (Glasgow et al., 2006; Hedley et al., 2006; Rein et al., 2006), which might be due to relatively low expression of primary adenovirus receptors on many cells (Asaoka et al., 2000; Kim et al., 2003). The internalization process of Ad5 is initiated by attachment of its capsid fiber protein to the cell surface CAR receptor, followed by interaction of its base with surface receptors and internalization (Bai et al., 1993; Bergelson et al., 
1997).Many mammalian cells, however, express very low level of CAR rendering the virus resistant to Ad5 infection. Furthermore, trials aimed at utilizing adenovirus in the brain indicated the presence of inflammatory response even at moderate viral titer $\left(10^{7}\right.$ infectious units) (Thomas et al., 2000). It is possible that such an immune response may eliminate adenovirus before it is able to integrate and express its transgene. Another possibility is that our CRH promoter weakly triggered transgene expression. Using Ad5 as a delivery system, Zhang et al. (Zhang et al., 2013) showed that transgene expression in cortical neuron cultures and in the periventricular nucleus of rats was dependent upon utilization of a strong promoter. To try and overcome the limitations associated with Ad5, we re-amplified and cloned a shorter NTR/mCherry fusion gene (i.e. reducing the size by about 800 nucleotides) so it could be packaged in an adenoassociated virus, serotype 2 (AAV2). AAV2 has been used effectively as a gene delivery vector in the nervous system to target neurons and produce long-term expression of transgenes (Mandel et al., 2006).

At this point we had begun using CRH- and Sst-Cre transgenic mice in which the promoters for CRH or Sst drives expression of Cre recombinase exclusively in CRH or Sst expressing neurons in the brain (Song et al., 2012; Taniguchi et al., 2011). Several injections of this floxed-NTR/mCherry virus were conducted in Sst-cre mice revealing strong mCherry reporter fluorescence and, presumably, NTR expression. Nevertheless, we were unable to achieve cell death in vivo. Given the complexity of trying to figure out why the NTR construct worked in vitro but not in vivo, we decided to abandon cell 
ablation as a method to isolate specific peptidergic pathways and pursue a new optogenetic based approach utilizing the CRH- and Sst-cre mouse lines.
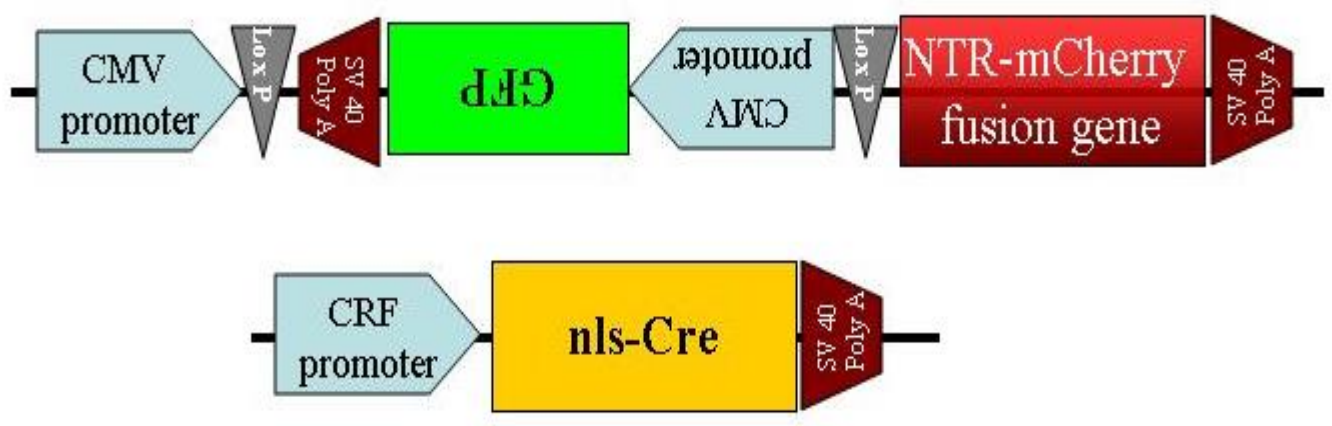

Figure 1. Schematic diagram of floxed NTR-mCherry (top) and CRF-Cre (bottom) constructs.

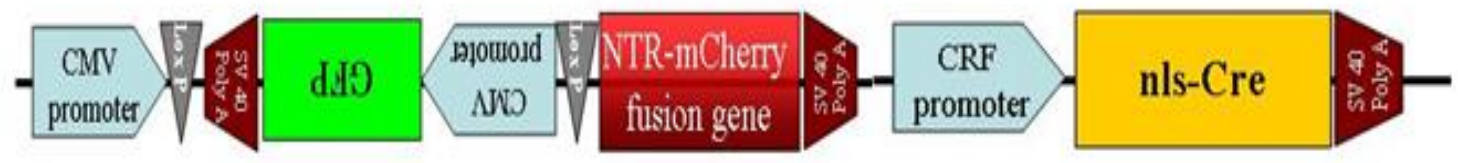

Figure 2.Schematic diagram of single vector containing the CMV-LoxPNTR-mCherry and CRF-Cre cassettes 


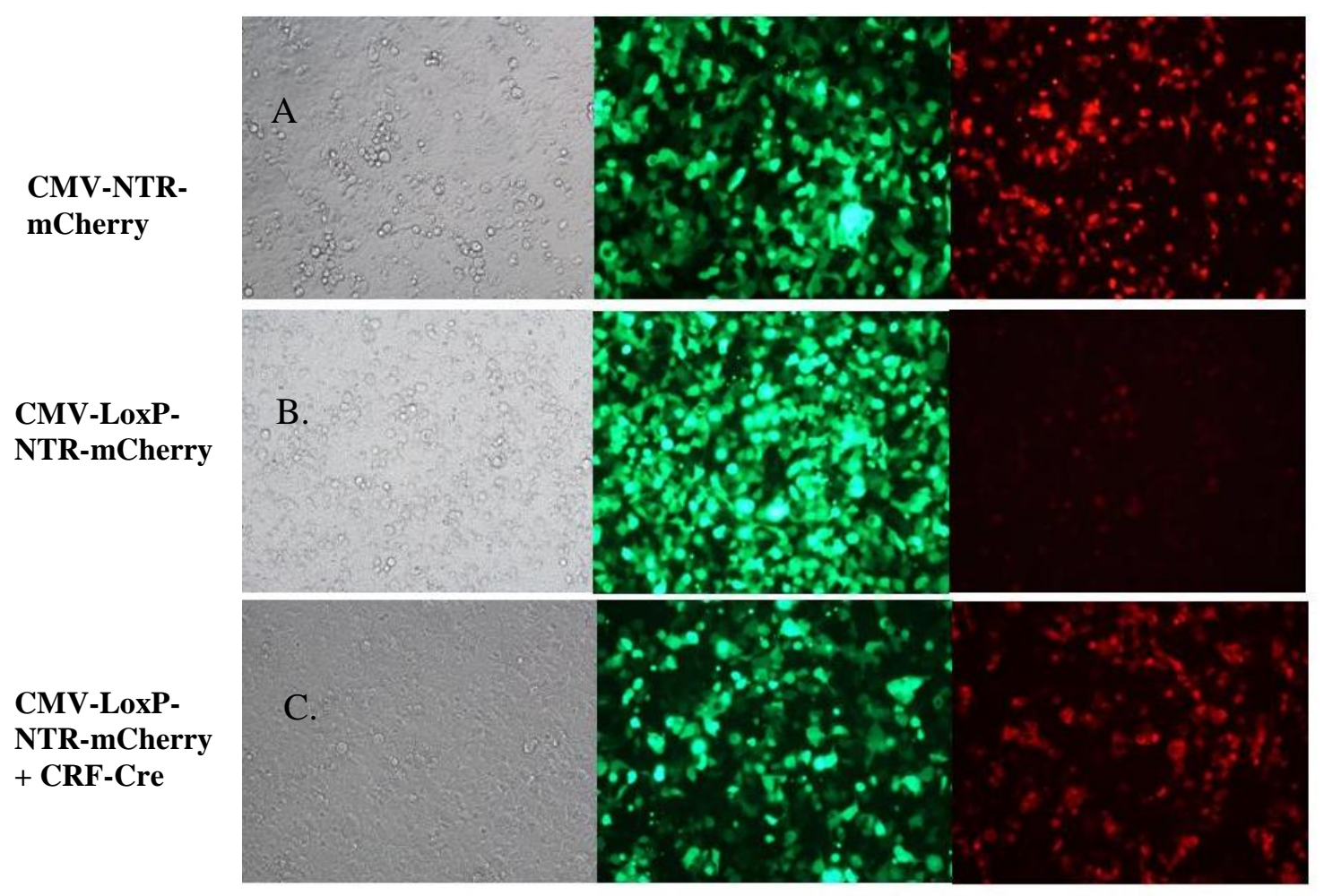

Figure 3. Transfection of CRH producing Y1 cell line with CMVNTR-mCherry construct (top panels), CMV-LoxP-NTR-mCherry construct (middle panels), or both CMV-LoxP-NTR-mCherry and CRF-Cre. All transfected cells exhibit green fluorescence as the pAdTrack vector has a GFP expression cassette. Red fluorescence signifies NTR-mCherry expression. 


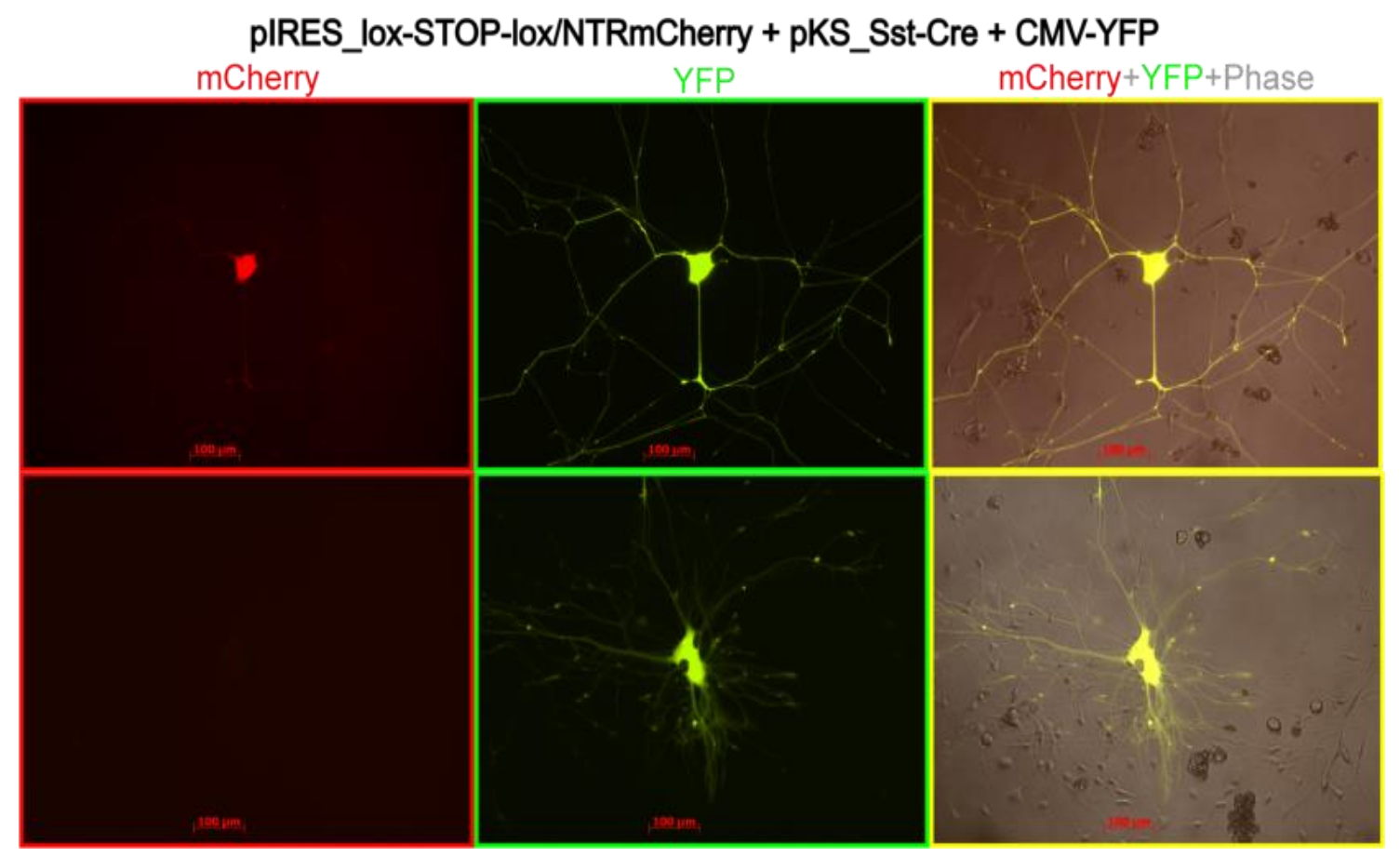

Figure 4. DRG neurons 48 hrs post electroporation with plasmids containing $1 \mu \mathrm{g}$ DNA for lox-STOP-lox/NTRmCherry, Sst promoter-Cre, and CMV-YFP. Top row indicates Sst positive neuron; bottom row indicates Sst negative. 


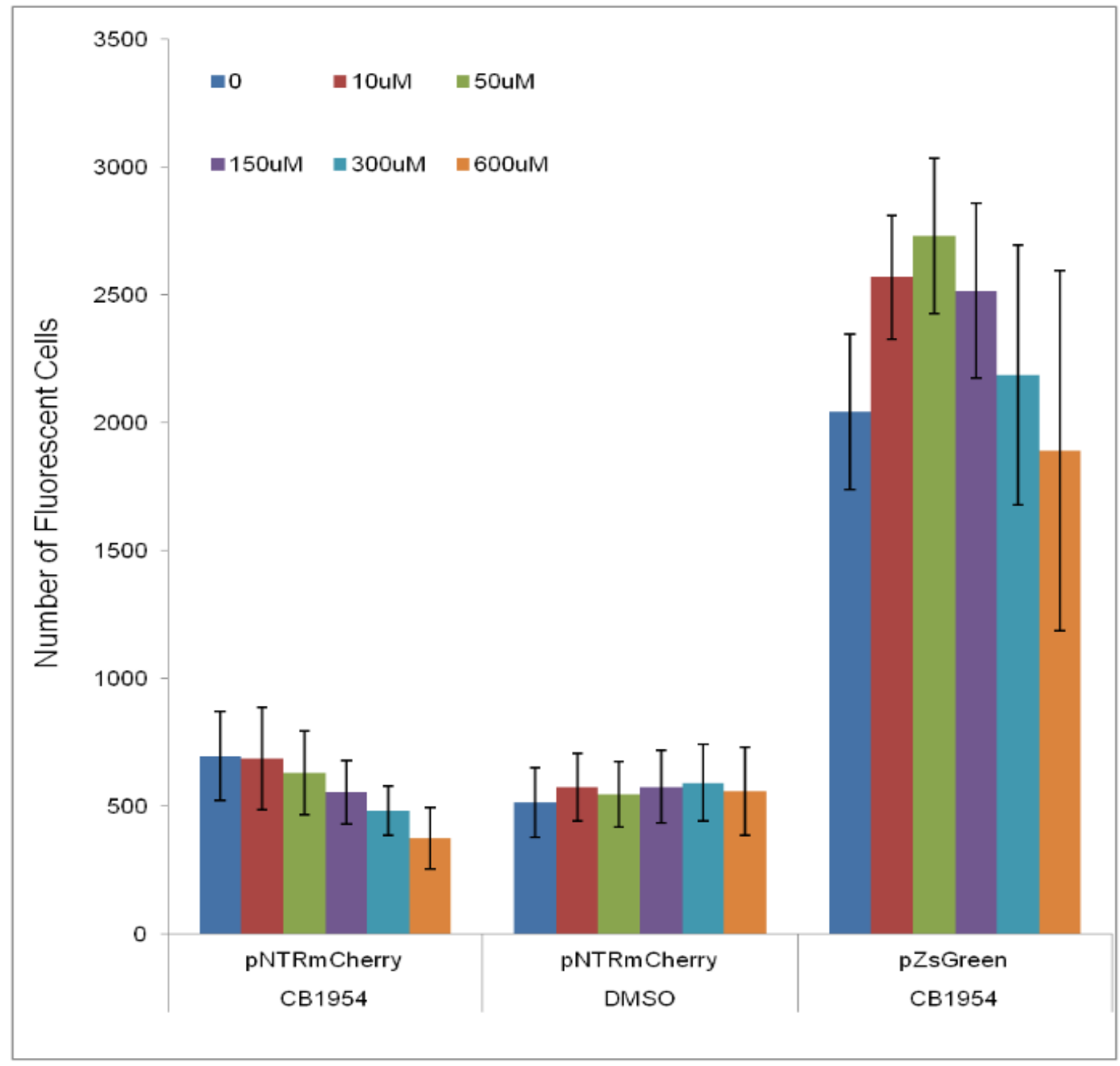

Figure 5. FACS analysis showing the number of HEK 293 cells expressing $\mathrm{NTR} / \mathrm{mCherry}$ or blank plasmid and treated with increasing concentration of CB1954 or the solvent DMSO. Each point represents the mean \pm s.d. of duplicates. 


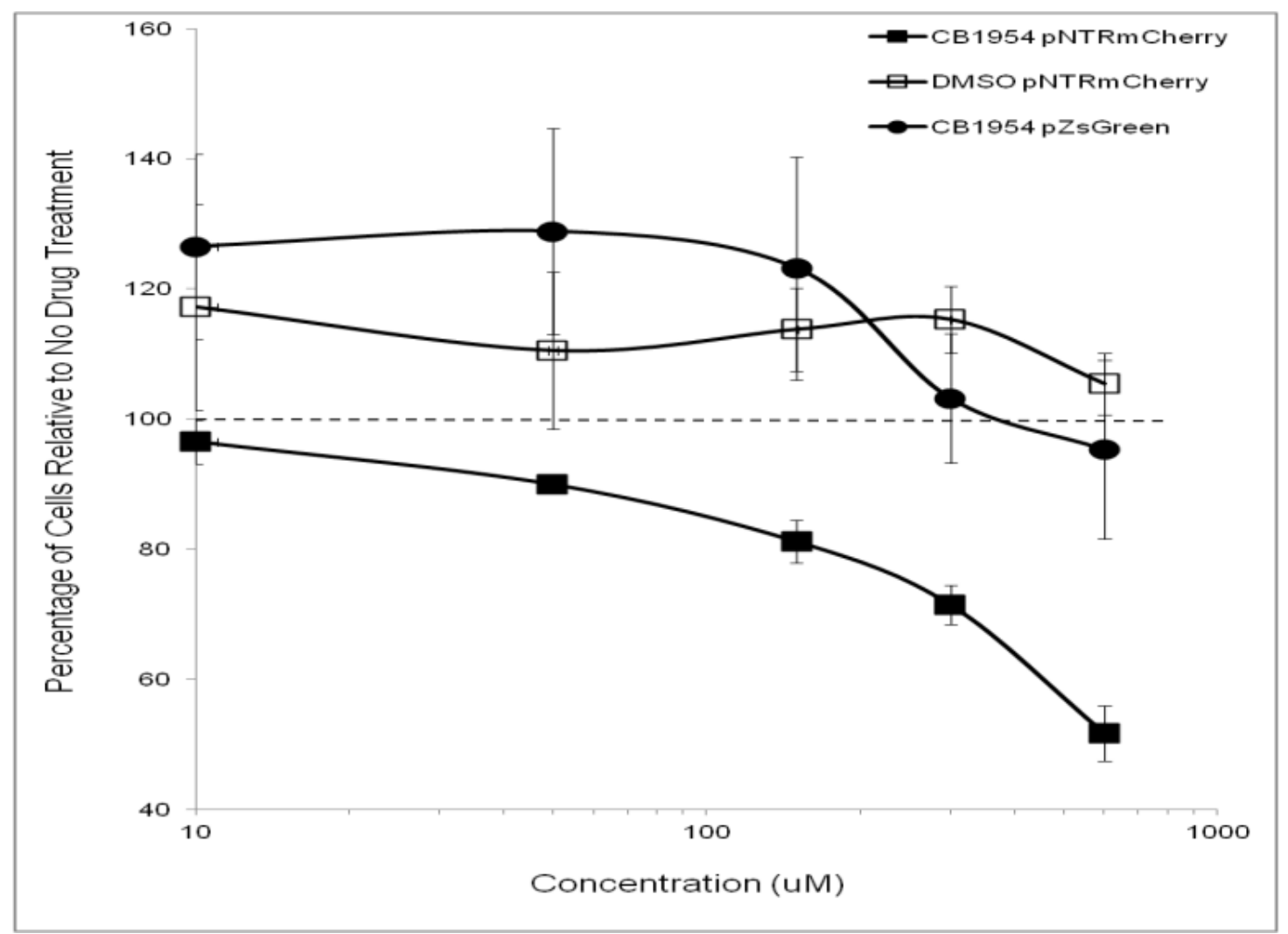

Figure 6. FACS analysis showing the percentage of HEK 293 cells expressing NTR/mCherry or blank plasmid and treated CB1954 or the solvent DMSO relative to no drug treatment. Each point represents the mean \pm s.d. of duplicates. 


\section{Ad5_CRF-Cre + Ad5_lox-STOP-lox/NTRmCherry}

Phase

mCherry

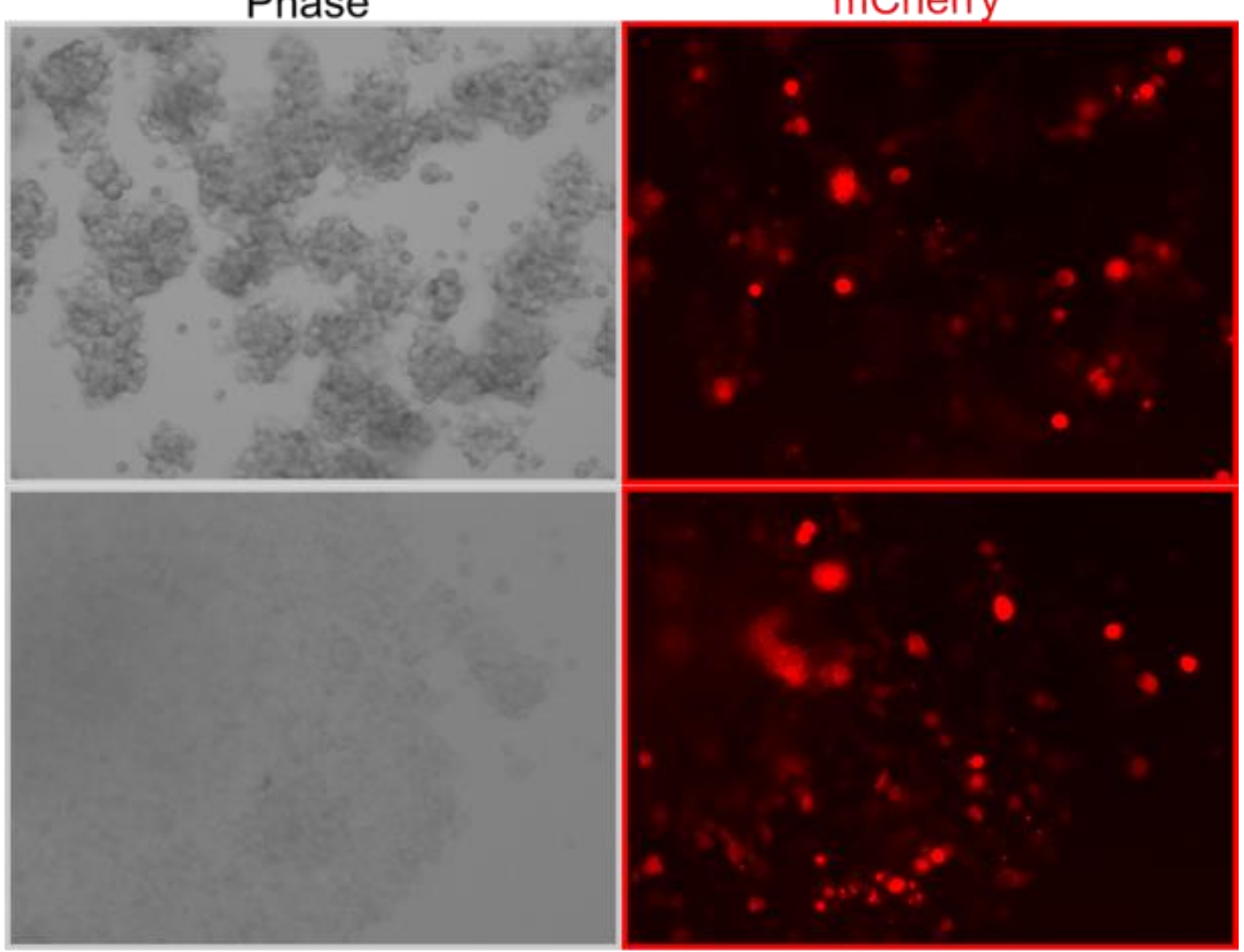

Figure 7. HEK 293 cells transfected with both Ad5-Crh-cre virus $\left(5 \times 10^{7}\right)$ and Ad5-lox-stop-lox-NTR/mCherry virus $\left(5 \times 10^{7}\right)$ and treated with DMSO (top row) or $600 \mathrm{mM} \mathrm{CB} 1954$ (bottom row). 


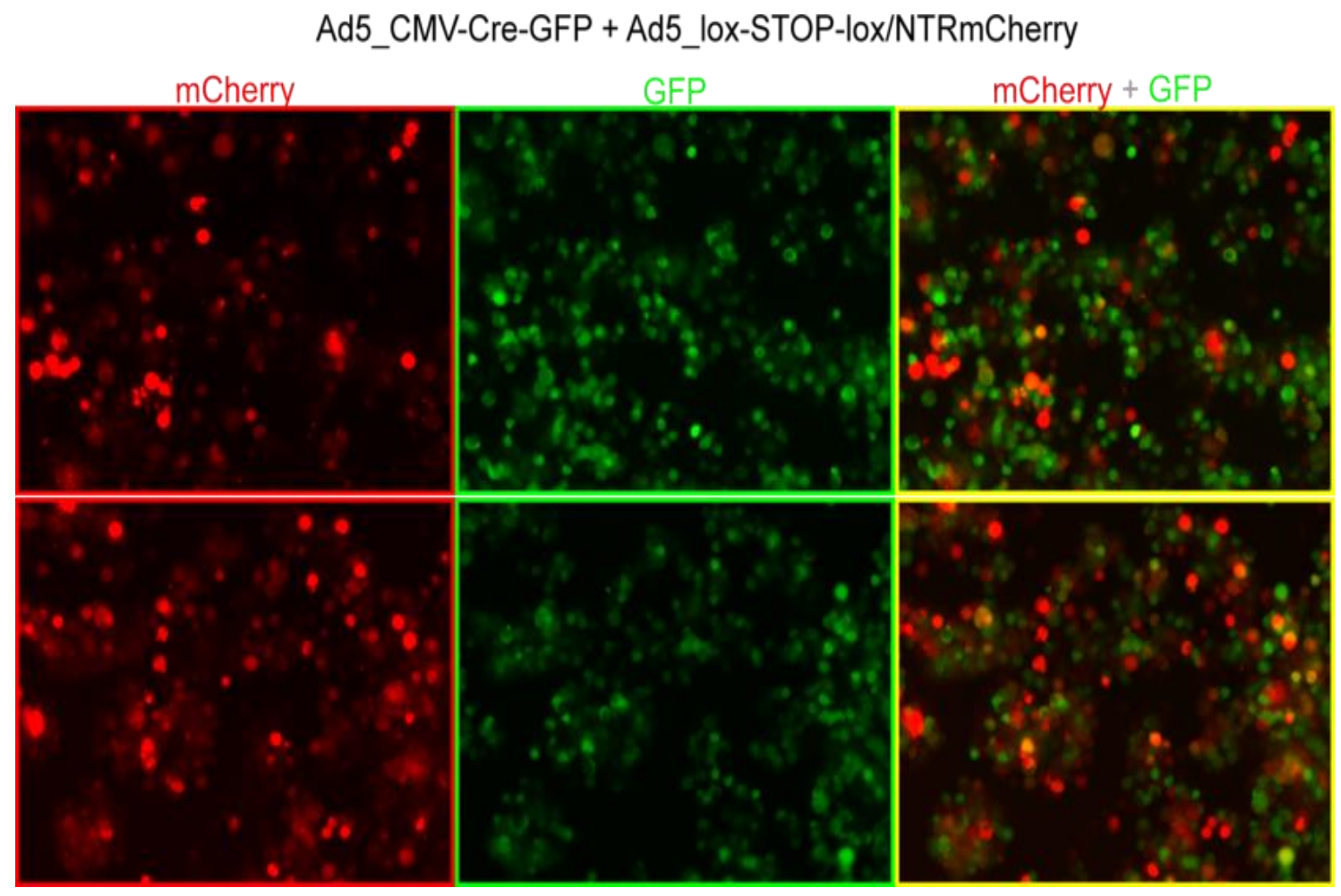

Figure 8. HEK 293 cells transfected with both Ad5-CMV-cre-GFP virus $\left(5 \times 10^{7}\right)$ and Ad5-lox-stop-lox-NTR/mCherry virus $\left(5 \times 10^{7}\right)$ and treated with DMSO (top row) or 600 mM CB1954 (bottom row). 


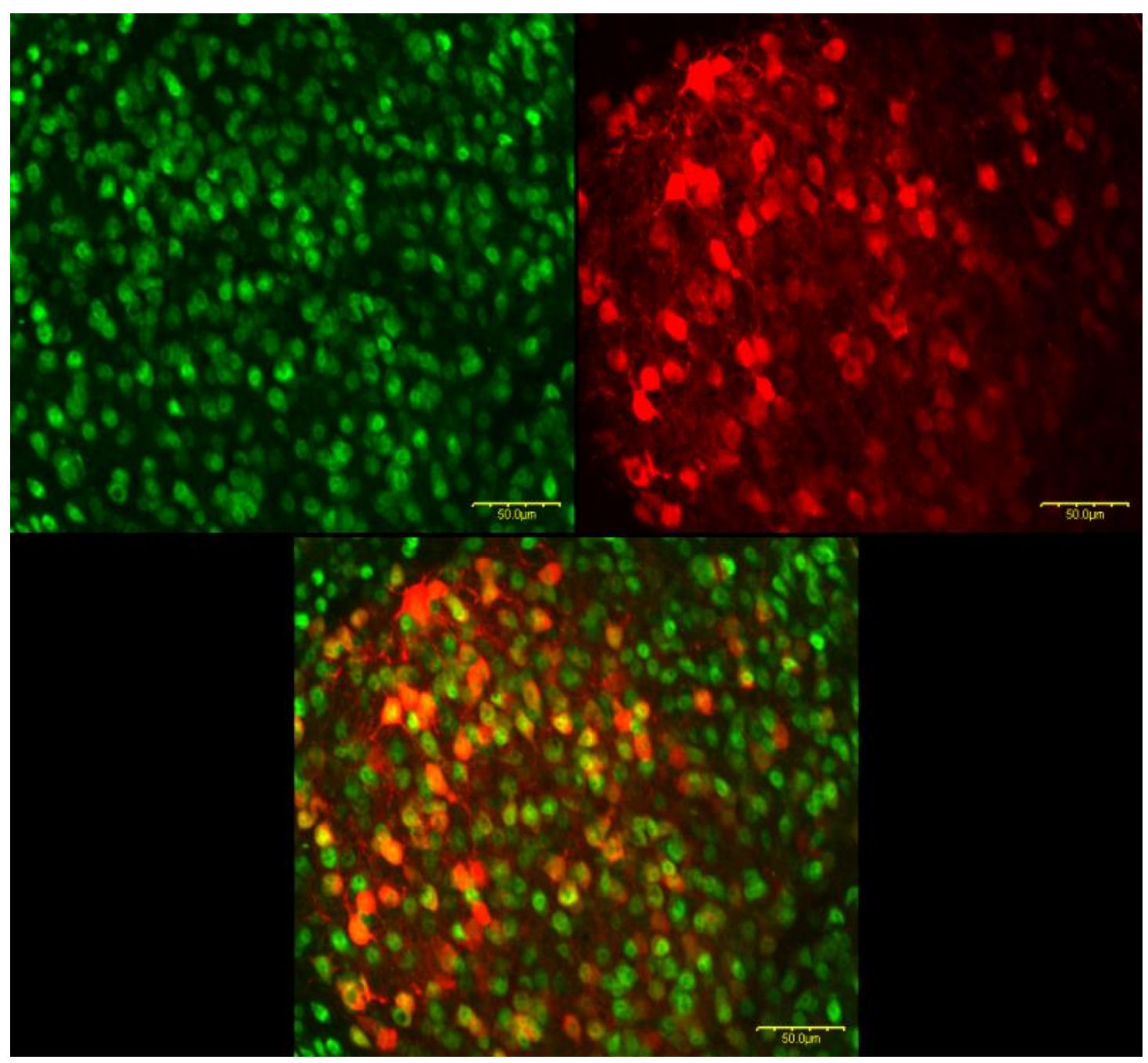

Figure 9. Confocal image of mCherry fluorescent cells (red) in the CeA of Sst-cre mice following injection of AAV2-EF1alpha-DIO-NTRmCherry-WPRE (600 nl). Green fluorescent cells indicate RBFox3/NeuN positive neurons. Scale bars $=50$ um. 


\section{CHAPTER II}

\section{MAPPING THE SOMATOSTATIN AND CORTICOTROPIN RELEASING FACTOR \\ CELL TYPES THAT PROJECT TO PARABRAICHIAL NUCLEUS FROM THE AMYGDALA AND BED NUCLUES OF STRIA TERMINALIS}

Substantial evidence suggests that the PBN is obligate for learned and some forms of unlearned taste-guided behavior. For example, conditioned taste aversion (CTA) and sodium imbalance (sodium appetite) alter taste palatability coincident with changes in taste-evoked responses in $\mathrm{PBN}$, and switch the behavioral response to a gustatory stimulus from ingestion to rejection or vice versa (Berridge et al., 1984; Breslin et al., 1992; Nachman and Ashe, 1973; Shimura et al., 1997a; Shimura et al., 1997c). Animals with bilateral lesions of the PBN fail to acquire a CTA or express a sodium appetite (Grigson et al., 1998; Scalera et al., 1995), while those with thalamic lesions are unaffected (Reilly and Pritchard, 1996; Scalera et al., 1997). In addition to the thalamocortical pathway, PBN gustatory efferents target several ventral forebrain areas directly including the LH, CeA, and BNST (Li and Cho, 2006; Norgren, 1976), and, in turn, receives projections from these forebrain areas that can modulate neural responsiveness (Li et al., 2005; Li and Cho, 2006; Lundy and Norgren, 2004). This descending neuromodulatory input likely plays a prominent role in affective meaning arising from gustatory activity because: 1) chronically decerebrate rats, which lack connections between the forebrain and hindbrain, fail to express CTA or sodium appetite 
(Grill and Norgren, 1978c; Grill et al., 1986) and 2) altered PBN taste responses normally observed following CTA are absent in decerebrate animals (Tokita et al., 2004).

Previous studies have identified several neuropeptide-immunoreactive cell populations in the $\mathrm{CeA}$ and $\mathrm{LH}$ that project to the PBN including Sst, neurotensin, CRH, enkephalin, substance P, and galanin (Moga and Gray, 1985; Moga et al., 1990). Electrophysiologically guided injections of a retrograde tracer into the PBN shows that the CeA contains, by far, the largest number of output neurons to the caudal gustatory region of the PBN (Kang and Lundy, 2009; Panguluri et al., 2009; Saggu and Lundy, 2008; Zhang et al., 2010). A significant number of these output cells express somatostatin Sst or CRH (Panguluri et al., 2009). Thus, Sst and CRH cell types of CeA origin are well positioned to exert neuromodulatory effects on central taste processing. The caveat being that the majority of previous neurophysiological and anatomical studies were conducted using rats.

The mouse is becoming an increasing important model for the study of the gustatory system. The current state of knowledge indicates striking similarity in the anatomical connectivity of the PBN and ventral forebrain in mice compared to rats and hamsters. That is, neurons in the mouse PBN are reciprocally connected to the CeA, BNST, and LH (Tokita et al., 2009; Tokita et al., 2010). The neurochemical cell types that comprise these centrifugal pathways have not yet been elucidated. The present study used transgenic mouse strains to compare the degree to which Sst and CRH cell types of forebrain origin project to caudal regions of the PBN; the area where neurons responsive 
to taste stimulation of the anterior tongue are concentrated (Tokita and Boughter, 2012; Tokita et al., 2012). These data have been previously published (Magableh and Lundy, 2014).

\section{Materials and Method}

\section{Animals:}

Two strains of mice, Sst-cre and CRH-cre (Jackson Laboratories, Sst ${ }^{\mathrm{tm} 2.1(\mathrm{Cre}) \mathrm{Zjh} / \mathrm{J}}$

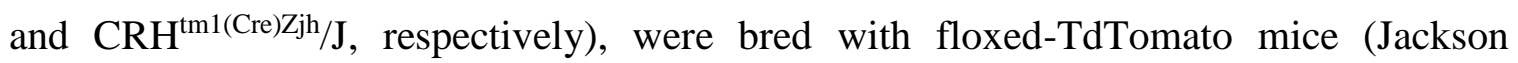
Laboratories, B6.Cg-Gt(ROSA)26Sor $\left.{ }^{\mathrm{tm} 14(\mathrm{CAG}-\mathrm{TdTomato}) \mathrm{Hze}} / \mathrm{J}\right)$ to generate two reporter mouse lines that expressed TdTomato in Sst and CRH cell types (Sst/TdTomato and CRH/TdTomato lines). Three male and three female mice from each reporter line weighing 18-23g were used in this study. The animals were maintained in a temperature-controlled colony room on a 12-h light/dark cycle and allowed free access to normal rodent chow and distilled water. All procedures conformed to National Institutes of Health guidelines and were approved by the University of Louisville Institutional Animal Care and Use Committee.

\section{Surgery:}

The mice were anesthetized with an intraperitoneal injection of Ketamine/Xylazine mixture $[(100 \mathrm{mg} / \mathrm{kg}(\mathrm{K}) / 10 \mathrm{mg} / \mathrm{kg}(\mathrm{X})]$. If needed, an additional dose of Ketamine $(50 \mathrm{mg} / \mathrm{kg})$ was administered to continue a deep level of anesthesia. The animals were placed on a feedback-controlled heating pad, and rectal temperature was monitored to maintain body temperature at $37 \pm 1^{\circ} \mathrm{C}$. Animals were secured in a stereotaxic instrument and the skull was exposed with a midline incision then leveled 
with reference to bregma and lambda cranial sutures. A small hole was drilled through the bone overlying the cerebellum to allow access to the PBN. The analgesic buprenex $(0.1 \mathrm{mg} / \mathrm{kg})$ was administered prior to wound incision and again for at least 2 days postsurgery.

\section{$\underline{\text { Retrograde tracer injection: }}$}

The caudal PBN was located using the following stereotaxic coordinates relative to bregma, -5.4 posterior, -1.2 lateral, and -2.9 ventral. Injections were performed using a $10-\mu \mathrm{L}$ nanofil syringe (34-g beveled needle, WPI) mounted in a microprocessorcontrolled injector (UltraMicroPump III, WPI) attached to the stereotaxic instrument. The syringe was first front-filled with light mineral oil followed by a $0.2 \%$ solution of cholera toxin subunit B (CTb, Alexa Fluor 488 conjugate, Life Technologies) in $0.1 \mathrm{M}$ phosphate-buffered saline. The microprocessor was set to deliver $75 \mathrm{nl}$ of $\mathrm{CTb}$ at a rate of $25 \mathrm{nl} / \mathrm{min}$, and the syringe retracted 5 min post-injection. Five to 6 days following $\mathrm{CTb}$ injection, the animals were administered a lethal dose of Nembutal $(150 \mathrm{mg} / \mathrm{kg})$ and perfused through the ascending aorta with $8 \mathrm{ml}$ of $4 \%$ paraformaldehyde containing $4 \%$ sucrose in $0.1 \mathrm{M}$ phosphate buffer (Electron Microscopy Sciences). The brains were removed, blocked just rostral to the $\mathrm{PBN}$, and post-fixed overnight at $4^{\circ} \mathrm{C}$ in the same fixative. Coronal $(50 \mu \mathrm{m})$ sections were cut using a freezing microtome.

\section{Data Analysis:}

Cell bodies positive for $\mathrm{CTb}$ and TdTomato (fluorescein isothiocyanate; excitation filter: 490nm; barrier filter: 550nm; Cy-3; excitation filter: 520-554nm; barrier filter: 580nm) in the insular cortex (IC), CeA, BNST, and LH were identified using sequential scanning with an Olympus confocal microscope. In every other section, the 
number of fluorescent positive cells was calculated for each forebrain site and used for statistical analyses. The color segmentation function in Image-Pro Plus software was used to separate and count retrogradely labeled, peptide positive, and double-labeled neurons (Panguluri et al., 2009; Zhang et al., 2010). Briefly, confocal images were opened in Image-Pro Plus and invert contrast applied, which changed the black background to white, the green color of retrogradely labeled cells to pink, the red color of TdTomato cells to turquoise, and double-labeled cells to dark blue/purple. The threshold for counting a cell as singly or double labeled was set to $>10$ adjacent pixels exhibiting the same color. For each neurochemical, separate one-way analysis of variance was used to compare differences between forebrain sites resulting from caudal PBN injections (SPSS 17.0). The results are presented as mean \pm SE. A value of $P<0.05$ was considered statistically significant.

\section{Results}

\section{Injection Sites}

Figure 10 shows photomicrograph examples of $\mathrm{CTb}-488$ injected into the caudal PBN. Images such as these were used to create accurate reconstructions of the location and extent of tracer injections (Figure 11). Each panel contains a medial and lateral view of a Neurolucida 3D reconstruction of $\mathrm{CTb}-488$ injected into the PBN of an individual mouse. To maximize visualization of the $\mathrm{CTb}-488$ injections, the orientations vary somewhat across cases as indicated by the 3-vector-axis in each panel. Each injection targeted predominately the medial, ventral lateral, and waist portions of the caudal PBN with minimal spread into the rostral regions. The asterisks in each panel denote the 
approximate location of the "waist area" in which gustatory responsive neurons are typically encountered (Tokita and Boughter, 2012; Tokita et al., 2012). As an example, the 2D images in Figure $\mathbf{1 0}$ were used to create the 3D representations shown in the bottom middle panel of Figure 11 (i.e. animal ET-71).

\section{Distribution of CRH, Sst and CTb positive neurons}

Since the distributions of forebrain-PBN projecting neurons were similar to those described in earlier tracing studies derived mostly from rats, the present findings are only briefly summarized (Kang and Lundy, 2009; Moga and Gray, 1985; Moga et al., 1989; Tokita et al., 2009). Retrogradely labeled neurons were observed in the LH, CeA, BNST and IC following injections in the caudal regions of PBN. The IC was identified as the area from bregma to approximately $0.6 \mathrm{~mm}$ anterior and directly lateral to the claustrum. The BNST was identified as the area approximately $0.3 \mathrm{~mm}$ anterior and $0.1 \mathrm{~mm}$ posterior to bregma directly medial to the internal capsule above the anterior commissure. The CeA was identified as the area approximately 0.7 to $1.9 \mathrm{~mm}$ posterior to bregma ventral to the striatum, medial to the basolateral nucleus of the amygdala, and lateral to the optic tract. The LH was identified as the area approximately 1.8 to $2.3 \mathrm{~mm}$ posterior to bregma sandwiched between the internal capsule lateral and the fornix medial. Subsequent analyses of cell counts exclude the IC because no evidence was found for co expression of CTb-488 and CRH or Sst, despite the fact that these peptidergic cell types were intermingled with $\mathrm{CTb}$ labeled projection neurons in IC. 
Figure 12 shows photomicrograph examples of TdTomato reporter expression in the CeA and BNST of Sst and CRH mice. Tissue is arranged from rostral to caudal and corresponds to the sections from which cell counts were obtained. Visual inspection indicates a clear difference between Sst and CRH cell types where Sst cells are more densely packed in both forebrain nuclei. In the CeA, CTb-488 labeled cells were found throughout the rostrocaudal extent, while in the BNST they were more densely packed around the midline crossing of the anterior commissure with few cells observed in the most rostral sections. In the LH (not shown), CTb-488 cells were scattered between internal capsule lateral and the fornix medial with retrogradely labeled cells concentrating around the ventral tip of the internal capsule posteriorly. Statistically significant differences were observed in the number of $\mathrm{CTb}$ labeled cells between forebrain areas $\left(\mathrm{Sst} /\right.$ TdTomato mice, $\mathrm{F}_{2,12}=5.1, \mathrm{P}=0.02 ; \mathrm{CRH} / \mathrm{TdT}$ Tomato mice, $\left.\mathrm{F}_{2,16}=6.2, \mathrm{P}=0.01\right)$. More neurons were retrogradely labeled in the CeA following tracer injections into the caudal PBN compared to the LH and BNST (Figures 13A \& B; P's $\leq 0.04$ ), which were not different from one another (P's $\geq 0.4)$.

\section{Double labeled neurons}

A significant main effect for forebrain site was observed for the percentage of CTb labeled cells that co-expressed CRH $\left(\mathrm{F}_{2,16}=20.0, \mathrm{P}<0.01\right)$ and Sst $\left(\mathrm{F}_{2,12}=63.5\right.$, $\mathrm{P}<0.01)$. The BNST contained a greater percentage of $\mathrm{CTb}$ cells that co-express $\mathrm{CRH}$ compared to the CeA and LH (P's $<0.01$ ), which were not statistically different from one another (Figure 13C, P>0.5). Across animals, the average number of PBN projection cells that co-expressed CRH was $27.4 \pm 6.3$ in the BNST, $22.8 \pm 3.5$ in the $\mathrm{CeA}$ and 8.3 
\pm 1.7 in the $\mathrm{LH}$. In contrast to $\mathrm{CRH}$, the order of greatest percentage of $\mathrm{CTb}$ cells that coexpressed Sst was CeA $>$ BNST $>$ LH (Figure 13D, P's $<0.01$ ). Across animals, the average number of PBN projection cells that co-expressed Sst was $457.8 \pm 70.6$ in the CeA, $75 \pm 10.4$ in the BNST and $3.5 \pm 0.6$ in the LH. Figure 14shows photomicrograph examples of single and double labeled forebrain neurons. The amygdala images from Sst and $\mathrm{CRH}$ mice correspond to the posterior part of the CeA (e.g. roughly the $7^{\text {th }}$ section from the top in Figure 12), while those for the BNST correspond to the level at which the anterior commissure crosses the midline (e.g. roughly the $5^{\text {th }}$ section from the top in Figure 12). It was at these anatomical levels in which the bulk of double labeled cells were observed. In Sst mice, the percentage of $\mathrm{CTb}$ positive cells in the three most caudal sections of the CeA that co-expressed Sst was $70.7 \pm 5.8 \%$ compared to $33.5 \pm 7.5 \%$ in the three most rostral sections. In the BNST of CRH mice, the percentage of $\mathrm{CTb}$ positive cells that co-expressed CRH was $13.5 \pm 2.3 \%$ in the three mid rostrocaudal sections compared to $5.4 \pm 1.1 \%$ and $3.5 \pm 1.8 \%$ in the two most caudal and rostral sections, respectively. These data are consistent with previous studies in rats where peptide expressing cells in the CeA that project to the PBN were concentrated in the caudal regions (Moga and Gray, 1985; Panguluri et al., 2009; Veening et al., 1984). Our results also indicate spatial organization of BNST-to-PBN peptidergic cells.

\section{Discussion}

The objective of the present experiments was to further our knowledge of the mouse central gustatory system by delineating neurochemical pathways from the forebrain to the caudal PBN. Our results extend prior investigations by showing that 
corticotrophin releasing hormone and somatostatin cell types in certain forebrain regions are a major source of descending input to caudal regions of the PBN that receive gustatory orosensory signals.

In general, our data are in good agreement with a prior study in mice examining the afferent connections of the PBN (Tokita et al., 2009). Similar to the present study, Tokita and colleagues placed retrograde tracer injections centered on the caudal waist region of the PBN and observed labeled neurons in the $\mathrm{IC}, \mathrm{LH}, \mathrm{CeA}$, and BNST. Neurons projecting to the PBN were found almost exclusively ipsilateral to the injection site in the BNST and CeA, but bilateral with ipsilateral dominance in the IC and LH. Both the present and previous study indicates that the CeA contained the largest number of neurons projecting to the caudal PBN compared to the other forebrain regions. Together, these results are consistent with previous studies in rats that placed retrograde tracer injections into the caudal gustatory responsive region of the PBN under electrophysiological guidance (Kang and Lundy, 2009; Panguluri et al., 2009).

Prior studies investigating descending peptidergic pathways to the $\mathrm{PBN}$ in rats have reported somewhat discrepant results in particular concerning co-expression in the CeA. For example, the percentage of retrogradely labeled cells in the CeA that coexpressed Sst-ir ranged from 6 - 50\% (Moga and Gray, 1985; Panguluri et al., 2009; Veening et al., 1984), while those co-expressing CRH-ir ranged from 11 - 66\% (Moga and Gray, 1985; Panguluri et al., 2009). For the LH, 9 - 21\% of retrogradely labeled cells were found to be immunoreactive for $\mathrm{CRH}$, but only 1 - $4 \%$ were immunoreactive for Sst 
(Moga et al., 1990; Panguluri et al., 2009). Finally, 14 - 20\% of retrogradely labeled cells in the BNST were CRH-ir, while 4 - 11\% were Sst-ir (Moga et al., 1989; Panguluri et al., 2009). Some of this inconsistency might be related to the size of retrograde tracer injections into the PBN and, thus, the region of the PBN targeted.

A previous study from our laboratory using electrophysiology to guide small injections of retrograde tracer that targeted either the caudal gustatory responsive or rostral non gustatory responsive regions of the PBN in rats reported difference in terms of peptide co-expression (Panguluri et al., 2009). Compared to caudal PBN injections, injections into the rostral PBN produced a significantly greater percentage of cells that co-expressed retrograde tracer and CRH-ir or Sst-ir in the BNST and CeA. The largest discrepancy between our previous data set in rat and the present mouse data set relates to peptide co expression in the $\mathrm{CeA}$ and IC. The present results indicate that a far greater of percentage of Sst cell types in the CeA project to the caudal PBN in mice $(46.3 \pm 3.8 \%)$ compared to that observed in rats $(6.2 \pm 1.1 \%)$. Moreover, a small percentage of $\mathrm{CRH}$ cell types in the IC of rats projected to the caudal PBN, but not in the present mouse study. These inconsistencies might represent species differences or differences in experimental approaches such as different retrograde tracers, tracer injection techniques, and/or approaches to reveal peptidergic expression.

Although each of the circuits investigated in the present study are known to participate in ingestive behavior (Bielavska and Roldan, 1996; Caulliez et al., 1996; Lamprecht et al., 1997; Roldan and Bures, 1994; Roth et al., 1973; Schwartz and 
Teitelbaum, 1974; Zardetto-Smith et al., 1994), the precise role(s) of specific descending peptidergic inputs is not yet defined. Previous electrophysiological studies demonstrate that stimulation or inactivation of the IC, BNST, CeA and LH produces inhibitory and/or excitatory effects on PBN taste cells (Dilorenzo and Monroe, 1992; Li et al., 2005; Li and Cho, 2006; Lundy and Norgren, 2001; Lundy and Norgren, 2004). Thus, CRH and/or Sst forebrain-PBN pathways, in particular those arising from the BNST and CeA, might be involved in mediating these neurophysiological changes thought to play a role in the elaboration of gustatory preference/aversion and, consequently, ingestive behavior (Grossman et al., 2008; Li et al., 2013a; Moran and Katz, 2014; Shimura et al., 1997a; Shimura et al., 1997c; Tokita et al., 2004). Centrally administered CRH and its homologue urocortin have been shown to diminish intake in a variety of species including rodent, while Sst administration augmented intake (Benoit et al., 2000; Fekete et al., 2007; Heinrichs et al., 1993; Jones et al., 1998; Karasawa et al., 2014; Parrott, 1990; Spina et al., 1996; Stengel et al., 2010). Furthermore, injections of CRH into the lateral PBN inhibits sodium chloride intake in sodium depleted rats, while injections of a CRH receptor antagonist had the opposite effect, increasing sodium chloride intake (Silva et al., 2006). To the best of our knowledge the action(s) of CRH and Sst on gustatory neurons in the PBN has not been determined; however, in several other brain regions the influence of CRH on neural activity is predominately excitatory (Blank et al., 2003; Kash et al., 2008; Lowry et al., 2000; Ugolini et al., 2008), while that for Sst is inhibitory (Chieng and Christie, 2010; Connor et al., 2004; Jacquin et al., 1988; Saleh and Cechetto, 1993; Saleh and Cechetto, 1995). 


\section{Perspective}

Sensory systems play a fundamental role in allowing us to perceive and appreciate the world around us. Information processing in sensory circuits is not fixed, but modifiable at every level of the pathway. Such neuromodulation enables flexibility in neural circuits and, thus, adaptive behavior in the face of changing conditions. Within the gustatory system, flexibility in taste-guided behavior involves neural communication between specific forebrain and hindbrain gustatory nuclei to extract meaning from the sensory stream that can promote or discourage consumption. While this functional association between hindbrain and forebrain taste areas involved in eating has been clear for decades, the neuromodulatory substances and cellular mechanisms that mediate input/output interactions remain ill-defined. The use of transgenic mice in which $\mathrm{Cre}$ recombinase expression is driven by specific promoters provides a unique and powerful tool for future investigations aimed at delineating the contribution of specific neurochemical pathways to gustatory sensory processing. The results of the present study provide a first step by identifying two specific peptidergic pathways of forebrain origin that are well positioned to influence taste processing in the PBN; a hindbrain nucleus critical for adaptive taste-guided behavior. 


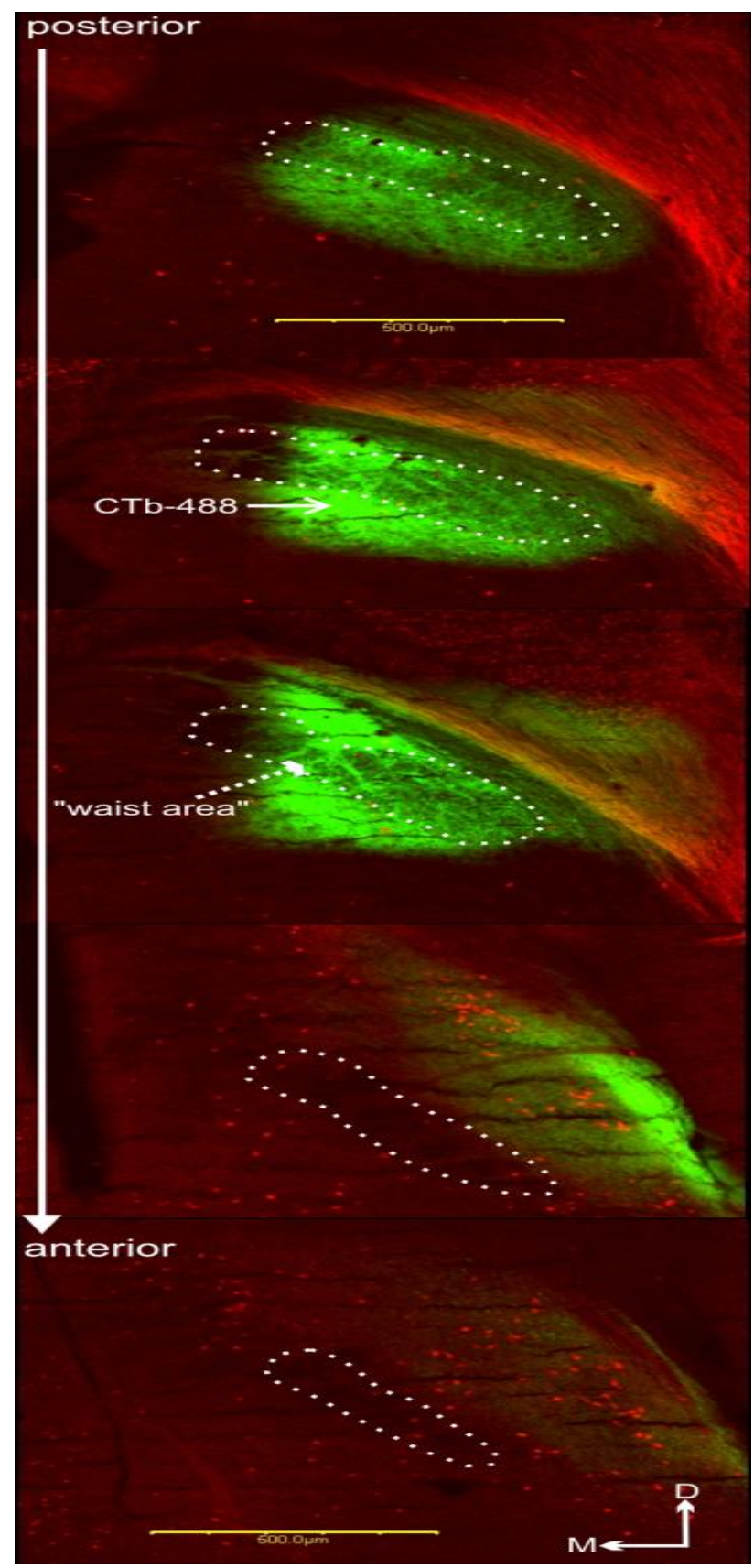

Figure 10. Example photomicrographic images for ear tag-71 (ET-71) showing CTb488 tracer injection (solid arrow) into the caudal region of the PBN. The boundary of the superior cerebellar peduncle is outlined by white dots. Scale bar equals $500 \mu \mathrm{m}$. 


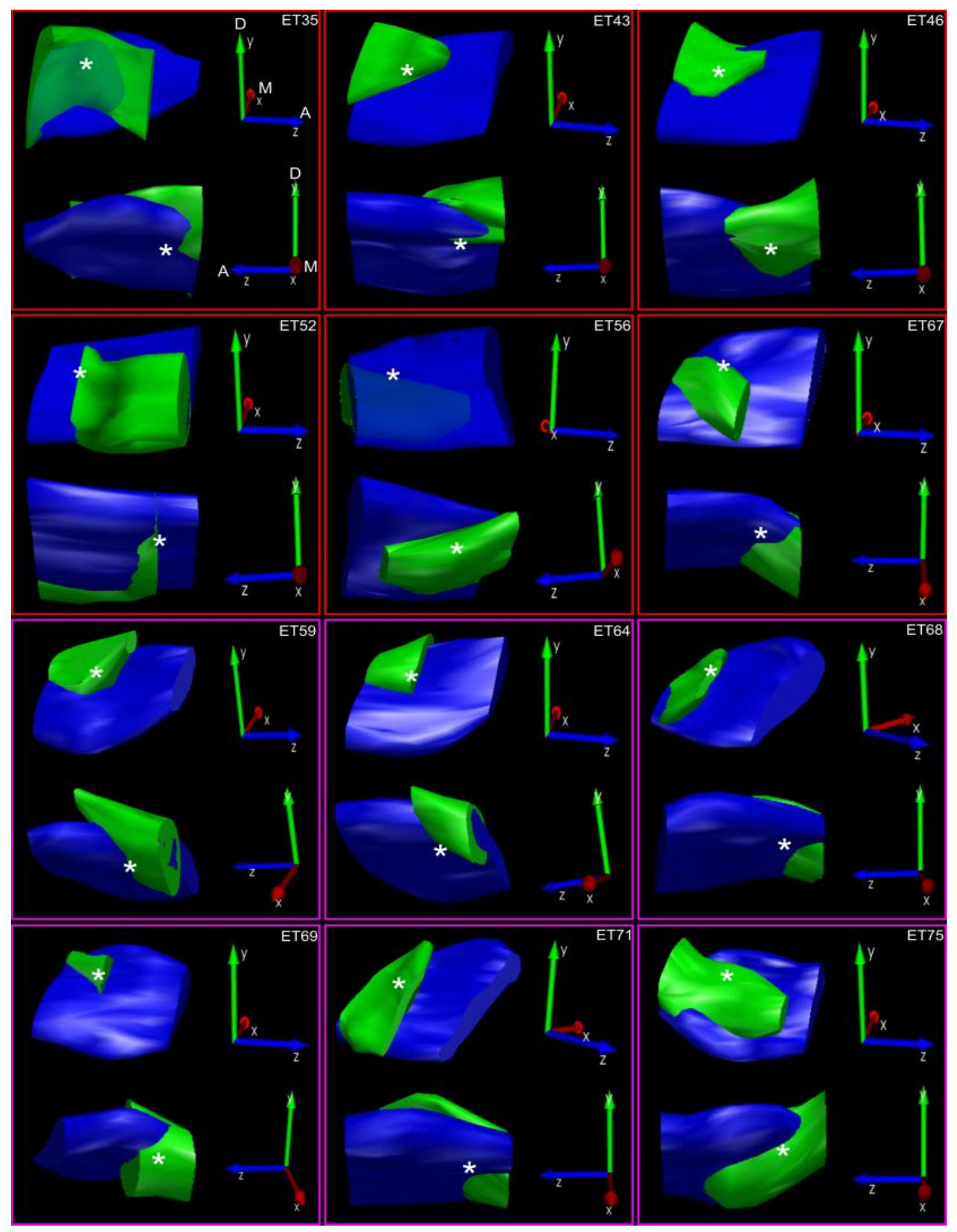


Figure 11. Neurolucida reconstructions of $\mathrm{CTb}-488$ injections into the PBN of Sst/TdTomato mice (ET’s 35, 43, 46, 52, 56 \& 67) and CRH/TdTomato mice (ET’s 59, $64,68,69,71 \& 75)$. The darker solid in each panel represents the contour traced around the superior cerebellar peduncle and the lighter solid the contour traced around the CTb488 fluorescence. Two 3D representations are shown for each animal; a lateral view (top image in each panel) and a medial view (bottom image in each panel) of the injection. The orientation of the $3 \mathrm{D}$ axis shown to the right of each image is as follows: $\mathrm{Y}$ arrow points dorsal, $\mathrm{Z}$ arrow points anterior and $\mathrm{X}$ arrow points medial. 


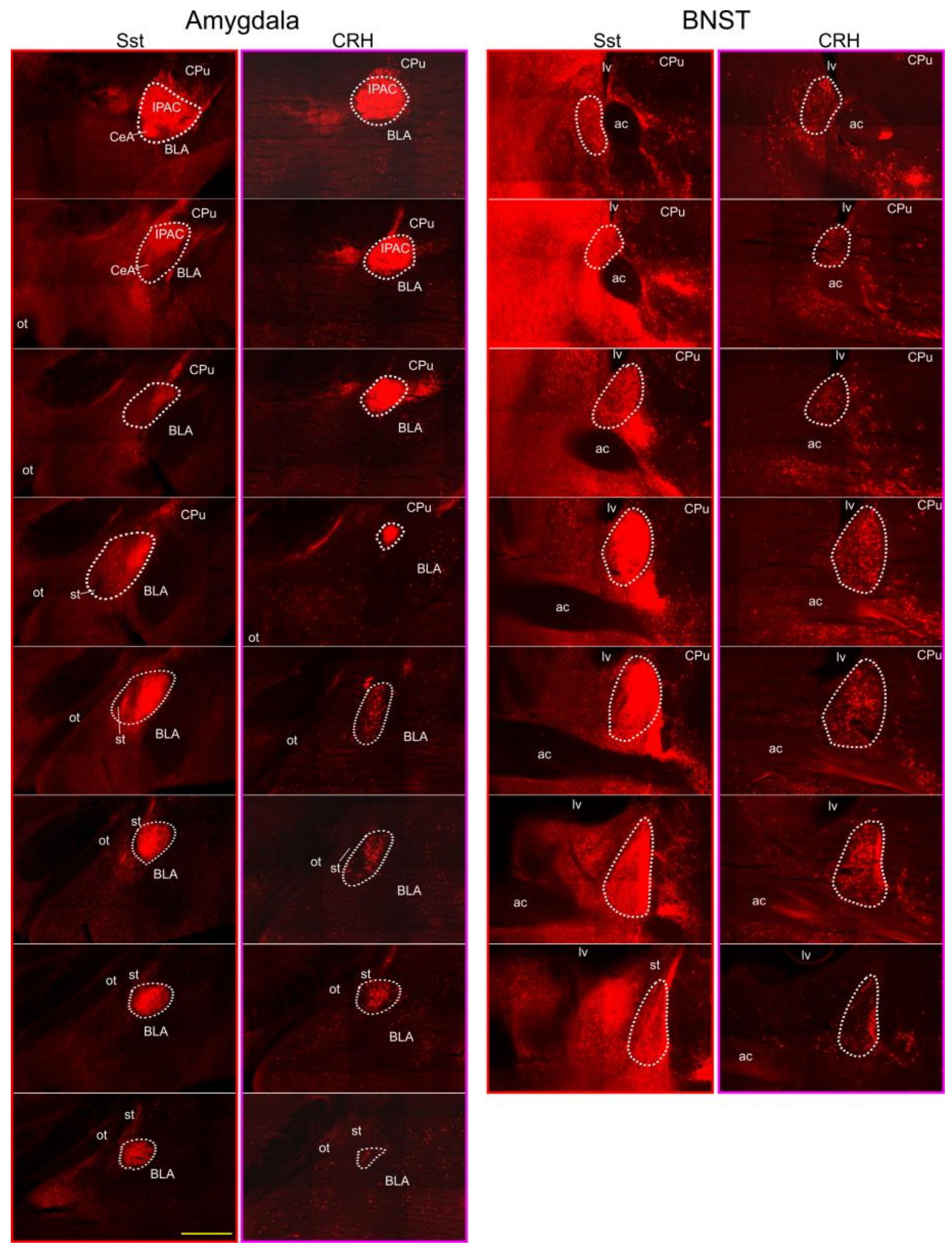


Figure 12. Montage images (10x) showing TdTomato expression in the amygdala (left panels) and BNST (right panels) of an Sst/TdTomato mouse and CRH/TdTomato mouse. Tissue sections are arranged from anterior (top) to posterior (bottom) and correspond to the levels from which cell counts were obtained. Medial is to the left and dorsal to the top. The core of fluorescent reporter expression in each area is outlined with white dots. ac, anterior commissure; BLA, basolateral nucleus of the amygdala; $\mathrm{CPu}$, caudate/putamen; IPAC, interstitial nucleus of the posterior limb of the anterior commissure; 1v, lateral ventricle; ot, optic tract; st, striaterminalis. Scale bar equals 500 $\mu \mathrm{m}$. 

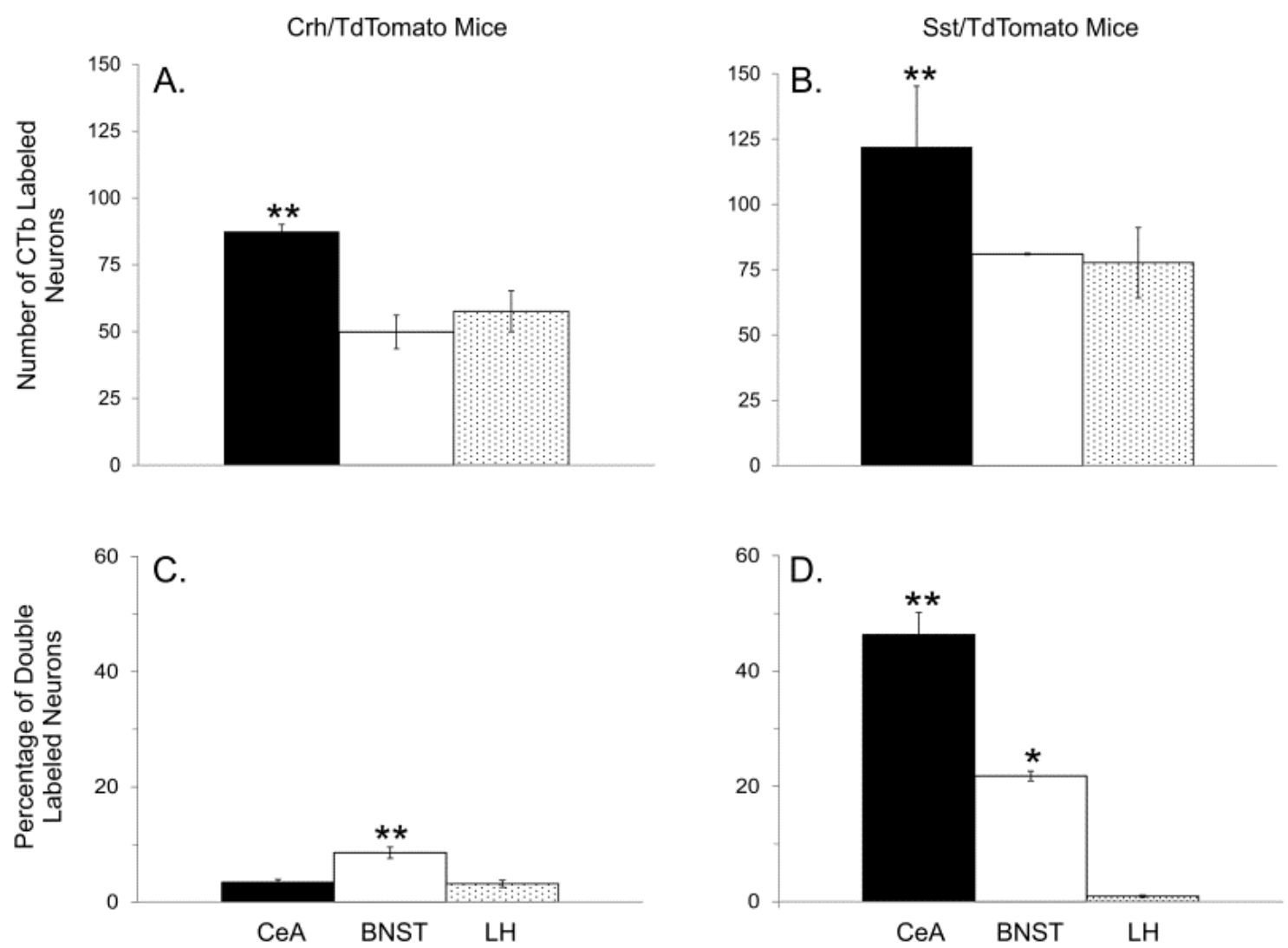

D show, respectively, the per section average percentage of retrogradely labeled neurons that co-expressed $\mathrm{CRH}$ or Sst. *, significantly different from LH. **, significantly different from other two brain areas. 

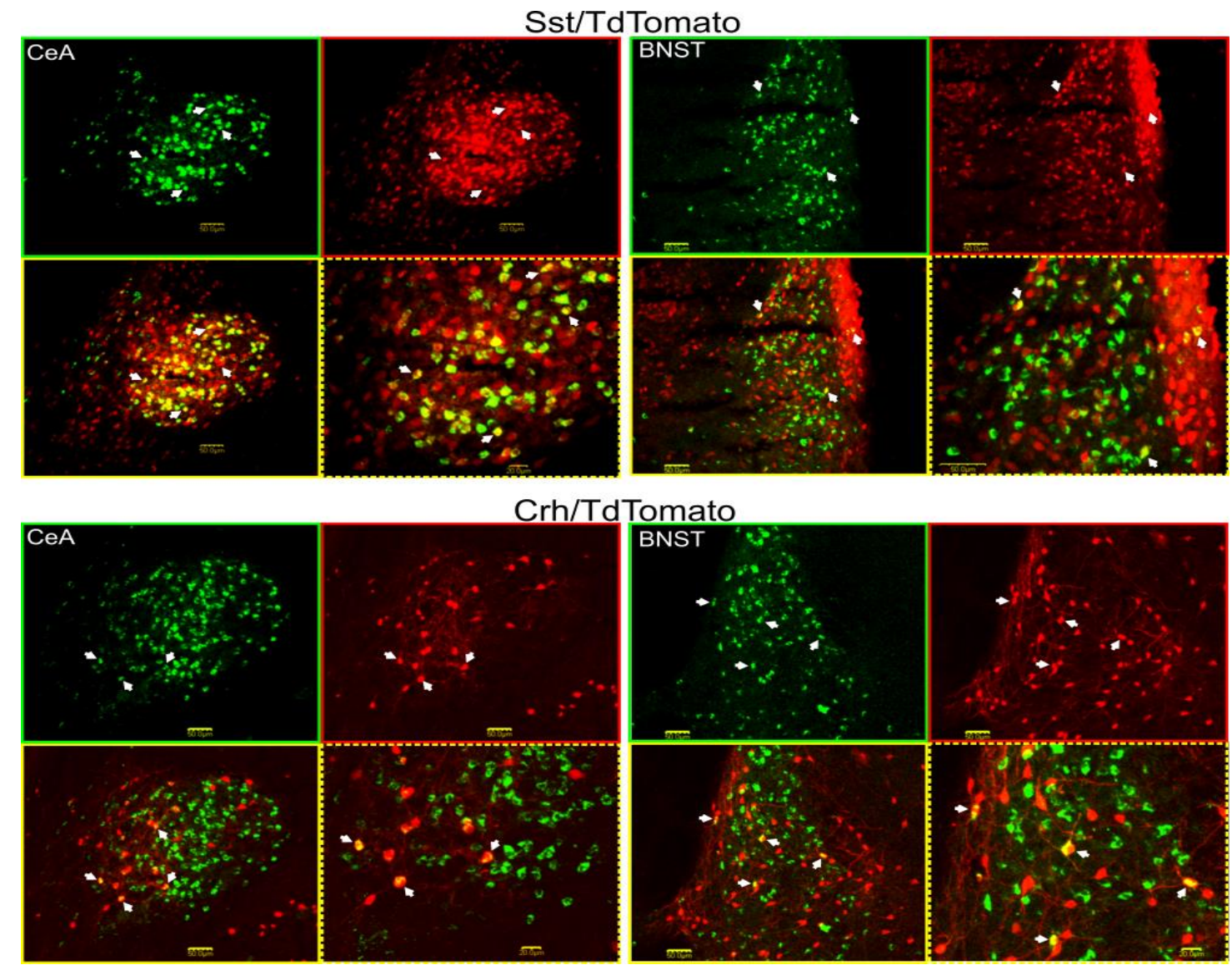

Figure 14. Example photomicrographs of neurons projecting to the caudal PBN and TdTomato fluorescence in the CeA and BNST of an Sst/TdTomato mouse (top panels) and $\mathrm{CRH} / \mathrm{TdTomato}$ mouse (bottom panels). In each panel, the image at top left shows $\mathrm{CTb}-488$ retrogradely labeled neurons only, top right TdTomato positive peptidergic cells only, bottom left the merged confocal images and bottom right higher magnification of the merged images. Single headed arrows point to neurons positive for $\mathrm{CTb}-488$ and $\mathrm{CRH}$ or $\mathrm{CTb}-488$ and Sst. A scale bar is shown in each image. 
CHAPTER III

\section{SYNAPTIC ORGANIZATION OF CONNECTIONS BETWEEN THE \\ CENTRAL NUCLEUS OF AMYGDALA, BEDNUCLUES OF STRIA \\ TERMINALIS AND PARABRACHIAL NUCLEUS IN MICE}

Centrally administered $\mathrm{CRH}$ has been shown to diminish food intake in a variety of species (Fekete et al., 2007; Jones et al., 1998; Parrott, 1990), while Sst administration increases intake and taste preference (Karasawa et al., 2014; Scalera, 2003; Stengel et al., 2010). Furthermore, injections of CRH into the PBN inhibits sodium appetite, while a $\mathrm{CRH}$ receptor antagonist has the opposite effect, increasing sodium chloride intake (Silva et al., 2006). One possibility is that $\mathrm{CRH}$ and Sst cell types of forebrain origin differentially influence feeding behavior by modulating taste processing in the PBN.

In rat, taste responses in the PBN are modulated by CeA stimulation (Lundy and Norgren, 2001; Lundy and Norgren, 2004). The primary effect of CeA activation was inhibition of taste-evoked responses suggesting a role for the inhibitory neurotransmitter GABA. Indeed, GABA has been shown to produce a concentration-dependent reduction in input resistance of neurons in the caudomedial gustatory zone of the PBN (Kobashi and Bradley, 1998). Blockade of activity in the PBN with the GABAergic receptor agonist muscimol induces strong hypertonic $\mathrm{NaCl}$ intake that is dependent upon the integrity of the CeA (ndrade-Franze et al., 2010). Moreover, enhancement of PBN GABA neurotransmission via midazolam microinjection increased food intake and 
selectively enhanced positive behavioral reactions to oral infusion of solutions containing bitter and sweet compounds (Soderpalm and Berridge, 2000). CRH and Sst have been shown to differentially influence GABA neurotransmission in other brain areas (Chen et al., 2014; Kash et al., 2008; Leresche et al., 2000; Momiyama and Zaborszky, 2006; Roberto et al., 2010).

Despite the evidence for potential interactions between $\mathrm{CRH}$, Sst, and GABA in the PBN, previous anatomical studies suggest that CeA input to the gustatory $\mathrm{PBN}$ is non GABAergic (Jia et al., 2005; Saggu and Lundy, 2008; Sun et al., 1994). One possibility is that intrinsic GABAergic neurons interface between descending axon terminals and PBN gustatory neurons. This synaptic arrangement has been hypothesized to mediate the inhibitory influence of GC on second-order taste neurons in the nucleus of the solitary tract (Smith and $\mathrm{Li}, 2000$ ). Another possibility is that centrifugal influences might be mediated by an indirect pathway to PBN taste cells that first synapses in the lateral visceral sensitive region of the PBN. The PBN is a critical substrate for the integration of gustatory and more rostrolaterally processed visceral information, and physiological factors associated with ingestion modulate PBN taste responses (Baird et al., 2001; Hajnal et al., 1999). CeA terminals innervating the lateral PBN have been reported to contain GABA (Jia et al., 2005). Alternatively, GABA synthesis might occur locally within axon terminals (Beltran and Gutierrez, 2012; Wu et al., 2007), and previous studies using retrograde tracer injections into the PBN combined with GABA staining in forebrain neurons would have been unable to detect co-localization. 
In this study, we aimed to investigate synapses in the PBN that contain $\mathrm{CRH}$ and Sst and determine if there is a correlation with expression of the inhibitory neurotransmitter GABA using electron microscopy. First, Sst or CRH terminals in the PBN were labeled by crossing Sst-cre or CRH-cre mice with a floxed Ai9 TdTomato fluorescent reporter mouse. This allowed the study all CRH and Sst terminals in the PBN regardless of origin. We then used site specific injection of floxed reporter virus into the CeA of Sst-cre mice to examine the GABA content of Sst terminals of CeA origin in the PBN.

\section{Materials and Method}

Animals: Sst-cre and CRH-cre (Jackson Laboratories, Sst ${ }^{\mathrm{tm} 2.1(\mathrm{Cre}) Z \mathrm{jh} / \mathrm{J}}$ and $\mathrm{Crh}^{\mathrm{tm} 1(\mathrm{Cre}) Z \mathrm{jh}} / \mathrm{J}$, respectively) were bred with floxed-TdTomato mice (Jackson Laboratories, B6.CgGt(ROSA)26Sor ${ }^{\text {tm14(CAG-tdTomato)Hze } / J)}$ to generate two reporter mouse lines that expressed TdTomato in Sst and CRH cell types (Sst/TdTomato and CRH/TdTomato lines). Two CRH/TdTomato mice, one Sst/TdTomato mouse, and one Sst-cre mouse each weighing 18-23g were used in this study. The animals were maintained in a temperaturecontrolled colony room on a 12-h light/dark cycle and allowed free access to normal rodent chow and distilled water. All procedures conformed to National Institutes of Health guidelines and were approved by the University of Louisville Institutional Animal Care and Use Committee.

Surgery: The Sst-cre mouse was anesthetized with an intraperitoneal injection of Ketamine/Xylazine mixture [(100mg/kg (K)/10mg/kg (X)]. If needed, an additional dose of Ketamine $(50 \mathrm{mg} / \mathrm{kg})$ was administered to continue a deep level of anesthesia. The 
animal was placed on a feedback-controlled heating pad, and rectal temperature was monitored to maintain body temperature at $37 \pm 1^{\circ} \mathrm{C}$. A stereotaxic instrument secured the animals head and the skull was exposed with a midline incision then leveled with reference to bregma and lambda cranial sutures. A small hole was drilled through the bone to allow access to the CeA. The analgesic buprenex $(0.1 \mathrm{mg} / \mathrm{kg})$ was administered prior to wound incision and again for at least 2 days post-surgery.

Virus Injection: A floxed stop EYFP virus (600 nl of AAV2-Ef1 $\alpha$-DIO-EYFP; UNC Vector Core, USA) was injected into the CeA (relative to bregma; posterior -1.4; lateral 2.7; ventral -4.6) using an UltraMicroPump (WPI, USA). Because the EYFP gene is preceded by a floxed stop codon, expression of EYFP is restricted to SST neurons and their terminals in the PBN. Two to three weeks post-injection, mice were administered a lethal dose of Nembutal $(150 \mathrm{mg} / \mathrm{kg})$ and perfused through the ascending aorta with a solution of $2 \%$ paraformaldehyde $/ 2 \%$ glutaraldehyde in phosphate buffer. $\mathrm{CRH} / \mathrm{TdT}$ Tomato and Sst/TdTomato did not receive any viral injections and were similarly perfused at 30 days of age. Coronal sections $(70 \mu \mathrm{m})$ were cut using a vibrating microtome and processed for immunohistochemical detection of EYFP and GABA.

Electron Microscopy: Sst and CRH immunoreactivity was revealed by incubating freefloating sections containing the PBN or CeA (i.e. virus injected mouse) in goat anti-GFP (Novus Biochemicals, USA). Sections were then incubated in biotinylated anti-goat (Sigma-Aldrich, USA) followed by avidinbiotinylated-horseradish peroxidase complex (Vector Labs, USA). The HRP was then revealed with a DAB reaction. The location of 
EYFP is thus revealed by an electron dense reaction product. Caudal sections of the PBN containing DAB labeled axons were post fixed in $1 \%$ osmium tetroxide (45 min), dehydrated in ethyl alcohol, and flat-embedded in Durcupan resin (Ted Pella, USA). Ultra-thin sections were cut $(70-80 \mathrm{~nm})$ and every tenth section collected on Formvarcoated grids. The grids were then incubated in a rabbit anti-GABA antibody (Sigma, USA) followed by a goat anti-rabbit antibody conjugated to $15 \mathrm{~nm}$ gold particles. The grids are subsequently stained with uranyl acetate and lead citrate $(2 \mathrm{~min})$. Grids were allowed to air dry before examination in an electron microscope (JEOL, JEM 1200EX).

GABA content: The characteristics of Sst and CRH synaptic terminals and their postsynaptic target(s) were characterized on the basis of size and overlying gold particle density. For each cut of the embedded tissue block, the gold particle density of all neural elements within an image containing an Sst or CRH positive synapse was calculated. The gold particle densities for each cut were entered into SPSS statistical software and a two-step cluster analysis performed to partition the densities into two groups. An Sst or $\mathrm{CRH}$ labeled terminal or its postsynaptic target were considered GABA positive if the gold particle density was greater than the average between the upper bound of the lowestdensity group and the lower bound of the highest-density group.

Results: As predicted by the results obtained using retrograde tracer injections into the PBN (Chapter II), Sst and CRH neural elements were observed throughout the PBN (Figure 15). Although TdTomato expression in these reporter mice indicates cell phenotype (i.e. terminals from Sst or CRH neurons), it does not provide information 
about the source of Sst and CRH terminals in the PBN. However, injection of floxed reporter virus indicates that the majority of Sst axons in the PBN originate from the CeA. AAV injections into the CeA of Sst-cre mice resulted in dense expression of fluorescent marker in CeA axons within the PBN (Figure 16, Sst/AAV/PBN), which is comparable to the pattern of all Sst axons in sections of the PBN of Sst-cre mice crossed with the Ai9 reporter mice (Figure 16, Sst/TdTomato/PBN).

Electron microscopic analyses showed that the majority of Sst positive terminals (Figure17A), but not CRH terminals (Figure 17B), co-expressed GABA. Seventy-five percent of Sst synaptic terminals (27 of 36) in the PBN of Sst/TdTomato mouse tissue had a gold particle density above the calculated cut-off value and were considered GABA positive (Figure 18A, red bars). An even greater percentage of Sst terminals in the PBN were categorized as GABAergic (29 of 32) following injection of floxed AAV virus into the CeA of an Sst-cre mouse (Figure 18A, pink bars). In contrast, only 8 of $28(28 \%)$ CRH synaptic terminals in the PBN of CRH/TdTomato mouse tissue had a gold particle density above cut-off (Figure 18A, green bars). In all cases, the majority of postsynaptic targets was below cut-off and considered to be non-GABAergic (not shown). The actual density values for Sst terminals were right shifted compared to CRH terminals indicating greater gold particle density (Figure 18B). Together, these data provide an anatomical substrate for an interaction between Sst and GABA neurotransmission in the PBN.

\section{$\underline{\text { Discussion }}$}


The PBN contains several subnuclei that process gustatory, visceral, and somatosensory signals. Electrical stimulation of the CeA demonstrates an inhibitory effect on PBN taste-responsive neurons (Kang et al., 2004; Lundy and Norgren, 2001; Lundy and Norgren, 2004; Tokita et al., 2004) suggesting a role of an inhibitory neurotransmitter like GABA. We showed that Sst terminals in the PBN, but not CRH terminals, co-express GABA. The majority of Sst/GABA terminals in the PBN arise from the $\mathrm{CeA}$, thus, providing a major source of extrinsic GABAergic input to the PBN which may play an important role in regulating taste responses.

Although the CeA contains GABA neurons, previous research concluded that these cells do not project to the gustatory area of the PBN (Saggu and Lundy, 2008; Sun et al., 1994). These studies relied mostly on low resolution immunohistological techniques that focused only on GABA positive cell bodies. Importantly, GABA has been shown to be synthesized and released within axon terminals of the cerebellum (Beltran and Gutierrez, 2012). Our present data using cell type specific anterograde labeling combined with high-resolution electron microscopy suggest a similar scenario for CeA projections to the PBN.

The non-GABAergic cells postsynaptic to Sst and CRH terminals are likely output neurons of the PBN (i.e. those that project to the medulla, thalamus, and/or forebrain) suggesting that intrinsic GABAergic neurons do not interface between descending axon terminals and PBN gustatory neurons. This arrangement provides a mechanism whereby activation of Sst CeA cell types can monosynaptically inhibit PBN 
neurons. We also observed some GABA-ir neurons that were not Sst positive as the PBN receives GABAergic input from other places such as the hypothalamus (Wu et al., 2009).

The peptides $\mathrm{CRH}$ and Sst have centrally mediated actions on autonomic function and ingestive behavior (Benoit et al., 2000; Feifel and Vaccarino, 1990; Feifel and Vaccarino, 1994; Fisher and Brown, 1993; Jones et al., 1998; Karasawa et al., 2014; Scalera, 2003; Spina et al., 1996; Stengel et al., 2010). Although the pathways mediating these effects are not well understood, they likely involve parallel regulation of the flow of gustatory and visceral sensory information to forebrain structures.

Previous studies show that 1) injections of $\mathrm{CRH}$ into the lateral $\mathrm{PBN}$ inhibits sodium chloride intake in sodium depleted rats, while injections of a CRH receptor antagonist had the opposite effect, increasing sodium chloride intake (Silva et al., 2006) and 2) intra PBN infusion of Sst inhibits the spontaneous activity of thalamic neurons responsive to vagal stimulation (Saleh and Cechetto, 1993). The CeA has been implicated in some forms of learned (e.g. CTA) and/or unlearned control (e.g. sodium appetite) of taste-guided behavior (Bielavska and Roldan 1996; Caulliez et al. 1996; Lamprecht et al. 1997; Roldan and Bures 1994; Roth et al. 1973; Schwartz and Teitelbaum 1974; Zardetto-Smith et al. 1994). In varying degree, CRH and Sst neurons in the CeA projected to gustatory and visceral regions of PBN (Magableh and Lundy, 2014; Moga and Gray, 1985). 
Electrophysiological studies demonstrate that neural responses to a conditioned taste stimulus are enhanced after CTA acquisition, while expression of sodium appetite is accompanied by decreased sensitivity of taste cells to sodium salt. Inhibitory and excitatory effects on taste cells can also be produced by stimulation of the CeA. Thus, $\mathrm{CRH}$ and Sst forebrain-PBN pathways might be involved in mediating these neurophysiological changes thought to play a role in the adding affective meaning to gustatory activity. In the case of Sst, our experiments suggests a direct inhibitory action on PBN neurons. CRH likely has an excitatory effect on PBN neural activity as it does in several other brain regions like the amygdala, dorsal raphe nucleus, and hippocampus (Blank et al., 2003; Lowry et al., 2000; Ugolini et al., 2008).

A parallel pathway by which $\mathrm{CRH}$ and Sst might modulate ingestive behavior includes descending forebrain input to the DMC (i.e. dorsal motor nucleus of the vagus and medial NST that receives vagal afferent input), rostral gustatory NST, and regions of the medullary and pontine reticular formation that contain oral pre motor neurons. Each of these brainstem structures receives input from $\mathrm{CeA}$ some of which has been shown to modulate neural responses (Cho et al., 2003; Liubashina et al., 2000; Liubashina et al., 2002; Rogers et al., 1996). For instance, both CRH and Sst neurons in the CeA project to the DMC (Gray and Magnuson, 1987; Saha et al., 2002). Activation of the CeA has been shown to modulate DMC neurons and/or gastric function (Liubashina et al., 2002), as does direct administration of CRH and Sst to the DMC (Lewis et al., 2002; Martinez et al., 2000; Yoneda and Tache, 1995). Importantly, experimental treatments that enhance eating have parallel excitatory effects on gastric motility and emptying [e.g. Sst], while 
those inhibiting intake have parallel inhibitory effects [e.g. CRH] (Cato et al., 1990; Flanagan et al., 1989; McCann et al., 1989). Thus, the widespread distribution of descending forebrain axons in the brainstem are well suited to exert coordinated and/or independent control of ascending gustatory and visceral information as well as neural signals to gastric and oral motor nuclei. 

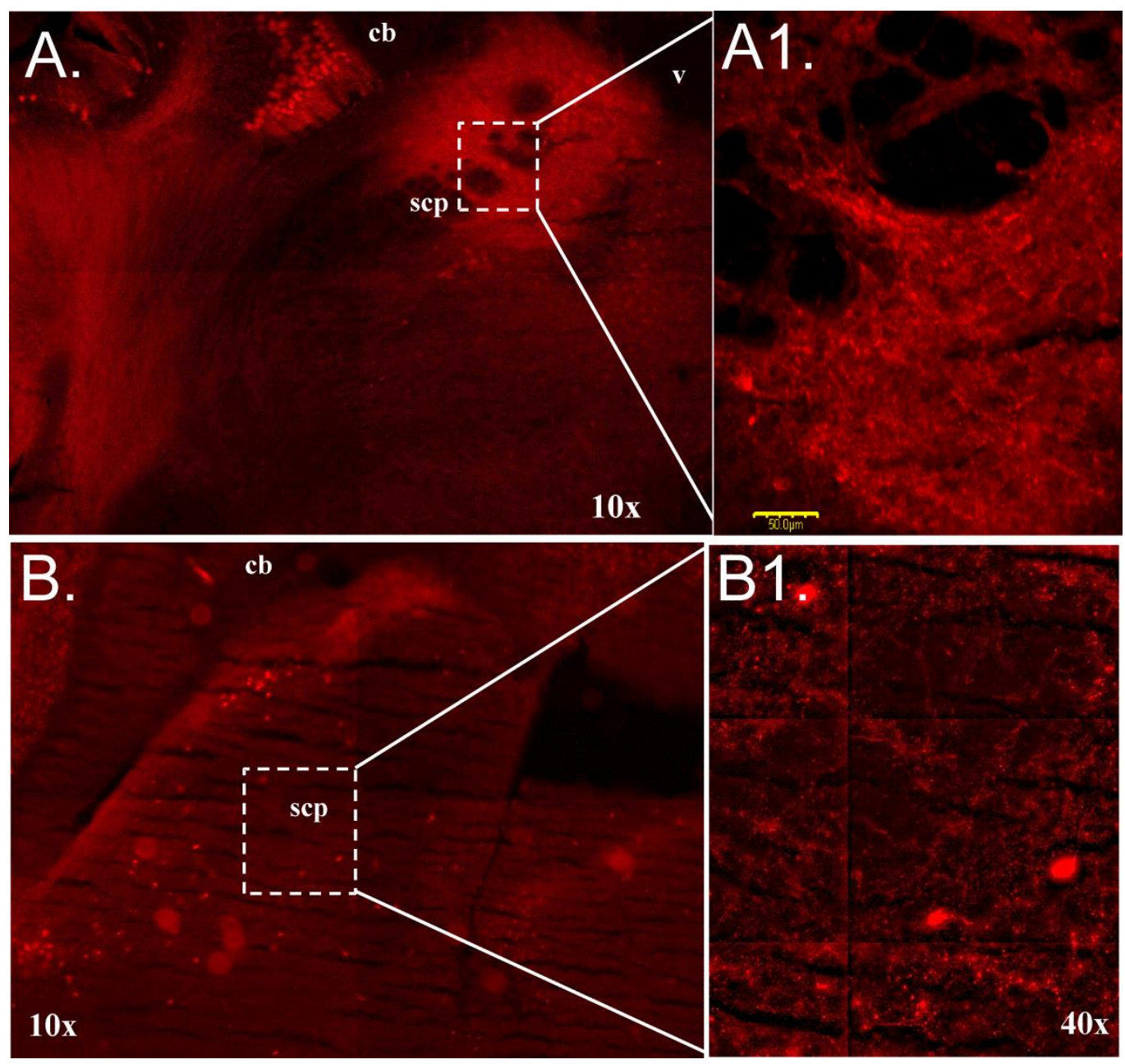

Figure 15. Fluorescent images of TdTomato reporter expression in the PBN of offspring from breeding Sst-cre (A) and Crh-cre (B) mice with floxed Ai9 TdTomato mice. Higher magnification images are shown in panels A1 and B1. Scp, superior cerebellar peduncle; v, fourth ventricle; cb, cerebellum. 

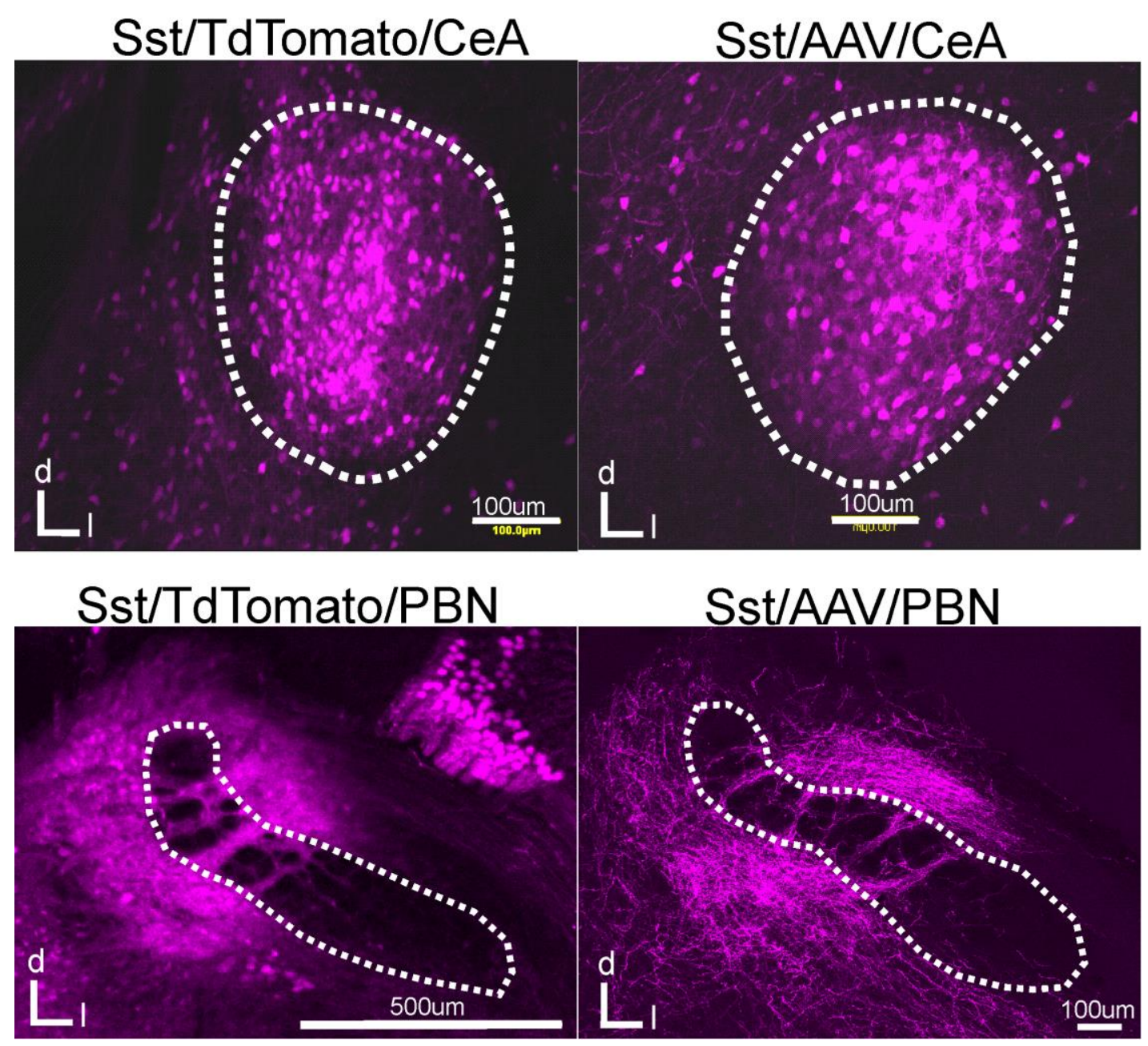

Figure 16. Confocal images of: 1) TdTomato fluorescence in the CeA (A1) and PBN (A2) resulting from breeding Sst-cre and Ai9 reporter mice and 2) mCherry fluorescence in the CeA (B1) and PBN (B2) resulting from injection of AAV2EfI $\alpha$-DIO-mCherry into the CeA of an Sst-cre mouse. Viral injection produced fluorescent expression within axons of the PBN comparable to that obtained in Ai9 reporter mice. White dots outline the CeA (top images) or superior cerebellar peduncle (bottom images). Arrow points to the waist area of PBN where cells responsive to taste are concentrated. 

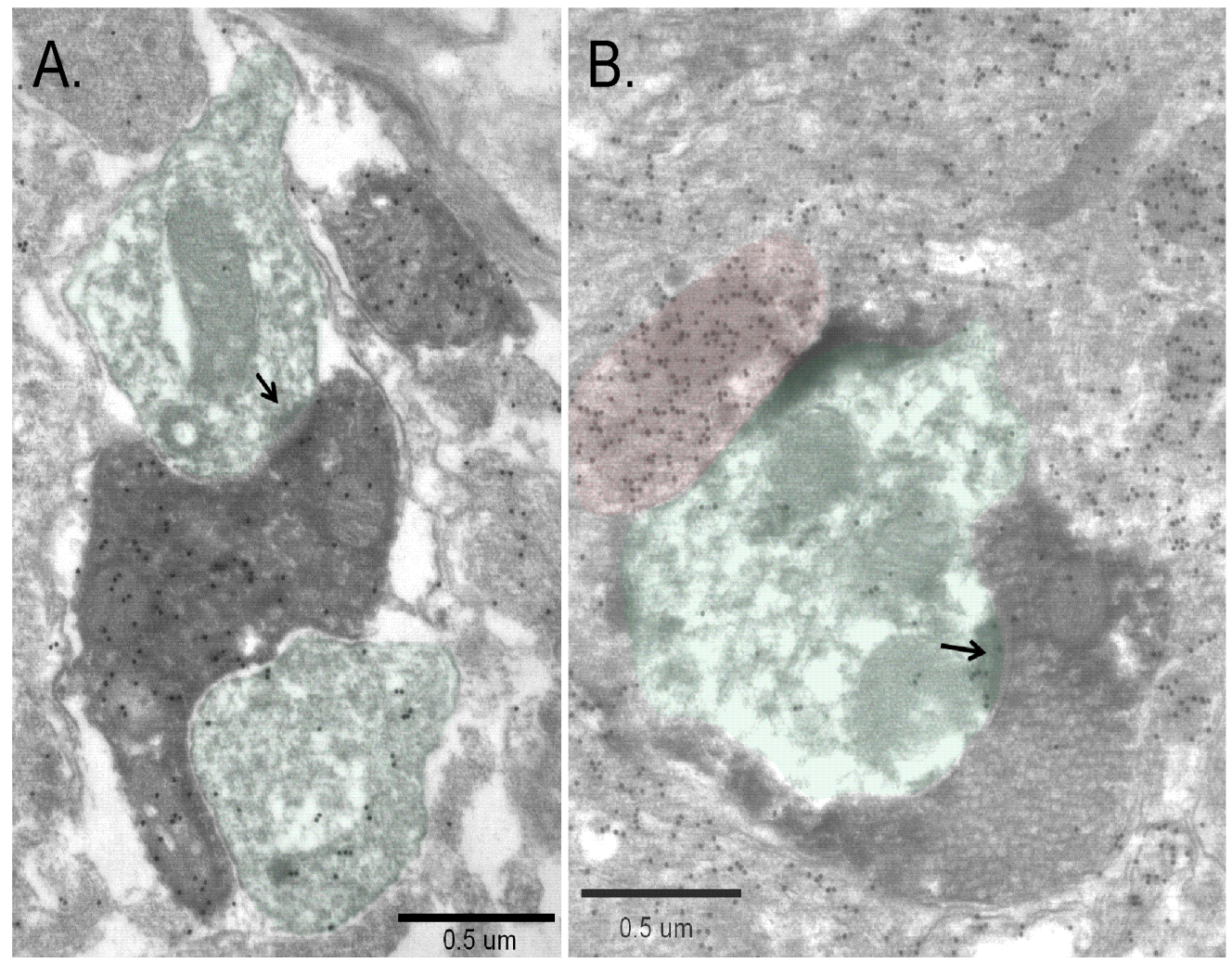

Figure 17. (A) Sst positive terminal in the PBN following floxed viral injection into the CeA of an Sst-cre mouse. (B) CRH terminal in the PBN of offspring from breeding Crh-cre and floxed TdTomato mice. Arrows point to synapse with DAB labeled terminal. A non-DAB labeled GABAergic terminal is shaded red (right). 


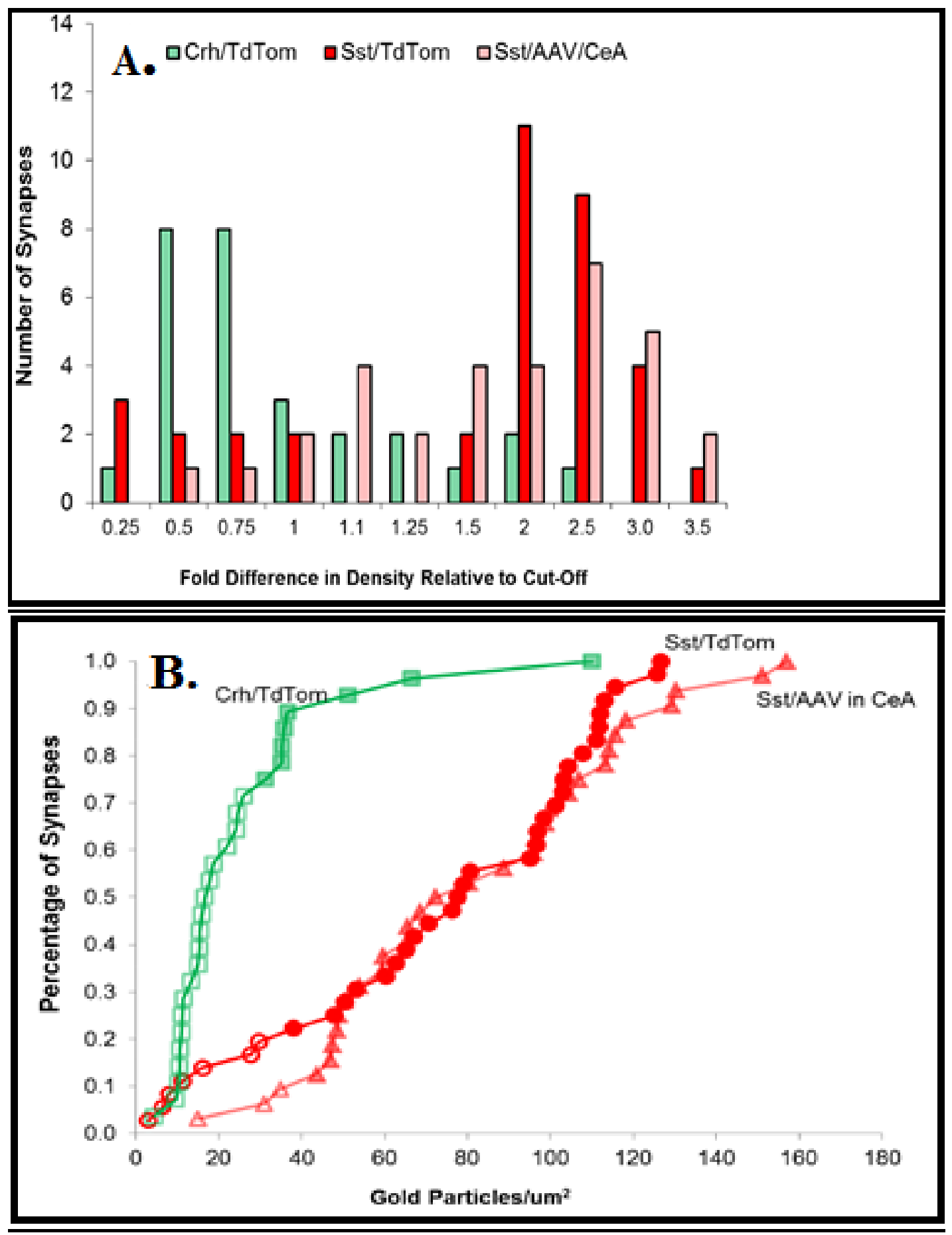


Figure 18. (A) The distribution of gold particle densities relative to cut-off value for Sst terminals in the PBN (red bars, Sst/TdTomato terminals; pink bars, Sst terminals following injection of floxed virus into the CeA of Sst-cre mouse. For comparison, the distribution in $\mathrm{CRH}$ terminals from $\mathrm{CRH} / \mathrm{TdT}$ Tomato mouse tissue is shown (green bars). A value of 0.5 indicates terminals with a gold particle density half that of the cut-off density, while a value of 2 indicates densities twice that of the cut-off value. B) The cumulative distribution of raw gold particle densities in the DAB labeled pre synaptic terminals depicted in $\mathbf{A}$. 


\section{CHAPTER IV \\ GENERAL DISCUSSION AND FUTURE DIRECTIONS}

The gustatory system evolved to identify the content of foods and fluids for the fundamental purpose of ingesting energy rich substances or rejecting and avoiding toxic substances. The isolated brainstem contains not only the sensory and motor apparatus necessary to produce ingestive behavior, but also the integrative capacity to organize

discriminative responses to appropriate gustatory stimuli (Grill and Norgren, 1978a; Grill and Norgren, 1978b). In many mammalian species, the nucleus of the solitary tract (NST) and the parabrachial nucleus (PBN) are the first and second central synapses for the ascending gustatory system (Hamilton and Norgren, 1984; Norgren, 1978). The PBN distributes gustatory information to the $\mathrm{CeA}$ and, in turn, receives projections from the CeA (Bernard et al., 1993; Norgren, 1976). This forebrain region has been implicated in the expression of complex taste-guided behaviors (Bermudez-Rattoni and McGaugh, 1991; Zardetto-Smith et al., 1994). Thus, the anatomical connections of the CeA are well suited to modulate information processing in brainstem gustatory nuclei.

The decision to accept or reject a taste stimulus is heavily influenced by affective value arising from gustatory activity. However, the exact mechanisms by which the brain adds affective meaning to gustatory signals are unknown. At the level of the NST and PBN, taste responses are modifiable. Within these hindbrain nuclei, neuronal activity is strongly affected by GABAergic inhibition (Grabauskas and Bradley, 2003; Kobashi and Bradley, 1998; Suwabe and Bradley, 2009; Wang and Bradley, 1995), indicating that 
GABAergic circuits within the NST and PBN are critical for the initial shaping of peripheral taste signals.

The NTS appears to contain numerous GABAergic interneurons (Davis, 1993; Lasiter and Kachele, 1988; Wang and Bradley, 2010), while the PBN appears to utilize GABA from extrinsic sources (Guthmann et al., 1998). Previous electrical or pharmacological studies show that projections from the CeA predominately inhibit taste-evoked responses in the PBN (Kang et al., 2004; Lundy and Norgren, 2001; Lundy and Norgren, 2004). However, anatomical studies utilizing immunohistochemistry concluded that GABA is not produced in CeA neurons that project to the PBN (Jia et al., 2005; Saggu and Lundy, 2008; Sun et al., 1994). Results from our studies challenge this conclusion by showing that Sst/GABA expressing neurons in the CeA project to the PBN. This provides a mechanism whereby the CeA can gate the relay of taste signals through the PBN by the release of GABA from direct synaptic contacts on PBN projection neurons. As in other brain regions, Sst might function to regulate the gain of GABA neurotransmission (Chen et al., 2014; Momiyama and Zaborszky, 2006).For example, in vitro patch clamp recordings showed that somatostatin presynaptically inhbited the release of GABA and glutame onto baseal forebrain cholinerigic neurons (Momiyama and Zaborszky, 2006)

We recently provided evidence for the first time that GABA is present in $\mathrm{CeA}$ somatostatin neuronal terminals in the $\mathrm{PBN}$, providing a novel explanation for the inhibitory effect observed in the PBN during CeA electrical stimulation. Whether descending Sst/GABA input targets projection neurons in the PBN remains to be investigated. Our initial estimation was that most of these GABAergic terminals target non-GABAergic neurons in the $\mathrm{PBN}$, which was the main reasoning behind our 
prediction that these PBN neurons project to brain regions outside of the PBN. Because somatostatin acts in the brain to influence feeding and taste preference (Karasawa et al., 2014; Scalera, 2003; Stengel et al., 2010), this discovery of a major inhibitory pathway from the CeA to the PBN will certainly encourage future studies to characterize the exact physiological function of somatostatin within central taste circuitry.

Somatostatin was discovered in 1973 as a growth hormone release inhibitor (Ling et al., 1973). Somatostatin is a 14-28 amino acid long peptide that regulates the endocrine system, neurotransmission, cell proliferation, and growth inhibition (Peng et al., 2014). There are two biologically active forms of somatostatin produced by alternative cleavage of a single preproprotein: somatostatin-14 (Sst-14) and its elongated form, somatostatin-28 (Sst-28) (Patel, 1999). The somatostatin gene is relatively conserved across species existing in only six different orthologs in vertebrates (Liu et al., 2010) including the one identified in humans (Shen et al., 1982; Shen and Rutter, 1984). In the brain, somatostatin deficiency is associated with several diseases such as Alzheimer's and Mood Disorders (Li et al., 2013b). Somatostatin seems to serve a physiological function in the brain as it was also found to regulate the metabolism of insulin degrading enzyme and potentially regulate the function of microglia in the brain (Tundo et al., 2012). In the spinal cord and peripheral nervous system, somatostatin seems to influence nociceptive signaling (Shi et al., 2014).

The synthesis of somatostatin in the CNS occurs in different parts of the brain and seems to be ubiquitous (Brownstein et al., 1975; Elde et al., 1985). The endocrine role of somatostatin in the CNS seems to be carried out by neuroendocrine cells of the ventro- 
medial nucleus of the hypothalamus in neurons that project to the median eminence(Kawano and Daikoku, 1988). Somatostatin is made in the soma of these cells and transported via anterograde transport mechanism down the axons of these neurons to be released from their neurosecretory nerve endings into the hypothalamo-hypophysial portal system in the median eminence. From there, somatostatin flows with the blood to the anterior pituitary to regulate hormonal release via feedback inhibition (Epelbaum, 1986; Kraicer et al., 1988).

Besides being synthesized by endocrine and neuroendocrine systems, somatostatin and somatostatin receptors are widely expressed throughout the brain and the spinal cord (Gahete et al., 2010; Kumar, 2007; Magableh and Lundy, 2014; Moller et al., 2003; Panguluri et al., 2009). Somatostatin exerts its function on target cells via G protein-coupled receptors. There are five known subtypes of somatostatin receptors (Sst 1-5) with 40-60\% sequence homology (Gahete et al., 2010). The somatostatin receptors recognize both Sst-14 and Sst-28 with high affinity regardless of the difference in peptide length but not at equal levels (Reubi et al., 2000). Pharmacological analysis of Sst1 and Sst2, the most predominant Sst receptors in the brain, concluded that they have equal affinity to Sst-14 and Sst-28 (Rens-Domiano et al., 1992), while analysis of Sst4 receptors concluded that it has higher affinity toward Sst-28 (O'Carroll et al., 1992). Regardless of variation in binding affinity, somatostatin still binds strongly to all receptors (Lewis et al., 2003) and triggers the same intracellular signaling pathway.

In rodents,Sst 2 receptors exist in two variants generated by alternative splicing, Sst2A and Sst2B (Schulz et al., 1998). Sst2A receptors seem to be the predominant form 
and has been identified in dorsal root ganglia(Maubert et al., 1994) and brain areas like the hypothalamus, paraventricular nucleus, and arcuate nucleus implicated in feeding behaviors (Csaba et al., 2003; Schindler et al., 1997; Stepanyan et al., 2003). Sst2A receptors are also highly expressed in the pons (Dournaud et al., 1996). Activation of Ssst2Areceptors increases expression of the immediate early gene c-fos in gustatory and visceral regions of the PBN (Goebel et al., 2010). Additionally, Sst2 receptors mediate somatostatin inhibition of spontaneous firing of locus coeruleus neurons (Chessell et al., 1996; Ikeda et al., 2009), as well as augmentation of water and food intake associated with central administration of somatostatin (Karasawa et al., 2014).. It is therefore plausible to hypothesize that the inhibitory effects of CeA activation on PBN taste neurons are mediated by CeA Sst/GABA neurons, where synaptic release of Sst binds to presynaptic Sst2 receptors and regulates GABA release on post-synaptic PBN cells. This circuit has implications for the control of taste-guided behavior since reciprocal communication between the CeA and PBN is implicated in an animal's ability to attach emotional significance to gustatory activity and regulate appetite (Bielavska and Roldan, 1996; Carter et al., 2013).

Another possibility is that Sst influences transcription. In growth hormones cells, Sst has been shown to decrease transcription of mRNA for its own receptor as well as that for growth hormone receptor (Bruno et al., 1994; Very and Sheridan, 2007). Somatostatin also reduces the transcription of some regulatory proteins in cultured rat astrocytes (Masmoudi et al., 2005). Sst3 receptor activation leads to induction of proapoptotic proteins and triggers phosphotyrosine phosphatase-dependent apoptosis (Sharma et al., 1996). Both isoforms of somatostatin seem to exert their biological effect 
via MAP kinase pathway leading to a cascade of events involving ERK1/2 (Florio, 2008; Peng et al., 2014). Therefore, the possibility that Sst regulates GAD expression should not be disregarded. Although Sst is not made by all CNS neurons, it co-localizes with GABA expressing neurons in several brain regions (Buijs et al., 1995; Gentet et al., 2012; Kawaguchi and Kondo, 2002; Lee et al., 2010). Somatostatin is even found to be transported retrogradely (Shi et al., 2014).If Sst indeed regulates transcription within this circuitry, we would hypothesize transcriptional regulation of neurons in the CeA rather than in the PBN since GAD expression in PBN neurons is scarce (Guthmann et al., 1998).

In summary, the PBN distributes gustatory information to the forebrain and, in turn, receives projections from the forebrain (Bernard et al., 1993; Norgren, 1976).In rat, taste responses in the PBN are modulated by activating these same forebrain regions including the CeA (Lundy and Norgren, 2001; Lundy and Norgren, 2004). The neurochemical(s) mediating modulation of taste processing in the PBN remain unknown. We showed that Sst terminals in the PBN, but not CRH terminals, co-express GABA. The majority of Sst/GABA terminals in the PBN arise from the CeA, thus, providing a major source of extrinsic GABAergic input to the PBN which may play an important role in regulating taste responses. The PBN neurons postsynaptic to Sst and CRH terminals were nearly exclusively non GABAergic and are likely output neurons of the PBN (i.e. those that project to the medulla, thalamus, and/or forebrain) suggesting that intrinsic GABAergic neurons do not interface between descending axon terminals and PBN gustatory neurons. We also observed some GABA-ir neurons that were not Sst positive as 
the $\mathrm{PBN}$ receives $\mathrm{GABAergic}$ input from other places such as the hypothalamus $(\mathrm{Wu}$ et al., 2009).

To identify whether the PBN neurons receiving terminals from the CeA project to other brain regions, an experiment involving the concurrent application of retrograde and anterograde tracers must be done. I will focus these experiments on CeA Sst neurons since this cell type represents a major descending pathway to the PBN (Magableh and Lundy, 2014). This study will clarify the degree to which CeA Sst neurons make synaptic contact with PBN cells that project to the lateral hypothalamus ( $\mathrm{LH})$ and/or those that project back to the CeA. A previous study in mice indicate that the majority of cells in the gustatory region of the PBN project to one or the other forebrain nucleus (Tokita et al., 2010).

\section{Future Study}

We have already characterized the descending input from the CeA to the gustatory $\mathrm{PBN}$ and established that it arises predominately from Sst/GABA neurons. These CeA Sst/GABA terminals contact non GABAergic dendrites suggesting synaptic influences on PBN projection neurons. To test this hypothesis, our lab will use Sst-cre transgenic mouse strains in conjunction with site specific injections of floxed reporter virus and retrograde tracer. Combined with electron microscopy, these experiments will allow us to determine whether amygdala somatostatin-producing neurons make synaptic contact with PBN output neurons that target the $\mathrm{LH}$ and/or CeA. Our lab and others have shown that the gustatory region of the PBN also projects to LH (Magableh and Lundy, 2014; Tokita et al., 2009; Tokita et al., 2010). 
All experiments will use an Sst-cre mouse line commercially available at Jackson Laboratories $\left(\mathrm{Sst}, \mathrm{Sst}^{\mathrm{tm} 2.1}(\mathrm{cre})^{\mathrm{Zjh} / \mathrm{J}}\right.$ (Song et al., 2012; Taniguchi et al., 2011). To identify the PBN neurons that receive input from the CeA, Sst-cre mice strain will have floxed AAV1/2-EF1alpha-DIO-mCherry virus injected into the CeA. To identify PBN neurons that project to the ventral forebrain, virus injected mice will have $\mathrm{CTb}$ injected into the LH or CeA. Fourteen days post injection, mice will be administered a lethal dose of Nembutal $(150 \mathrm{mg} / \mathrm{kg})$ and perfused through the ascending aorta with a solution of $2 \%$ paraformaldehyde $/ 2 \%$ glutaraldehyde in phosphate buffer. Coronal sections $(70 \mu \mathrm{m})$ will be cut using a vibrating microtome and processed for immunohistochemical detection of $\mathrm{CTb}$ and mCherry.

Sst immunoreactivity of CeA origin will be revealed by incubating free-floating sections containing the PBN in rabbit anti-DsRed. Sections are then incubated in biotinylated anti-rabbit followed by avidinbiotinylated-horseradish peroxidase complex. The HRP is revealed with a DAB reaction producing an electron dense reaction product. In the same PBN sections, $\mathrm{CTb}$ immunoreactivity of $\mathrm{CeA}$ or $\mathrm{LH}$ origin will be revealed by incubating in goat anti-CTb. Sections are then incubated in biotinylated anti-goat followed by avidinbiotinylated-horseradish peroxidase complex. The HRP is revealed with a VIP reaction producing a diffuse electron dense reaction product that is discernable from that resulting from DAB. Caudal sections of the PBN containing DAB labeled terminals and VIP labeled dendrites are post fixed in 1\% osmium tetroxide, dehydrated in ethyl alcohol, and flat-embedded in Durcupan resin. Ultra-thin sections arecut $(70-80 \mathrm{~nm})$ and every tenth section collected on Formvar-coated grids. The grids are subsequently stained with uranyl acetate and lead citrate. Grids are allowed to air dry 
before examination in an electron microscope (JEOL, JEM 1200EX).Because mCherry is restricted to Sst terminals of CeA origin and retrograde tracer is injected into either the LH or CeA, CTb-positive dendrites that receive synaptic contact from Sst-positive terminals are considered projection neurons. Although some Sst labeled terminals will synapse with non $\mathrm{CTb}$ labeled dendrites, we cannot conclude with certainty that these PBN neurons have intrinsic connections. This is because the PBN projects to other areas in addition to the $\mathrm{LH}$ and $\mathrm{CeA}$, and these experiments only examine synaptic contacts between the CeA and PBN cells that project to a single brain region.

Based on our previous studies, we don't anticipate any problems locating DABstained terminals. There is a possibility that the retrograde tracer $\mathrm{CTb}$ will not adequately fill small caliber distal dendrites and, therefore, we might underestimate synaptic contacts between CeA Sst terminals and PBN projection neurons. If this presents a significant shortcoming, alternative retrograde tracers are available. With the recent development of retrograde tracing viral strains such as herpes simplex virus and pseudorabies (PRV) we anticipate to quickly overcome any limitation generated by the use of CTb. Both herpes simplex and pseudorabies viruses have been used for studying synaptic connectivity in the CNS and are available with genes encoding fluorescent protein (Desai and Person, 1998). Even if the need dictates, we can bypass the need for fluorescent protein because surface proteins of herpes simplex virus can be labeled and visualized using a modified biotin-streptavidin label (Skulstad et al., 1995).

The techniques used in the present work are applicable to study neuromodulatory circuits in other gustatory nuclei. Also these techniques will be applicable to studying 
other cell types in limbic system nuclei with projections to brainstem gustatory nuclei such as corticotrophin-releasing factor. Yet other studies might investigate the specific post synaptic membrane currents such as the hyperpolarization-activated currents $\left(\mathrm{I}_{\mathrm{h}}\right)$ that are influenced by descending neuromodulatory inputs. $I_{h}$ currents are unique in their gating properties and mixed cationic currents carried by $\mathrm{Na}+$ and $\mathrm{K}+($ Alonso and Llinas, 1989; Mayer and Westbrook, 1983; Spain et al., 1987). $\mathrm{I}_{\mathrm{h}}$ activation is also facilitated by cAMP(DiFrancesco and Tortora, 1991) a binding nucleotide of the G-protein coupled somatostatin receptor. Once we more fully understand how Sst regulates neural excitability in the PBN, we can design additional experiments that investigates function in a behavioral context. This might be accomplished using somatostatin receptor-2 knockout mice(Zheng et al., 1997) and/or site specific inhibition of Sst neurons using optogenetic techniques (Gradinaru et al., 2010).

In summary, I predict that the inhibitory effect exerted by CeA activation on taste processing in the PBN is mediated by CeA neurons that co-express Sst and GABA. The CeA gates the relay of taste signals through the PBN by the release of GABA from direct synaptic contacts on PBN projection neurons. I further hypothesize that Sst functions to regulate the gain of GABA neurotransmission by binding to presynaptic Sst2 receptors (Leresche et al., 2000; Momiyama and Zaborszky, 2006). This circuit has implications for the control of taste-guided behavior since reciprocal communication between the $\mathrm{CeA}$ and PBN is implicated in an animal's ability to attach emotional significance to gustatory activity and regulate appetite (Bielavska and Roldan, 1996; Carter et al., 2013). 


\section{REFERENCES}

Alonso, A., Llinas, R.R., 1989. Subthreshold Na+-dependent theta-like rhythmicity in stellate cells of entorhinal cortex layer II. Nature. 342, 175-7.

Anlezark, G.M., et al., 1992. The bioactivation of 5-(aziridin-1-yl)-2,4-dinitrobenzamide (CB1954)--I. Purification and properties of a nitroreductase enzyme from Escherichia coli--a potential enzyme for antibody-directed enzyme prodrug therapy (ADEPT). Biochem Pharmacol. 44, 2289-95.

Asaoka, K., et al., 2000. Dependence of efficient adenoviral gene delivery in malignant glioma cells on the expression levels of the Coxsackievirus and adenovirus receptor. J Neurosurg. 92, 1002-8.

Bai, M., Harfe, B., Freimuth, P., 1993. Mutations that alter an Arg-Gly-Asp (RGD) sequence in the adenovirus type 2 penton base protein abolish its cell-rounding activity and delay virus reproduction in flat cells. J Virol. 67, 5198-205.

Baird, J.P., Travers, S.P., Travers, J.B., 2001. Integration of gastric distension and gustatory responses in the parabrachial nucleus. Am.J.Physiol Regul.Integr.Comp Physiol. 281, R1581-R1593.

Bartoshuk, L.M., 1978. The psychophysics of taste. Am J Clin Nutr. 31, 1068-77.

Bassant, M.H., et al., 2005. Medial septal GABAergic neurons express the somatostatin sst2A receptor: functional consequences on unit firing and hippocampal theta. J.Neurosci. 25, 2032-2041.

Beltran, J.Q., Gutierrez, R., 2012. Co-release of glutamate and GABA from single, identified mossy fibre giant boutons. J Physiol. 590, 4789-800.

Benoit, S.C., et al., 2000. Comparison of central administration of corticotropin-releasing hormone and urocortin on food intake, conditioned taste aversion, and c-Fos expression. Peptides. 21, 345-351.

Bergelson, J.M., et al., 1997. Isolation of a common receptor for Coxsackie B viruses and adenoviruses 2 and 5. Science. 275, 1320-3.

Bermudez-Rattoni, F., McGaugh, J.L., 1991. Insular cortex and amygdala lesions differentially affect acquisition on inhibitory avoidance and conditioned taste aversion. Brain Res. 549, 165-170.

Bernard, J.F., Alden, M., Besson, J.M., 1993. The organization of the efferent projections from the pontine parabrachial area to the amygdaloid complex: a Phaseolus vulgaris leucoagglutinin (PHA-L) study in the rat. J.Comp Neurol. 329, 201-229.

Berridge, K.C., et al., 1984. Sodium depletion enhances salt palatability in rats. Behav.Neurosci. 98, 652-660.

Bielavska, E., Roldan, G., 1996. Ipsilateral connections between the gustatory cortex, amygdala and parabrachial nucleus are necessary for acquisition and retrieval of conditioned taste aversion in rats. Behav.Brain Res. 81, 25-31.

Blank, T., et al., 2003. Corticotropin-releasing factor receptors couple to multiple Gproteins to activate diverse intracellular signaling pathways in mouse hippocampus: role in neuronal excitability and associative learning. J.Neurosci. 23, 700-707. 
Boudreau, J.C., et al., 1987. Taste systems of the petrosal ganglion of the rat glossopharyngeal nerve. In: Chem.Senses. Vol. 12, ed.^eds., pp. 437-458.

Breitman, M.L., et al., 1987. Genetic ablation: targeted expression of a toxin gene causes microphthalmia in transgenic mice. Science. 238, 1563-5.

Breslin, P.A., Spector, A.C., Grill, H.J., 1992. A quantitative comparison of taste reactivity behaviors to sucrose before and after lithium chloride pairings: a unidimensional account of palatability. Behav.Neurosci. 106, 820-836.

Bridgewater, J.A., et al., 1995. Expression of the bacterial nitroreductase enzyme in mammalian cells renders them selectively sensitive to killing by the prodrug CB1954. Eur J Cancer. 31A, 2362-70.

Brownstein, M., et al., 1975. The regional distribution of somatostatin in the rat brain. Endocrinology. 96, 1456-61.

Bruno, J.F., Xu, Y., Berelowitz, M., 1994. Somatostatin regulates somatostatin receptor subtype mRNA expression in GH3 cells. Biochem Biophys Res Commun. 202, 1738-43.

Buijs, R.M., Wortel, J., Hou, Y.X., 1995. Colocalization of gamma-aminobutyric acid with vasopressin, vasoactive intestinal peptide, and somatostatin in the rat suprachiasmatic nucleus. J Comp Neurol. 358, 343-52.

Carter, M.E., et al., 2013. Genetic identification of a neural circuit that suppresses appetite. Nature. 503, 111-114.

Cato, R.K., et al., 1990. Effects of glucoprivation on gastric motility and pituitary oxytocin secretion in rats. Am.J.Physiol. 259, R447-R452.

Caulliez, R., Meile, M.J., Nicolaidis, S., 1996. A lateral hypothalamic D1 dopaminergic mechanism in conditioned taste aversion. Brain Res. 729, 234-245.

Chen, W., et al., 2014. Somatostatin receptor-mediated suppression of gabaergic synaptic transmission in cultured rat retinal amacrine cells. Neuroscience. 273, 118-127.

Chessell, I.P., et al., 1996. Operational characteristics of somatostatin receptors mediating inhibitory actions on rat locus coeruleus neurones. Br J Pharmacol. 117, 1673-8.

Chieng, B., Christie, M.J., 2010. Somatostatin and nociceptin inhibit neurons in the central nucleus of amygdala that project to the periaqueductal grey. Neuropharmacology. 59, 425-30.

Cho, Y.K., Li, C.S., Smith, D.V., 2003. Descending influences from the lateral hypothalamus and amygdala converge onto medullary taste neurons. Chem.Senses. 28, 155-171.

Ciccocioppo, R., et al., 2003. The bed nucleus is a neuroanatomical substrate for the anorectic effect of corticotropin-releasing factor and for its reversal by nociceptin/orphanin FQ. J.Neurosci. 23, 9445-9451.

Clark, A.J., et al., 1997. Selective cell ablation in transgenic mice expression E. coli nitroreductase. Gene Ther. 4, 101-10.

Connor, M., et al., 2004. Cellular actions of somatostatin on rat periaqueductal grey neurons in vitro. Br.J.Pharmacol. 142, 1273-1280.

Corson, J., et al., 2012. A survey of oral cavity afferents to the rat nucleus tractus solitarii. J.Comp Neurol. 520, 495-527.

Csaba, Z., et al., 2003. Targeting sst2A receptor-expressing cells in the rat hypothalamus through in vivo agonist stimulation: neuroanatomical evidence for a major role of this subtype in mediating somatostatin functions. Endocrinology. 144, 1564-73. 
Davis, B.J., 1993. GABA-like immunoreactivity in the gustatory zone of the nucleus of the solitary tract in the hamster: light and electron microscopic studies. Brain Res.Bull. 30, 69-77.

Dayawansa, S., et al., 2011. Parabrachial and hypothalamic interaction in sodium appetite. Am.J.Physiol Regul.Integr.Comp Physiol. 300, R1091-R1099.

Desai, P., Person, S., 1998. Incorporation of the green fluorescent protein into the herpes simplex virus type 1 capsid. J Virol. 72, 7563-8.

DiFrancesco, D., Tortora, P., 1991. Direct activation of cardiac pacemaker channels by intracellular cyclic AMP. Nature. 351, 145-7.

Dilorenzo, P.M., Monroe, S., 1992. Corticofugal Input to Taste-Responsive Units in the Parabrachial Pons. Brain Research Bulletin. 29, 925-930.

Dournaud, P., et al., 1996. Localization of the somatostatin receptor SST2A in rat brain using a specific anti-peptide antibody. J Neurosci. 16, 4468-78.

Drabek, D., et al., 1997. The expression of bacterial nitroreductase in transgenic mice results in specific cell killing by the prodrug CB1954. Gene Ther. 4, 93-100.

Dunn, L.T., Everitt, B.J., 1988. Double dissociations of the effects of amygdala and insular cortex lesions on conditioned taste aversion, passive avoidance, and neophobia in the rat using the excitotoxin ibotenic acid. Behav.Neurosci. 102, 323.

Edwards, D.I., 1993. Nitroimidazole drugs--action and resistance mechanisms. I. Mechanisms of action. J Antimicrob Chemother. 31, 9-20.

Elde, R., Johansson, O., Hokfelt, T., 1985. Immunocytochemical studies of somatostatin neurons in brain. Adv Exp Med Biol. 188, 167-81.

Epelbaum, J., 1986. Somatostatin in the central nervous system: physiology and pathological modifications. Prog Neurobiol. 27, 63-100.

Feifel, D., Vaccarino, F.J., 1990. Central somatostatin: a re-examination of its effects on feeding. Brain Res. 535, 189-194.

Feifel, D., Vaccarino, F.J., 1994. Growth hormone-regulatory peptides (GHRH and somatostatin) and feeding: a model for the integration of central and peripheral function. Neurosci.Biobehav.Rev. 18, 421-433.

Fekete, E.M., et al., 2007. Delayed satiety-like actions and altered feeding microstructure by a selective type 2 corticotropin-releasing factor agonist in rats: intrahypothalamic urocortin 3 administration reduces food intake by prolonging the post-meal interval. Neuropsychopharmacology. 32, 1052-1068.

Felmer, R., Cui, W., Clark, A.J., 2002. Inducible ablation of adipocytes in adult transgenic mice expressing the E. coli nitroreductase gene. J Endocrinol. 175, 487-98.

Felmer, R.N., Clark, J.A., 2004. The gene suicide system Ntr/CB1954 causes ablation of differentiated 3T3L1 adipocytes by apoptosis. Biol Res. 37, 449-60.

Fisher, L.A., Brown, M.R., 1993. Neuropeptides and the autonomic nervous system. Psychother.Psychosom. 60, 39-45.

Flanagan, L.M., Verbalis, J.G., Stricker, E.M., 1989. Effects of anorexigenic treatments on gastric motility in rats. Am.J.Physiol. 256, R955-R961.

Florio, T., 2008. Somatostatin/somatostatin receptor signalling: phosphotyrosine phosphatases. Mol Cell Endocrinol. 286, 40-8. 
Flynn, F.W., et al., 1991. Central gustatory lesions: I. Preference and taste reactivity tests. Behav.Neurosci. 105, 933-943.

Frank, M.E., Contreras, R.J., Hettinger, T.P., 1983. Nerve fibers sensitive to ionic taste stimuli in chorda tympani of the rat. J.Neurophysiol. 50, 941-960.

Gahete, M.D., et al., 2010. Somatostatin and its receptors from fish to mammals. Ann N Y Acad Sci. 1200, 43-52.

Galaverna, O., et al., 1992. Deficits in $\mathrm{NaCl}$ ingestion after damage to the central nucleus of the amygdala in the rat. Brain Res.Bull. 28, 89-98.

Gentet, L.J., et al., 2012. Unique functional properties of somatostatin-expressing GABAergic neurons in mouse barrel cortex. Nat Neurosci. 15, 607-12.

Glasgow, J.N., Everts, M., Curiel, D.T., 2006. Transductional targeting of adenovirus vectors for gene therapy. Cancer Gene Ther. 13, 830-44.

Goebel, M., et al., 2010. Pattern of Fos expression in the brain induced by selective activation of somatostatin receptor 2 in rats. Brain Res. 1351, 150-64.

Gotoh, K., et al., 2007. Hypothalamic neuronal histamine mediates the thyrotropinreleasing hormone-induced suppression of food intake. J.Neurochem. 103, 11021110 .

Grabauskas, G., Bradley, R.M., 2003. Frequency-dependent properties of inhibitory synapses in the rostral nucleus of the solitary tract. J Neurophysiol. 89, 199-211.

Gradinaru, V., et al., 2010. Molecular and cellular approaches for diversifying and extending optogenetics. Cell. 141, 154-65.

Gray, T.S., Magnuson, D.J., 1987. Neuropeptide neuronal efferents from the bed nucleus of the stria terminalis and central amygdaloid nucleus to the dorsal vagal complex in the rat. J.Comp Neurol. 262, 365-374.

Grigson, P.S., Shimura, T., Norgren, R., 1997. Brainstem lesions and gustatory function: II. The role of the nucleus of the solitary tract in $\mathrm{Na}+$ appetite, conditioned taste aversion, and conditioned odor aversion in rats. Behav.Neurosci. 111, 169-179.

Grigson, P.S., et al., 1998. Ibotenic acid lesions of the parabrachial nucleus and conditioned taste aversion: further evidence for an associative deficit in rats. Behav.Neurosci. 112, 160-171.

Grill, H.J., Norgren, R., 1978a. The taste reactivity test. II. Mimetic responses to gustatory stimuli in chronic thalamic and chronic decerebrate rats. Brain Res. 143, 281-297.

Grill, H.J., Norgren, R., 1978b. The taste reactivity test. I. Mimetic responses to gustatory stimuli in neurologically normal rats. Brain Res. 143, 263-279.

Grill, H.J., Norgren, R., 1978c. Chronically decerebrate rats demonstrate satiation but not bait shyness. Science. 201, 267-269.

Grill, H.J., Schulkin, J., Flynn, F.W., 1986. Sodium homeostasis in chronic decerebrate rats. Behav.Neurosci. 100, 536-543.

Grill, H.J., Schwartz, G.J., 1992. The contribution of gustatory nerve input to oral motor behavior and intake-based preference. II. Effects of combined chorda tympani and glossopharyngeal nerve section in the rat. Brain Res. 573, 105-113.

Grill, H.J., Schwartz, G.J., Travers, J.B., 1992. The contribution of gustatory nerve input to oral motor behavior and intake-based preference. I. Effects of chorda tympani or glossopharyngeal nerve section in the rat. Brain Res. 573, 95-104. 
Grossman, S.E., et al., 2008. Learning-related plasticity of temporal coding in simultaneously recorded amygdala-cortical ensembles. J.Neurosci. 28, 28642873.

Guthmann, A., et al., 1998. GABA, GABA transporters, GABA(A) receptor subunits, and GAD mRNAs in the rat parabrachial and Kolliker-Fuse nuclei. J.Comp Neurol. 400, 229-243.

Hajnal, A., Takenouchi, K., Norgren, R., 1999. Effect of intraduodenal lipid on parabrachial gustatory coding in awake rats. J.Neurosci. 19, 7182-7190.

Halsell, C.B., 1992. Organization of parabrachial nucleus efferents to the thalamus and amygdala in the golden hamster. J.Comp Neurol. 317, 57-78.

Hamilton, R.B., Norgren, R., 1984. Central projections of gustatory nerves in the rat. J.Comp Neurol. 222, 560-577.

Hedley, S.J., et al., 2006. Targeted and shielded adenovectors for cancer therapy. Cancer Immunol Immunother. 55, 1412-9.

Heinrichs, S.C., et al., 1993. Corticotropin-releasing factor in the paraventricular nucleus modulates feeding induced by neuropeptide Y. Brain Res. 611, 18-24.

Heinrichs, S.C., Richard, D., 1999. The role of corticotropin-releasing factor and urocortin in the modulation of ingestive behavior. Neuropeptides. 33, 350-359.

Holstege, G., Meiners, L., Tan, K., 1985. Projections of the bed nucleus of the stria terminalis to the mesencephalon, pons, and medulla oblongata in the cat. Exp.Brain Res. 58, 379-391.

Hopkins, D.A., Holstege, G., 1978. Amygdaloid projections to the mesencephalon, pons and medulla oblongata in the cat. Exp.Brain Res. 32, 529-547.

Ikeda, H., et al., 2009. Somatostatin receptors in the nucleus accumbens modulate dopamine-dependent but not acetylcholine-dependent turning behaviour of rats. Neuroscience. 159, 974-81.

Isles, A.R., et al., 2001. Conditional ablation of neurones in transgenic mice. J Neurobiol. 47, 183-93.

Jacquin, T., et al., 1988. Somatostatin depresses excitability in neurons of the solitary tract complex through hyperpolarization and augmentation of IM, a noninactivating voltage-dependent outward current blocked by muscarinic agonists. Proc.Natl.Acad.Sci.U.S.A. 85, 948-952.

Jia, H.G., Zhang, G.Y., Wan, Q., 2005. A GABAergic projection from the central nucleus of the amygdala to the parabrachial nucleus: an ultrastructural study of anterograde tracing in combination with post-embedding immunocytochemistry in the rat. Neurosci.Lett. 382, 153-157.

Jones, D.N., et al., 1998. The behavioural effects of corticotropin-releasing factor-related peptides in rats. Psychopharmacology (Berl). 138, 124-132.

Kang, Y., Yan, J., Huang, T., 2004. Microinjection of bicuculline into the central nucleus of the amygdala alters gustatory responses of the rat parabrachial nucleus. Brain Res. 1028, 39-47.

Kang, Y., Lundy, R.F., 2009. Terminal field specificity of forebrain efferent axons to brainstem gustatory nuclei. Brain Res. 1248, 76-85.

Karasawa, H., et al., 2014. Brain somatostatin receptor 2 mediates the dipsogenic effect of central somatostatin and cortistatin in rats: role in drinking behavior. Am.J.Physiol Regul.Integr.Comp Physiol. 
Kash, T.L., et al., 2008. Dopamine enhances fast excitatory synaptic transmission in the extended amygdala by a CRF-R1-dependent process. J.Neurosci. 28, 1385613865.

Kawaguchi, Y., Kondo, S., 2002. Parvalbumin, somatostatin and cholecystokinin as chemical markers for specific GABAergic interneuron types in the rat frontal cortex. J Neurocytol. 31, 277-87.

Kawano, H., Daikoku, S., 1988. Somatostatin-containing neuron systems in the rat hypothalamus: retrograde tracing and immunohistochemical studies. J Comp Neurol. 271, 293-9.

Kim, M., et al., 2003. The coxsackievirus and adenovirus receptor acts as a tumour suppressor in malignant glioma cells. Br J Cancer. 88, 1411-6.

Knox, R.J., et al., 1993. Identification, synthesis and properties of 5-(aziridin-1-yl)-2nitro-4-nitrosobenzamide, a novel DNA crosslinking agent derived from CB1954. Biochem Pharmacol. 46, 797-803.

Kobashi, M., Bradley, R.M., 1998. Effects of GABA on neurons of the gustatory and visceral zones of the parabrachial nucleus in rats. Brain Res. 799, 323-328.

Kraicer, J., et al., 1988. Failure of growth hormone (GH) to feed back at the level of the pituitary to alter the response of the somatotrophs to $\mathrm{GH}$-releasing factor. Endocrinology. 122, 1511-4.

Kumar, U., 2007. Colocalization of somatostatin receptor subtypes (SSTR1-5) with somatostatin, NADPH-diaphorase (NADPH-d), and tyrosine hydroxylase in the rat hypothalamus. J Comp Neurol. 504, 185-205.

Kwon, B., Houpt, T.A., 2012. Mitogen-activated protein kinase in the amygdala plays a critical role in lithium chloride-induced taste aversion learning. Neurobiol.Learn.Mem. 97, 132-139.

Lamprecht, R., Dudai, Y., 1996. Transient expression of c-Fos in rat amygdala during training is required for encoding conditioned taste aversion memory. Learn.Mem. 3, 31-41.

Lamprecht, R., Hazvi, S., Dudai, Y., 1997. cAMP response element-binding protein in the amygdala is required for long- but not short-term conditioned taste aversion memory. J.Neurosci. 17, 8443-8450.

Lasiter, P.S., Kachele, D.L., 1988. Organization of GABA and GABA-transaminase containing neurons in the gustatory zone of the nucleus of the solitary tract. Brain Res.Bull. 21, 623-636.

Lee, S., et al., 2010. The largest group of superficial neocortical GABAergic interneurons expresses ionotropic serotonin receptors. J Neurosci. 30, 16796-808.

Leresche, N., et al., 2000. Somatostatin inhibits GABAergic transmission in the sensory thalamus via presynaptic receptors. Neuroscience. 98, 513-522.

Lewis, I., et al., 2003. A novel somatostatin mimic with broad somatotropin release inhibitory factor receptor binding and superior therapeutic potential. J Med Chem. 46, 2334-44.

Lewis, M.W., et al., 2002. In vitro and in vivo analysis of the effects of corticotropin releasing factor on rat dorsal vagal complex. J.Physiol. 543, 135-146.

Li, C.S., Cho, Y.K., Smith, D.V., 2005. Modulation of parabrachial taste neurons by electrical and chemical stimulation of the lateral hypothalamus and amygdala. J.Neurophysiol. 93, 1183-1196. 
Li, C.S., Cho, Y.K., 2006. Efferent projection from the bed nucleus of the stria terminalis suppresses activity of taste-responsive neurons in the hamster parabrachial nuclei. Am.J.Physiol Regul.Integr.Comp Physiol. 291, R914-R926.

Li, J.X., et al., 2013a. Lateral hypothalamus contains two types of palatability-related taste responses with distinct dynamics. J Neurosci. 33, 9462-73.

Li, X., et al., 2013b. Specific somatostatin receptor II expression in arterial plaque: (68)Ga-DOTATATE autoradiographic, immunohistochemical and flow cytometric studies in apoE-deficient mice. Atherosclerosis. 230, 33-9.

Lindmark, D.G., Muller, M., 1976. Antitrichomonad action, mutagenicity, and reduction of metronidazole and other nitroimidazoles. Antimicrob Agents Chemother. 10, 476-82.

Ling, N., et al., 1973. The use of mass spectrometry in deducing the sequence of somatostatin--a hypothalamic polypeptide that inhibits the secretion of growth hormone. Biochem Biophys Res Commun. 50, 127-33.

Liu, Y., et al., 2010. The evolution of somatostatin in vertebrates. Gene. 463, 21-8.

Liubashina, O., Jolkkonen, E., Pitkanen, A., 2000. Projections from the central nucleus of the amygdala to the gastric related area of the dorsal vagal complex: a Phaseolus vulgaris-leucoagglutinin study in rat. Neurosci.Lett. 291, 85-88.

Liubashina, O., Bagaev, V., Khotiantsev, S., 2002. Amygdalofugal modulation of the vago-vagal gastric motor reflex in rat. Neurosci.Lett. 325, 183-186.

Lowry, C.A., et al., 2000. Corticotropin-releasing factor increases in vitro firing rates of serotonergic neurons in the rat dorsal raphe nucleus: evidence for activation of a topographically organized mesolimbocortical serotonergic system. J.Neurosci. 20, 7728-7736.

Lundy, R.F., Jr., Norgren, R., 2001. Pontine gustatory activity is altered by electrical stimulation in the central nucleus of the amygdala. J.Neurophysiol. 85, 770-783.

Lundy, R.F., Jr., Norgren, R., 2004. Activity in the hypothalamus, amygdala, and cortex generates bilateral and convergent modulation of pontine gustatory neurons. J.Neurophysiol. 91, 1143-1157.

Magableh, A., Lundy, R., 2014. Somatostatin and corticotrophin releasing hormone cell types are a major source of descending input from the forebrain to the parabrachial nucleus in mice. Chem Senses. 39, 673-82.

Mandel, R.J., et al., 2006. Recombinant adeno-associated viral vectors as therapeutic agents to treat neurological disorders. Mol Ther. 13, 463-83.

Martinez, V., et al., 2000. Intracisternal injection of somatostatin receptor 5-preferring agonists induces a vagal cholinergic stimulation of gastric emptying in rats. J.Pharmacol.Exp.Ther. 293, 1099-1105.

Masmoudi, O., et al., 2005. Somatostatin down-regulates the expression and release of endozepines from cultured rat astrocytes via distinct receptor subtypes. J Neurochem. 94, 561-71.

Maubert, E., et al., 1994. Developmental patterns of somatostatin-receptors and somatostatin-immunoreactivity during early neurogenesis in the rat. Neuroscience. 62, 317-25.

Mayer, M.L., Westbrook, G.L., 1983. A voltage-clamp analysis of inward (anomalous) rectification in mouse spinal sensory ganglion neurones. J Physiol. 340, 19-45. 
McCann, M.J., Verbalis, J.G., Stricker, E.M., 1989. LiCl and CCK inhibit gastric emptying and feeding and stimulate OT secretion in rats. Am.J.Physiol. 256, R463-R468.

Moga, M.M., Gray, T.S., 1985. Evidence for corticotropin-releasing factor, neurotensin, and somatostatin in the neural pathway from the central nucleus of the amygdala to the parabrachial nucleus. J.Comp Neurol. 241, 275-284.

Moga, M.M., Saper, C.B., Gray, T.S., 1989. Bed nucleus of the stria terminalis: cytoarchitecture, immunohistochemistry, and projection to the parabrachial nucleus in the rat. J.Comp Neurol. 283, 315-332.

Moga, M.M., Saper, C.B., Gray, T.S., 1990. Neuropeptide organization of the hypothalamic projection to the parabrachial nucleus in the rat. J.Comp Neurol. 295, 662-682.

Moller, L.N., et al., 2003. Somatostatin receptors. Biochim Biophys Acta. 1616, 1-84.

Momiyama, T., Zaborszky, L., 2006. Somatostatin presynaptically inhibits both GABA and glutamate release onto rat basal forebrain cholinergic neurons. J.Neurophysiol. 96, 686-694.

Moran, A., Katz, D.B., 2014. Sensory cortical population dynamics uniquely track behavior across learning and extinction. J Neurosci. 34, 1248-57.

Nachman, M., Ashe, J.H., 1973. Learned taste aversions in rats as a function of dosage, concentration, and route of administration of LiCl. Physiol Behav. 10, 73-78.

ndrade-Franze, G.M., et al., 2010. Lesions in the central amygdala impair sodium intake induced by the blockade of the lateral parabrachial nucleus. Brain Res. 1332, 5764.

Norgren, R., 1974. Gustatory afferents to ventral forebrain. Brain Res. 81, 285-295.

Norgren, R., 1976. Taste pathways to hypothalamus and amygdala. J.Comp Neurol. 166, 17-30.

Norgren, R., 1978. Projections from the nucleus of the solitary tract in the rat. Neuroscience. 3, 207-218.

Norgren, R., Nishijo, H., Travers, S.P., 1989. Taste responses from the entire gustatory apparatus. Ann.N.Y.Acad.Sci. 575, 246-263.

O'Carroll, A.M., et al., 1992. Molecular cloning and expression of a pituitary somatostatin receptor with preferential affinity for somatostatin-28. Mol Pharmacol. 42, 939-46.

Panguluri, S., Saggu, S., Lundy, R., 2009. Comparison of somatostatin and corticotrophin-releasing hormone immunoreactivity in forebrain neurons projecting to taste-responsive and non-responsive regions of the parabrachial nucleus in rat. Brain Res. 1298, 57-69.

Parrott, R.F., 1990. Central administration of corticotropin releasing factor in the pig: effects on operant feeding, drinking and plasma cortisol. Physiol Behav. 47, 519524.

Patel, Y.C., 1999. Somatostatin and its receptor family. Front Neuroendocrinol. 20, 15798.

Peng, Y., et al., 2014. Comparative study of somatostatin-human serum albumin fusion proteins and natural somatostatin on receptor binding, internalization and activation. PLoS One. 9, e89932. 
Pompei, P., et al., 1991. Bed nucleus of the stria terminalis: site for the antinatriorexic action of tachykinins in the rat. Pharmacol.Biochem.Behav. 40, 977-981.

Reilly, J.J., et al., 1994. The effects of lesions of the bed nucleus of the stria terminalis on sodium appetite. Acta Neurobiol Exp (Wars). 54, 253-7.

Reilly, S., Grigson, P.S., Norgren, R., 1993. Parabrachial nucleus lesions and conditioned taste aversion: evidence supporting an associative deficit. Behav.Neurosci. 107, 1005-1017.

Reilly, S., Pritchard, T.C., 1996. Gustatory thalamus lesions in the rat: II. Aversive and appetitive taste conditioning. Behav.Neurosci. 110, 746-759.

Rein, D.T., Breidenbach, M., Curiel, D.T., 2006. Current developments in adenovirusbased cancer gene therapy. Future Oncol. 2, 137-43.

Rens-Domiano, S., et al., 1992. Pharmacological properties of two cloned somatostatin receptors. Mol Pharmacol. 42, 28-34.

Reubi, J.C., et al., 2000. Affinity profiles for human somatostatin receptor subtypes SST1-SST5 of somatostatin radiotracers selected for scintigraphic and radiotherapeutic use. Eur J Nucl Med. 27, 273-82.

Roberto, M., et al., 2010. Corticotropin releasing factor-induced amygdala gammaaminobutyric Acid release plays a key role in alcohol dependence. Biol.Psychiatry. 67, 831-839.

Rogers, R.C., McTigue, D.M., Hermann, G.E., 1996. Vagal control of digestion: modulation by central neural and peripheral endocrine factors. Neurosci.Biobehav.Rev. 20, 57-66.

Roldan, G., Bures, J., 1994. Tetrodotoxin blockade of amygdala overlapping with poisoning impairs acquisition of conditioned taste aversion in rats. Behav.Brain Res. 65, 213-219.

Roth, S.R., Schwartz, M., Teitelbaum, P., 1973. Failure of recovered lateral hypothalamic rats to learn specific food aversions. J.Comp Physiol Psychol. 83, 184-197.

Ruch, S., Grigson, P.S., Norgren, R., 1997. The role of lateral hypothalamic neurons in conditioned taste aversion and sodium appetite. In: Soc.Neurosci.Abstr., Vol. 23, ed.^eds., pp. 1349.

Ruch, S., Grigson, P.S., Norgren, R., 1999. Further investigation of gustatory deficits in rats with ibotenic acid lateral hypothalamus lesions. In: Soc.Neurosci.Abstr., Vol. 25, ed.^eds., pp. 2141.

Saggu, S., Lundy, R.F., 2008. Forebrain neurons that project to the gustatory parabrachial nucleus in rat lack glutamic acid decarboxylase. Am.J.Physiol Regul.Integr.Comp Physiol. 294, R52-R57.

Saha, S., Henderson, Z., Batten, T.F., 2002. Somatostatin immunoreactivity in axon terminals in rat nucleus tractus solitarii arising from central nucleus of amygdala: coexistence with GABA and postsynaptic expression of sst2A receptor. J.Chem.Neuroanat. 24, 1-13.

Saleh, T.M., Cechetto, D.F., 1993. Peptides in the parabrachial nucleus modulate visceral input to the thalamus. Am.J.Physiol. 264, R668-R675.

Saleh, T.M., Cechetto, D.F., 1995. Neurochemical interactions in the parabrachial nucleus mediating visceral inputs to visceral thalamic neurons. Am.J.Physiol. 268, R786-R795. 
Saper, C.B., Loewy, A.D., 1980. Efferent connections of the parabrachial nucleus in the rat. Brain Res. 197, 291-317.

Scalera, G., Spector, A.C., Norgren, R., 1995. Excitotoxic lesions of the parabrachial nuclei prevent conditioned taste aversions and sodium appetite in rats. Behav.Neurosci. 109, 997-1008.

Scalera, G., Grigson, P.S., Norgren, R., 1997. Gustatory functions, sodium appetite, and conditioned taste aversion survive excitotoxic lesions of the thalamic taste area. Behav.Neurosci. 111, 633-645.

Scalera, G., 2003. Peptides that regulate food intake: somatostatin alters intake of amino acid-imbalanced diets and taste buds of tongue in rats. Am.J.Physiol Regul.Integr.Comp Physiol. 284, R1389-R1398.

Schafe, G.E., Bernstein, I.L., 1996. Forebrain contribution to the induction of a brainstem correlate of conditioned taste aversion: I. The amygdala. Brain Res. 741, 109-116.

Schafe, G.E., Thiele, T.E., Bernstein, I.L., 1998. Conditioning method dramatically alters the role of amygdala in taste aversion learning. Learn.Mem. 5, 481-492.

Schindler, M., et al., 1997. Immunohistochemical localization of the somatostatin SST2(A) receptor in the rat brain and spinal cord. Neuroscience. 76, 225-40.

Schulz, S., et al., 1998. Differential distribution of alternatively spliced somatostatin receptor 2 isoforms (sst2A and sst2B) in rat spinal cord. Neurosci Lett. 257, 37 40.

Schwartz, M., Teitelbaum, P., 1974. Dissociation between learning and remembering in rats with lesions in the lateral hypothalamus. J.Comp Physiol Psychol. 87, 384398.

Sharma, K., Patel, Y.C., Srikant, C.B., 1996. Subtype-selective induction of wild-type p53 and apoptosis, but not cell cycle arrest, by human somatostatin receptor 3 . Mol Endocrinol. 10, 1688-96.

Shen, L.P., Pictet, R.L., Rutter, W.J., 1982. Human somatostatin I: sequence of the cDNA. Proc Natl Acad Sci U S A. 79, 4575-9.

Shen, L.P., Rutter, W.J., 1984. Sequence of the human somatostatin I gene. Science. 224, 168-71.

Shi, T.J., et al., 2014. Somatostatin and its $2 \mathrm{~A}$ receptor in dorsal root ganglia and dorsal horn of mouse and human: expression, trafficking and possible role in pain. Mol Pain. 10, 12.

Shimura, T., Komori, M., Yamamoto, T., 1997a. Acute sodium deficiency reduces gustatory responsiveness to $\mathrm{NaCl}$ in the parabrachial nucleus of rats. Neurosci.Lett. 236, 33-36.

Shimura, T., et al., 1997b. Brainstem lesions and gustatory function: I. The role of the nucleus of the solitary tract during a brief intake test in rats. Behav.Neurosci. 111, 155-168.

Shimura, T., Tanaka, H., Yamamoto, T., 1997c. Salient responsiveness of parabrachial neurons to the conditioned stimulus after the acquisition of taste aversion learning in rats. Neuroscience. 81, 239-247.

Silva, D.C.e., Fregoneze, J.B., Johnson, A.K., 2006. Corticotropin-releasing hormone in the lateral parabrachial nucleus inhibits sodium appetite in rats. Am.J.Physiol Regul.Integr.Comp Physiol. 290, R1136-R1141. 
Skulstad, S., et al., 1995. Labeling of surface proteins of herpes simplex virus type 1 using a modified biotin-streptavidin system. Virus Res. 37, 253-70.

Smith, D.V., Li, C.S., 2000. GABA-mediated corticofugal inhibition of taste-responsive neurons in the nucleus of the solitary tract. Brain Res. 858, 408-415.

Soderpalm, A.H., Berridge, K.C., 2000. The hedonic impact and intake of food are increased by midazolam microinjection in the parabrachial nucleus. Brain Res. 877, 288-297.

Sollars, S.I., Hill, D.L., 2005. In vivo recordings from rat geniculate ganglia: taste response properties of individual greater superficial petrosal and chorda tympani neurones. J.Physiol. 564, 877-893.

Song, J., et al., 2012. Neuronal circuitry mechanism regulating adult quiescent neural stem-cell fate decision. Nature. 489, 150-154.

Spain, W.J., Schwindt, P.C., Crill, W.E., 1987. Anomalous rectification in neurons from cat sensorimotor cortex in vitro. J Neurophysiol. 57, 1555-76.

Spector, A.C., Grill, H.J., Norgren, R., 1993. Concentration-dependent licking of sucrose and sodium chloride in rats with parabrachial gustatory lesions. Physiol Behav. 53, 277-283.

Spector, A.C., Redman, R., Garcea, M., 1996. The consequences of gustatory nerve transection on taste-guided licking of sucrose and maltose in the rat. Behav.Neurosci. 110, 1096-1109.

Spina, M., et al., 1996. Appetite-suppressing effects of urocortin, a CRF-related neuropeptide. Science. 273, 1561-1564.

St John, S.J., Garcea, M., Spector, A.C., 1994. Combined, but not single, gustatory nerve transection substantially alters taste-guided licking behavior to quinine in rats. Behav.Neurosci. 108, 131-140.

Stengel, A., et al., 2010. Activation of brain somatostatin 2 receptors stimulates feeding in mice: analysis of food intake microstructure. Physiol Behav. 101, 614-622.

Stepanyan, Z., et al., 2003. Leptin-target neurones of the rat hypothalamus express somatostatin receptors. J Neuroendocrinol. 15, 822-30.

Sun, N., Yi, H., Cassell, M.D., 1994. Evidence for a GABAergic interface between cortical afferents and brainstem projection neurons in the rat central extended amygdala. J.Comp Neurol. 340, 43-64.

Suwabe, T., Bradley, R.M., 2009. Characteristics of rostral solitary tract nucleus neurons with identified afferent connections that project to the parabrachial nucleus in rats. J.Neurophysiol. 102, 546-555.

Taniguchi, H., et al., 2011. A resource of Cre driver lines for genetic targeting of GABAergic neurons in cerebral cortex. Neuron. 71, 995-1013.

Thomas, C.E., et al., 2000. Peripheral infection with adenovirus causes unexpected longterm brain inflammation in animals injected intracranially with first-generation, but not with high-capacity, adenovirus vectors: toward realistic long-term neurological gene therapy for chronic diseases. Proc Natl Acad Sci U S A. 97, 7482-7.

Tokita, K., et al., 2004. Centrifugal inputs modulate taste aversion learning associated parabrachial neuronal activities. J.Neurophysiol. 92, 265-279.

Tokita, K., Inoue, T., Boughter, J.D., Jr., 2009. Afferent connections of the parabrachial nucleus in C57BL/6J mice. Neuroscience. 161, 475-488. 
Tokita, K., Inoue, T., Boughter, J.D., Jr., 2010. Subnuclear organization of parabrachial efferents to the thalamus, amygdala and lateral hypothalamus in C57BL/6J mice: a quantitative retrograde double labeling study. Neuroscience. 171, 351-365.

Tokita, K., Boughter, J.D., Jr., 2012. Sweet-bitter and umami-bitter taste interactions in single parabrachial neurons in C57BL/6J mice. J.Neurophysiol. 108, 2179-2190.

Tokita, K., Yamamoto, T., Boughter, J.D., Jr., 2012. Gustatory neural responses to umami stimuli in the parabrachial nucleus of C57BL/6J mice. J.Neurophysiol. $107,1545-1555$.

Touzani, K., Bodnar, R.J., Sclafani, A., 2009. Lateral hypothalamus dopamine D1-like receptors and glucose-conditioned flavor preferences in rats. Neurobiol.Learn.Mem. 92, 464-467.

Travers, S.P., Norgren, R., 1995. Organization of orosensory responses in the nucleus of the solitary tract of rat. J.Neurophysiol. 73, 2144-2162.

Tundo, G., et al., 2012. Somatostatin modulates insulin-degrading-enzyme metabolism: implications for the regulation of microglia activity in AD. PLoS One. 7, e34376.

Ugolini, A., et al., 2008. CRF1 Receptor Activation Increases the Response of Neurons in the Basolateral Nucleus of the Amygdala to Afferent Stimulation. Front Behav.Neurosci. 2, 2.

Veening, J.G., Swanson, L.W., Sawchenko, P.E., 1984. The organization of projections from the central nucleus of the amygdala to brainstem sites involved in central autonomic regulation: a combined retrograde transport-immunohistochemical study. Brain Res. 303, 337-357.

Very, N.M., Sheridan, M.A., 2007. Somatostatin regulates hepatic growth hormone sensitivity by internalizing growth hormone receptors and by decreasing transcription of growth hormone receptor mRNAs. Am J Physiol Regul Integr Comp Physiol. 292, R1956-62.

Wang, L., Bradley, R.M., 1995. In vitro study of afferent synaptic transmission in the rostral gustatory zone of the rat nucleus of the solitary tract. Brain Res. 702, 188198.

Wang, M., Bradley, R.M., 2010. Properties of GABAergic neurons in the rostral solitary tract nucleus in mice. J.Neurophysiol. 103, 3205-3218.

Wong, R.S., et al., 1989. Mechanism of killing Chinese hamster ovary cells heated in G1: effects on DNA synthesis and blocking in G2. Radiat Res. 118, 295-310.

Wu, H., et al., 2007. Role of glutamate decarboxylase (GAD) isoform, GAD65, in GABA synthesis and transport into synaptic vesicles-Evidence from GAD65-knockout mice studies. Brain Res. 1154, 80-83.

Wu, Q., Boyle, M.P., Palmiter, R.D., 2009. Loss of GABAergic signaling by AgRP neurons to the parabrachial nucleus leads to starvation. Cell. 137, 1225-1234.

Yamamoto, T., et al., 1995. Conditioned taste aversion in rats with excitotoxic brain lesions. Neurosci.Res. 22, 31-49.

Yasoshima, Y., Shimura, T., Yamamoto, T., 1995. Single unit responses of the amygdala after conditioned taste aversion in conscious rats. Neuroreport. 6, 2424-2428.

Yasoshima, Y., et al., 2006. Acute suppression, but not chronic genetic deficiency, of cfos gene expression impairs long-term memory in aversive taste learning. Proc.Natl.Acad.Sci.U.S.A. 103, 7106-7111. 
Yoneda, M., Tache, Y., 1995. SMS 201-995-induced stimulation of gastric acid secretion via the dorsal vagal complex and inhibition via the hypothalamus in anaesthetized rats. Br.J.Pharmacol. 116, 2303-2309.

Zardetto-Smith, A.M., Beltz, T.G., Johnson, A.K., 1994. Role of the central nucleus of the amygdala and bed nucleus of the stria terminalis in experimentally-induced salt appetite. Brain Res. 645, 123-134.

Zhang, C., Kang, Y., Lundy, R.F., 2010. Terminal field specificity of forebrain efferent axons to the pontine parabrachial nucleus and medullary reticular formation. Brain Res.

Zhang, Y., et al., 2013. Adenoviral and adeno-associated viral vectors-mediated neuronal gene transfer to cardiovascular control regions of the rat brain. Int J Med Sci. 10, $607-16$.

Zheng, H., et al., 1997. Somatostatin receptor subtype 2 knockout mice are refractory to growth hormone-negative feedback on arcuate neurons. Mol Endocrinol. 11, 1709-17. 


\section{CURRICULUM VITA}

NAME:

ADDRESS:

EMAIL:

TELEPHONE: $\quad 708-945-4496$

EDUCATION

\& TRAINING:

AWARDS:
Ali Al-Magableh

Department of Anatomical Sciences

University of Louisville

School of Medicine

500 S Preston St \#A1001

Louisville, KY 40202

a0alma04@ louisville.edu

B.S., Jordan University of Science and Technology,

Irbid, Jordan 1995-1999

B.S., Northern Illinois University DeKalb, IL, 2001-2002

M.S., Chicago State University, Chicago IL, 2005-2007

M.S., University of Louisville, Louisville, KY 2013

Doctoral Dissertation Completion Fellowship, University of Louisville, Graduate School Spring, 2015

Graduate Fellowship-2010-2012. University of Louisville, School of Medicine

Graduate assistantship 2008-2009. University of Cincinnati, College of Medicine

University Graduate Scholarship 2008-2009. University of Cincinnati, College of Medicine

Graduate Division Award (Academic Achievement), Chicago State University-2007.

Graduate Fellowship-2005-2006. Chicago State University Graduate Fellowship-2006-2007. Chicago State University

TRAVEL AWARDS:

Achems housing scholarship, Achems Annual Meeting Huntington Beach, California 2013

University of Louisville Travel Award, Achems annual meeting Bonita Springs Florida 2014 
NATIONAL

MEETINGS:

The Annual Meeting for Research Louisville. Louisville, KY September 2014

The Annual Meeting of the American Society of Chemical Senses -Bonita Springs, FL. April 2014.

The Annual Meeting of the American Neuroscience Society- Louisville Chapter (Research Louisville), Louisville, KY April 2014

Graduate Student Annual Report-University of Louisville. November, 2013

The Annual Meeting of the Kentucky Science Foundation, Lexington, KY August, 2013.

The Annual Meeting of the American Neuroscience Society- Louisville Chapter (Research Louisville), Louisville, KY April 2013.

The Annual Meeting of the American Society of Chemical Senses Huntington Beach, CA. April 2013.

The Annual Meeting of the American Neuroscience Society- Louisville Chapter (Research Louisville), Louisville, KY April 2012

The Annual Meeting of the Kentucky Science Foundation, Louisville, KY June 2012.

Graduate Student Annual Report-Chicago State University. Spring 2007

Graduate Student Annual Report-Chicago State University. Spring 2006

PROFESSIONAL SOCIETIES:

PUBLICATIONS: Magableh, A., Lundy, R., 2014. Somatostatin and Corticotrophin Releasing Hormone Cell Types Are a Major Source of Descending Input From the Forebrain to the Parabrachial Nucleus in Mice. Chem.Senses.

EXPERIENCES:

1-TEACHING: $\quad$ University of Louisville- School of Medicine 2012

Actively participated in teaching medical students the Anatomy of the Brain and actively setting up and supervising exams.

University of Louisville- School of Medicine 2012

Actively teaching medical students the Anatomy of the Brain and actively setting up, supervising and grading exams.

2-RESEARCH: $\quad$ 1- University of Louisville

-Intensive training and practical work in the field of neuroscience and human anatomy with teaching experiences. Rotation in Macular Degeneration labs, Rotation in Muscle Degenerations labs, Rotation and thesis work in labs focused on the Neural Basis of Obesity. Made ground breaking discovery in the field of neurotransmitter synthesis and excretion was able to molecularly outline certain cell types within the connection between the brain 
nuclei involved in food consumption control; published a Novel work in the Journal of Chemical Senses.

Graduate Assistantship: 2012-2014

Graduate fellowship : 2010-2012

2- University of Cincinnati, College of Medicine (UCCOM)

-Rotation in the department of experimental hematology Cincinnati Children Hospital, June - September 2008

-Rotation in the Department of Dermatology UCCOM September 2008 - March 2009;

-Rotation in the Department of Cancer and Cell Biology UCCOM April - July2009:

Graduate Assistantship: 2008-2009

University Graduate scholarship : 2008-2009

\section{3- Chicago State University}

Rotation in the physiology lab studying the role of intestinal physiological changes in macroflora penetration and septic shock following thermal injury.

Rotation and thesis work in genetics lab mapping the gene responsible for an autosomal dominant mouse ataxia.

Graduate Assistantship for thesis project; mapping the gene responsible for an autosomal dominant mouse ataxia.2005-2007.

4- Northern Illinois University:

Undergraduate research in the effect of heat on the structure of collagen and the hydroxylation/dehydroxylation of hydoxyproline

5- Jordan University of Science and Technology (Medical City, Amman-Jordan)

Clinical laboratory rotations in departments of Microbiology, Hematology, Histopathology, Biochemistry, Urology, and Urgent testing (1998) 